\title{
Time-varying causality between crude oil and stock markets: What can we learn from a multiscale perspective?
}

\author{
Rania Jammazi ${ }^{\mathrm{a}}$, Román $\underline{\text { Ferrer }}^{\mathrm{b}}$, Francisco $\underline{\operatorname{Jareño}}^{\mathrm{c}}$, Syed Jawad Hussain \\ $\underline{\text { Shahzad }}^{\mathrm{d}}$ \\ a IPAG Business School, Boulevard Saint Germain, Paris (France) \& National School of Information \\ Sciences, Manouba,Tunisia, Jamrania2@yahoo.fr \\ ${ }^{\mathbf{b}}$ Department of Actuarial and Financial Economics, University of Valencia, Faculty of Economics, \\ Avda. Tarongers, s/n, 46022, Valencia (Spain), Roman.Ferrer@uv.es \\ c (corresponding author) Department of Economic Analysis and Finance, University of Castilla-La \\ Mancha, Economic and Business Science Faculty, Plaza de la Universidad, 1, 02071, Albacete (Spain), \\ Francisco.Jareno@uclm.es \\ d Energy and Sustainable Development (CESD), Montpellier Business School, Montpellier, France; \\ COMSATS Institute of Information Technology, Islamabad, Pakistan; University of Malaysia \\ Terengganu, Malaysia, jawad.kazmi5@gmail.com
}

\begin{abstract}
This paper investigates the presence of time-varying causal linkages in mean and variance between oil price changes and stock returns for six major oil-importing countries (France, Germany, Italy, Spain, the UK and the US) in a multiscale framework that combines wavelet analysis and a modified version of the dynamic causality test of Lu et al. (2014). The results show significant bidirectional causal relations between oil and stock markets at the different time horizons for all countries. The causal links tend to be stronger at coarser scales and in periods of financial turmoil, mainly during the recent global financial and European sovereign debt crises. This evidence provides useful insights to participants in oil and stock markets and to policymakers.
\end{abstract}

Keywords: Oil price, stock returns, wavelet analysis, Granger causality.

J.E.L. classification: C22, E44, G15, Q43 


\section{Introduction}

The recent global financial crisis and the subsequent economic downturn and later recovery along with the financialization process of commodities have brought about unprecedented sharp movements in crude oil and stock prices over the last few years. The instability governing the behavior of oil and stock markets has prompted a renewed interest in the dynamic interactions between oil price changes and equity returns. Understanding the nature of these linkages may be helpful for investors, portfolio managers and speculators in order to construct well-diversified portfolios, to make adequate risk management decisions and to enhance returns. It is also important for policy makers, who are interested in avoiding severe disturbances in the stock market caused by oil price shocks, particularly during periods of financial turmoil, and in the implementation of appropriate macroeconomic and energy policies.

The relationship between oil price fluctuations and stock returns has given rise to an extensive body of research, mainly focused on the time domain and characterized by the application of a wide variety of methodological approaches, although with mixed findings. An interesting segment of this literature has explored the causal nexus between oil and stock markets using the notion of causality introduced by Granger (1969) in order to determine whether there is a leader-follower pattern between both markets, and, if so, in what direction, or whether feedback effects are dominant. However, these studies, in addition to providing inconclusive results, share the limitation of adopting a static approach, even though the causal linkages between oil and equity markets may vary over time due to changing economic or financial conditions or certain major events.

The complexity and controversy around the true nature of the oil-stock link may be related, at least in part, to multiscale information. More specifically, oil and stock markets are complex systems consisting of a multitude of heterogeneous agents operating over very different time horizons (from minutes to years), who collectively determine aggregate market behavior. These market participants differ in terms of objectives, trading strategies, investment horizons, risk profiles, informational sets, etc. Accordingly, it seems logical to assume that the degree of connection between oil price changes and stock returns may vary over time and across time horizons. Wavelet analysis, a wellestablished technique for signal processing which was born in the mid-1980s (Goupillaud et al., 1984; Grossman \& Morlet, 1984), appears as a very promising framework that takes into account both time and frequency domains simultaneously. Wavelets offer a unique 
opportunity to study the dynamics of the comovement of oil prices and equity returns over time and across time horizons or scales, providing a broader picture than time domain methods, which aggregate all time horizons together. The wavelet methodology can be also very useful in exploring the oil-stock nexus because of its capacity to capture the inherent non-linearity and chaotic behavior of crude oil price changes and stock returns. As pointed out by Haven et al. (2012), ignoring these stylized facts may lead to erroneous conclusions. Another advantage of wavelet techniques is that there are no specific requirements such as normal distribution and stationarity of the series. A good proof of the prominent role of wavelets to examine the multiscale oil-stock interaction is the emergence of various recent empirical studies in this field based on the application of wavelet techniques (Baruník et al., 2016; Huang et al., 2015; Madaleno \& Pinho, 2014; Martín-Barragán et al., 2015; Reboredo \& Rivera-Castro, 2014). Despite its innovative insights, these wavelet-based studies ignore the possible existence of causal relations between oil price and stock returns as well as the direction of the causality. In this context, a research framework combining wavelet multiresolution analysis with an approach capable of efficiently capturing the causal links would be particularly appealing for obtaining a more comprehensive insight into the oil-stock relationship.

The aim of this research is to investigate the time-varying causal nexus in mean and variance between oil price fluctuations and stock markets in a multiscale framework for six major developed oil-importing countries, namely France, Germany, Italy, Spain, the UK and the US. To that end, wavelet techniques are first used to extract the multiscale information from the time series of oil price changes and stock returns. Specifically, the Haar à trous wavelet (HTW hereafter), a type of discrete wavelet transform proposed by Murtagh et al. (2004) that has a number of advantages on standard wavelet functions, is employed. Then, a modified version of the time-varying Granger causality test introduced by Lu et al. (2014) is implemented to examine the dynamic oil-stock causal linkages at different time scales.

This paper contributes to the existing literature in several ways. First, it combines two complementary approaches, namely wavelet analysis and Granger causality tests, allowing one to uncover if there are distinct causality patterns between oil price and stock returns at different time horizons. Second, to the best of our knowledge, this study is the first that addresses the time-varying nature of the causal links between oil price shocks and stock returns by means of a dynamic approach. The main advantage of applying a 
time-varying causality test is that it enables identifying specific time periods where the oil-equity causal relations are more intense and determining if such increases of causality coincide with periods of economic downturn and financial turbulence. The dynamic Granger causality test of Lu et al. (2014), based on the causality procedures developed by Cheung \& Ng (1996) and Hong (2001), is utilized for that purpose. The original causality procedure of $\mathrm{Lu}$ et al. (2014) estimates the dynamic correlation using the Dynamic Conditional Correlation-Generalized Autoregressive Conditional Heteroskedasticity (DCC-GARCH hereafter) model proposed by Engle (2002). However, to avoid the problems of inconsistency and bias of the DCC-GARCH estimates, the Asymmetric Generalized DCC-GARCH (AGDCC-GARCH hereafter) model put forward by Cappiello et al. (2006) is applied in this study. The AGDCC-GARCH process extends and improves the DCC framework to allow for asymmetries in the conditional correlation dynamics in response to positive and negative shocks. Third, unlike previous related literature, which is primarily oriented towards the causality in mean, this paper also analyzes the presence of causality in variance. Volatility can be transmitted between oil prices and stock returns even when the returns of these two markets are either uncorrelated or exhibit no causality in mean. Causality in variance has gained prominence because increasing market integration generated by the economic and financial globalization and technological advances in financial markets along with the recent financial turmoil may have significantly raised volatility transmission. In this regard, some authors argue that spillover effects across markets may be better captured by the conditional second moments than by the first moments of data series (Alikhanov, 2013; Awartani \& Maghyereh, 2013). To sum up, the wavelet-based dynamic Granger causality approach proposed here provides a flexible framework capable of describing in a more realistic manner the causal links between oil and equity markets, reflecting both shifts in causality over time and across time scales. Another distinctive feature of this study is the special attention paid to the effect of crisis periods on the time-varying oil-stock market causality pattern by estimating a probit regression model for each time horizon. By doing so, the graphical analysis of the causal relations is reinforced by the quantification of the marginal effects of the crisis episodes.

Our empirical results reveal significant bidirectional causal linkages, both in mean and variance, between oil price fluctuations and stock returns at the different time horizons considered during almost all the entire sample period for all countries. This important 
transmission of information between oil and stock markets of the major developed oilimporting countries may be explained by the financialization process of the crude oil market and by the fact that the oil and stock markets have been mainly driven by the strength of the global demand over the last years. It is also shown that the causal oil-stock interactions tend to be stronger at the coarser time scales and intensify during times of financial turbulence, mostly during the recent global financial and European sovereign debt crises.

The remainder of the article is organized as follows. Section 2 briefly reviews the relevant related literature. Section 3 presents the econometric framework used in this study, while Section 4 describes the dataset. Section 5 reports the principal empirical results. Finally, Section 6 offers some concluding remarks.

\section{Oil and stock markets: Transmission channels and related literature}

\subsection{Relationship between crude oil price and stock market}

Since the seminal work by Jones \& Kaul (1996), a great deal of academic research has attempted to shed light on the relationship between oil prices and the stock market. The link between oil price fluctuations and stock prices can be justified in the framework of a standard equity pricing model according to which the value of a stock is equal to the discounted sum of its expected future cash flows (Fisher, 1930; Williams, 1938). Thus, any factor that may alter the expected discounted cash flows should have a significant effect on stock prices. Therefore, oil price changes can impact stock prices through several channels. First, since oil is a crucial input in the production process of many goods and services, a rise in oil prices is likely to increase the cost of production of firms, which, in turn, dampen earnings and depress stock prices of non-oil related firms (Filis et al., 2011; Narayan \& Sharma, 2011; Sadorsky, 1999). Second, oil price movements can affect corporate cash flows from the demand side. For example, consumers may increase their precautionary savings and smooth their consumption expenditures in response to positive oil price shocks as they perceive a greater chance of future unemployment, thus leading to a reduction of firms' profits and stock prices (Kilian, 2008; Xu, 2015). Moreover, increased uncertainty about oil prices may also prompt firms to delay investments and households to postpone consumption of durable goods, thus again hampering future cash flows of firms (Edelstein \& Kilian, 2009). Third, oil price changes can also adversely impact stock prices through the discount rate used in valuation models. Indeed, increasing oil prices often generate inflationary pressures, which central banks tend to control by 
tightening their monetary policy and raising interest rates. Higher interest rates entail an increase of the discount rate, with the subsequent detrimental effect on share prices. In addition, higher interest rates make bonds more attractive investments than stocks, leading to a fall in stock prices (Ghosh \& Kanjilal, 2016; Huang et al., 1996; Miller \& Ratti, 2009). Based on these channels, there should be a significant negative relationship between oil price fluctuations and stock returns for oil-importing countries. In contrast, rising oil prices are expected to have a positive influence on the stock markets of oilexporting countries because higher oil prices provide additional income and wealth to oilproducing countries. Nevertheless, it is worth noting that the stock market performance can also exert a significant influence on the oil market. For instance, a bullish stock market reflects, at least in part, increased optimism about future economic prospects, which may lead to higher crude oil prices via increased demand for oil and stronger economic growth.

\subsection{Literature review}

Earlier contributions on the link between oil prices and stock returns were dominated by studies focused on the US (Ciner, 2001; Huang et al., 1996; Jones \& Kaul, 1996; Sadorsky, 1999). Subsequently, a large body of work has emerged exploring the oil-stock nexus in other developed countries. In fact, a central part of this line of research provides a multi-country analysis of the impact of oil price changes on the stock markets of the main developed economies, including the US, the major European countries and Japan (Apergis \& Miller, 2009; Cuñado \& Pérez de Gracia, 2014; Ding et al., 2016; Lee \& Zeng, 2011; Miller \& Ratti, 2009; Park \& Ratti, 2008). In addition, a more recent strand of literature has addressed the oil-stock nexus in developing countries (Al Janabi et al., 2010; Aloui et al., 2013; Basher \& Sadorsky, 2006; Narayan \& Narayan, 2010).

Despite the vast, and still growing, empirical literature on the relationship between oil price and stock returns, a general consensus has not yet been reached concerning the nature of the oil-stock nexus. Most studies document a significant negative effect of oil price movements on stock returns (Ciner, 2001; Driesprong et al., 2008; Jones \& Kaul, 1996; Park \& Ratti, 2008; Sadorsky, 1999). In contrast, other authors find a significant positive relationship between oil price and stock market performance (Lee et al., 2012; Narayan \& Narayan, 2010; Zhu et al., 2011 and 2014). Another group of studies states that the sign of the oil-stock link depends on several conditions. In this regard, Cong et al. (2008) and Park \& Ratti (2008) argue that the nature of the relationship between oil 
price and stock market mostly depends on whether a country is an oil-importer or an oilexporter. In turn, Hamilton (2009) and Kilian \& Park (2009) show that the response of stock returns to oil price changes differs greatly depending on the origin of the oil price shock. Specifically, aggregate demand-side shocks which correspond to unexpected changes in the demand for crude oil driven by global business cycle's fluctuations tend to have a persistent positive effect on stock prices. This occurs because oil and stock markets react similarly to shifts in expectations regarding future economic activity. Precautionary demand-side oil price shocks which reflect concerns about future crude oil supply shortfalls have generally a negative impact on stock markets. Instead, the supplyside oil price shocks due to a reduction of crude oil availability do not significantly influence the association between oil and stock markets. Lastly, a number of studies conclude that there is no significant relationship between oil price shocks and stock markets (Al Janabi et al., 2010; Apergis \& Miller, 2009; Huang et al., 1996).

From a methodological point of view, the bulk of this literature has been developed in the time domain employing a broad range of time series methods. Vector autoregressive (VAR) models are one of the most common approaches (Cong et al., 2008; Huang et al., 1996; Park \& Ratti, 2008; Sadorsky, 1999). Cointegration analysis (Ghosh \& Kanjilal, 2016; Narayan \& Narayan, 2010; Zhu et al., 2011) and vector error correction (VEC) models (Apergis \& Miller, 2009; Cuñado \& Pérez de Gracia, 2014; Lee et al., 2012; Miller \& Ratti, 2009) also constitute two methods widely used in this area. In view of the well documented stylized facts of oil price and stock return data (non-normality, fat tails, volatility clustering, etc.), a number of authors have resorted to univariate and multivariate GARCH specifications to address the oil-stock nexus (Aloui \& Jammazi, 2009; Filis et al., 2011; Khalfaoui et al., 2015). Other contributions have employed Markov switching regime models to investigate shifts in the oil-equity link (Aloui \& Jammazi, 2009; Jammazi \& Nguyen, 2015; Naifar \& Al Dohaiman, 2013). More recently, a few studies have estimated copula functions to describe the dependence structure between oil and stock markets (Aloui et al., 2013; Jammazi \& Reboredo, 2015; Zhu et al., 2014).

In addition, a substantial body of research has examined the presence of Granger causality relationships between oil price fluctuations and stock returns through a variety of econometric approaches. For instance, Arouri \& Nguyen (2010), Dagher \& El Hariri (2013) and Lee et al. (2012) have analyzed linear causal relations between oil and equity 
markets in a standard VAR or VEC model framework. Instead, Ciner (2001) has tested for nonlinear causal linkages between oil prices and stock returns using the HiemstraJones nonlinear causality test, while Ajmi et al. (2014) and Anoruo (2011) have applied the nonlinear asymmetric causality test proposed by Kyrtsou \& Labys (2006). In a similar vein, Hatemi-J et al. (2017) have utilized the asymmetric causality test developed by Hatemi-J. (2012). In turn, Balcilar \& Ozdemir (2013) have analyzed the nonlinear causal link between oil futures contracts and the equity market using a Markov switching-VAR model. Also from a nonlinear perspective, Ding et al. (2016) have investigated the presence of causal relations between oil and stock markets within the quantile causality framework proposed by Chuang et al. (2009). Likewise, Bouri et al. (2017) have tested for causality in mean and in variance using the procedure developed by Cheung $\& \mathrm{Ng}$ (1996) and Hong (2001). Additionally, Bouri (2015) has explored risk spillover effects through the causality in variance approach of Hafner \& Herwartz (2006). Most of these contributions have found significant causal linkages between oil price changes and stock returns. However, as can be seen in Table A1, the results vary greatly depending on the countries studied, methodology employed and time period covered. In any case, a clear limitation of all these studies is that they provide a static view of the causality, i.e. without taking into account possible time-varying patterns in the causal nexus between oil price and stock returns. Nevertheless, it seems reasonable to think that causal relations may evolve over time with changing financial or business conditions as well as with certain major events such as financial or economic crises, wars or geopolitical tensions that may have a significant impact on investors' confidence or asset allocation behavior. In this regard, no previous study has addressed explicitly the time-varying nature of Granger causality between oil price changes and stock returns using a dynamic approach.

All the above mentioned literature looks at the time domain aspect of the data while the information from the frequency domain has been ignored, hence offering only a limited view of the oil-stock nexus. To overcome this shortcoming, a rapidly growing body of work has emerged that deals with the link between oil price changes and stock returns within the wavelet framework. These studies apply different wavelet methods to quantify the strength of the oil-equity association at different time scales, providing a comprehensive description of dynamic interactions between oil price shocks and stock returns. For example, Baruník et al. (2016), Martín-Barragán et al. (2015) and Reboredo \& Rivera-Castro (2014) use wavelet correlations calculated with the maximal overlap 
discrete wavelet transform (MODWT hereafter), which is the type of discrete wavelet transform most widely employed in economic applications. Similarly, Jammazi (2012) examines the linkage between oil price and equity returns employing wavelet correlation measures derived from the HTW transform. In turn, Khalfaoui et al. (2015) investigate spillover effects between oil prices and stock markets through a wavelet-based bivariate GARCH model which also utilizes the MODWT for the wavelet decomposition. In a similar vein, Huang et al. (2015) explore the multiscale dynamic interactions between crude oil price and Chinese stock returns at the sector level using a wavelet-VAR model in which the multiscale information is extracted via the HTW transform. In another recent paper, Jammazi \& Reboredo (2016) combine the HTW transform and time-varying copulas to analyze the dependence structure between oil and stock markets. Additionally, Madaleno \& Pinho (2014) and Ftiti et al. (2016) apply the continuous wavelet transform to describe the dynamic interactions between crude oil and equity markets. This strand of literature provides no conclusive evidence on the multiscale characteristics of the oilstock linkage, although the comovement of these two markets tends to be more pronounced since the onset of the global financial crisis of 2008 (see Table A2).

The novel approach proposed in this paper is related to this line of research. However, unlike previous works, this study examines causal linkages between oil prices and stock markets combining wavelet analysis with a modified version of the time-varying Granger causality developed by Lu et al. (2014). The contribution by Huang et al. (2015) is so far the only study that has analyzed possible causal relations in the oil-stock interaction using wavelet techniques, although in the framework of a standard VAR model and from a static perspective.

\section{Econometric framework}

The econometric framework employed in this study is comprised of two parts. Firstly, the HTW transform is implemented to decompose the original series of oil price changes and stock returns into different time scales, which is also called multiscale analysis. Secondly, a modified version of the dynamic Granger causality test proposed by Lu et al. (2014) is used to examine the time-varying causal relations in mean and variance between oil price fluctuations and stock returns at different time scales. Below, we briefly describe the main distinctive features of both approaches.

\subsection{The Haar à trous wavelet (HTW) transform}


Wavelet analysis is a powerful mathematical tool that provides a time-frequency representation of a signal in the time domain and it can be used to analyze non-stationary time series, which are very common in economics and finance. Wavelets provide an intuitive way to study dynamic interactions between series at different frequencies separately, i.e., on a scale-by-scale basis. A wavelet is a small wave that grows and decays in a limited time period. The wavelet transform is based on two special functions: the father wavelet, $\Phi(t)$, and the mother wavelet, $\Psi(t)$. Based on the mother wavelet, a family of daughter wavelets, $\Psi_{u, s}(t)$, can be generated by simply scaling and translating $\Psi$ :

$$
\psi_{u, s}(t)=\frac{1}{\sqrt{s}} \psi\left(\frac{t-u}{s}\right)
$$

where $s$ is a scaling or dilation parameter that controls the length of the wavelet and $u$ is a location parameter which indicates the position of the wavelet in time. There are two types of wavelet transforms: the continuous wavelet transform (CWT) and the discrete wavelet transform (DWT). The CWT operates over every possible scale and position in time, while the DWT uses a specific subset of discrete scale and location values. The DWT is the most commonly used of the two transforms because, by rendering the continuous function discrete, it requires less computational time and resources to be implemented.

The HTW transform developed by Murtagh et al. (2004) is used in the present study. This wavelet function is a combination of the à trous wavelet, which is a type of redundant or non-decimated wavelet transform, and the Haar wavelet, which represents one of the simplest wavelets. The HTW transform overcomes the drawbacks of conventional wavelet functions. First, unlike the MODWT, which is affected by boundary problems and requires the removal of some biased wavelet coefficients at each scale to be efficient, the HTW is immune to boundary effects, thus ensuring the conservation of the whole information contained in the original series. Second, the HTW transform is flexible enough to accurately capture the non-linear and chaotic dynamics typical of many economic and financial time series. Third, the redundancy inherent in the à trous wavelet function means that all wavelet components have the same length as the original series, so it is easy to relate information at each resolution scale for the same time point. This property of redundancy also implies that the HTW is translation-invariant, i.e. the results are not sensitive to the choice of the starting point. 
In the framework of the HTW transform, the smoothed version, $S_{j}(t)$, of a signal $x(t)$ at a given scale $j$ and a position $t$ can be obtained by the following convolution:

$$
S_{j}(t)=\sum_{l=-\infty}^{+\infty} h(l) S_{j-1}\left(t+2^{j-1} \times l\right)
$$

where $h=(1 / 2,1 / 2)$ is the scaling low-pass filter associated with the HTW. In turn, $S_{0}$, the finest scale, represents the raw time series.

The detail component, $d_{j}(t)$, which captures detail features of the signal $x(t)$ at scale $j$, can be derived as the difference between two smoothed versions at two consecutive resolution levels:

$$
d_{j}(t)=S_{j-1}(t)-S_{j}(t)
$$

The set $\left\{d_{1}(t), d_{2}(t), \ldots, d_{J}(t), S_{J}(t)\right\}$ represents the wavelet transform of the signal up to scale $J$ and the original signal can be reconstructed as a sum of the wavelet coefficients and the scaling coefficient:

$$
x(t)=S_{J}(t)+\sum_{j=1}^{J} d_{j}(t)
$$

where $J$ is the number of scales or resolution levels.

\subsection{Time-varying Granger causality test of Lu et al. (2014)}

The second stage of the analysis consists of applying a modified version of the timevarying causality test developed by Lu et al. (2014) on the results of the HTW multiscale decomposition to detect the existence and direction of causal links in mean and variance between oil price changes and stock returns on a scale-by-scale basis.

Causal relations between economic and financial variables have been extensively addressed in the literature since Granger introduced the concept of causality in 1969. Granger (1969) defined causality in terms of predictability, stating that a stochastic variable causes another distinct stochastic variable if the historical information of the former variable helps to improve the predictability of the latter variable. Granger causality tests have traditionally focused on the conditional mean of the variables. However, Cheung \& $\mathrm{Ng}$ (1996) extended the notion of Granger causality to the conditional variance of the variables and this procedure was, in turn, improved by Hong (2001). ${ }^{\mathrm{i}}$ The Cheung \& Ng (1996) and Hong (2001) approach allows testing for both causality in mean and in 
variance. In particular, these causality in mean and in variance tests are based on the sample cross-correlation function $(\mathrm{CCF})$ of standardized residuals and squared standardized residuals extracted from the estimation of univariate GARCH-type models, respectively.

Given two stationary time series $\left\{y_{i, t}\right\}, i=1,2$ and $t=1, \ldots, T$ where $T$ is the sample size, and being $I_{t}=\left(I_{1, t}, I_{2, t}\right)$ the information set of time series $\left\{y_{i, t}\right\}$ available at time $t$, Granger causality stipulates that $y_{2, t}$ Granger-causes $y_{1, t}$ in mean with respect to $I_{t-1}$ if:

$$
E\left(y_{1, t} \mid I_{1, t-1}\right) \neq E\left(y_{1, t} \mid I_{t-1}\right)
$$

Analogously, $y_{2, t}$ is said to cause $y_{1, t}$ in variance with respect to $I_{t-1}$ if:

$$
E\left\{\left(y_{1, t}-\mu_{1, t}\right)^{2} \mid I_{1, t-1}\right\} \neq E\left\{\left(y_{1, t}-\mu_{1, t}\right)^{2} \mid I_{t-1}\right\}
$$

where $\mu_{1, t}$ is the mean of $y_{1}$ conditioned on $I_{1, t-1}$.

The dynamic causality test proposed by of Lu et al. (2014) is an extension of the Granger causality approach of Hong (2001) to the time-varying case. In essence, the time-varying Granger causality test of Lu et al. (2014) has four major advantages over conventional causality methods. First, it reflects the dynamics of causal links, permitting the identification of the specific time periods during which significant Granger causality exists between the series involved. Second, it makes possible to detect both unidirectional and bidirectional causality directions. Third, it allows testing for both causality in mean and variance from a dynamic perspective, thus providing a more complete picture of the causal links. Fourth, this test enables one to capture the common stylized facts of most economic and financial time series (e.g., asymmetry, fat tails, volatility clustering), whose no consideration may lead to misleading results in terms of Granger causality.

In the more advanced version of the Lu et al. (2014) time-varying causality test, the dynamic conditional correlation between the two time series under study is estimated by means of the DCC-GARCH framework proposed by Engle (2002). ${ }^{\text {ii }}$ However, given the problems of inconsistency and downward bias of the estimated parameters of the DCCGARCH model documented by Aielli (2013), it seems more appropriate to use an alternative specification. In this context, the AGDCC-GARCH model developed by Cappiello et al. (2006) is employed in the present study. The AGDCC-GARCH model generalizes and improves substantially the DCC-GARCH process by accounting for asymmetries in the conditional correlation dynamics that are not considered in the DCC 
framework. Thus, the AGDCC-GARCH model takes into account not only the timevarying correlation between assets, but also the asymmetric response of correlation to positive and negative shocks. ${ }^{\text {iii }}$

In general, the estimation process of the AGDCC model comprises two steps. In the first step, univariate GARCH processes are fitted for each series. In the second step, the dynamic conditional correlation dynamics incorporating asymmetric effects is estimated employing a quasi-maximum likelihood procedure. According to Cappiello et al. (2006), a generic AGDCC-GARCH model can be formulated as follows:

$$
\begin{gathered}
y_{t}(j) \mid I_{t-1} \sim \mathrm{N}\left(0, H_{t, j}\right) \\
H_{t, j}=D_{t, j} R_{t, j} D_{t, j} \\
z_{t, j}=D_{t, j}^{-1} \varepsilon_{t, j} \\
R_{t, j}=\left\lfloor\operatorname{diag}\left(Q_{t, j}\right)^{-1 / 2}\right\rfloor Q_{t, j}\left\lfloor\operatorname{diag}\left(Q_{t, j}\right)^{-1 / 2}\right\rfloor
\end{gathered}
$$

where $y_{t}(j)=\left(\begin{array}{c}y_{1, t} \\ y_{2, t-j}\end{array}\right)$ with lag $j, H_{t, j}$ denotes the conditional covariance matrix with lag $j$ of the series $y_{i, t}, i=1,2, D_{t, j}$ is a diagonal matrix containing the time-varying standard deviations derived from univariate GARCH equations and $R_{t, j}$ represents the conditional time-varying cross correlation matrix with $\operatorname{lag} j$. In addition, $\varepsilon_{t, j}$ is a vector of residuals, $z_{t, j}$ is a vector of standardized residuals and $Q_{t, j}$ denotes the conditional correlation matrix with $\operatorname{lag} j$ of standardized residuals.

The evolution of the dynamic conditional correlation in the AGDCC model is given by:

$$
Q_{t, j}=\left(1-\theta_{1}-\theta_{2}\right) \bar{Q}_{j}-\phi \bar{N}_{j}+\theta_{1}\left(z_{t-1 . j} z_{t-1 . j}^{\prime}\right)+\theta_{2} Q_{t-1, j}+\phi\left(\eta_{t-1 . j} \eta_{t-1, j}^{\prime}\right)
$$

where $\bar{Q}_{j}=E\left[z_{t}, z_{t-j}^{\prime}\right]$ is the unconditional correlation matrix with lag $j$ of standardized residuals, $\eta_{t}=I\left(z_{t}<0\right) \circ z_{t}$ is an indicator function that takes the value of one if the argument is true and zero otherwise, being $\circ$ the Hadamard product, $\bar{N}_{j}=E\left[\eta_{t}, \eta_{t-j}^{\prime}\right]$ is the unconditional correlation matrix of $\eta_{t}$ and $\theta_{1}, \theta_{2}$ and $\phi$ are nonnegative scalar parameters. It is worth mentioning that $\phi$ is the parameter of correlation asymmetry. Setting $\phi=0$ reduces ADCC to the standard DCC model, which ignores correlation asymmetry. 
In the setting provided by the AGDCC model, the conditional cross correlation coefficient with lag $j$ between the standardized residuals of the two time series involved can be estimated as follows:

$$
\rho_{12, t}(j)=\frac{q_{12, t}(j)}{\sqrt{q_{11, t}(j) q_{22, t}(j)}}
$$

where $\rho_{12, t}(j)$ represents the AGDCC conditional cross correlation with lag $j$ between the standardized residuals, $q_{12, t}(j)$ is the cross covariance estimator with $\operatorname{lag} j$ and $q_{11, t}(j)$ and $q_{22, t}(j)$ are the AGDCC variances with lag $j$ of the two standardized residuals.

From here, the time-varying causality tests of Lu et al. (2014) are constructed by incorporating the dynamic correlation estimator from the AGDCC-GARCH specification to the Hong's (2001) causality test. Thus, the unidirectional time-varying Hong causality test statistic from $\mathrm{y}_{2}$ to $\mathrm{y}_{1}$ is denoted as $\mathrm{H}_{1, \mathrm{t}}(\mathrm{k})$ and can be defined as follows:

$$
H_{1, t}(k)=\frac{T \sum_{j=1}^{T-1} k^{2}\left(\frac{j}{M}\right) r_{12, t}^{2}(j)-C_{1 T}(k)}{\sqrt{2 D_{1 T}}(k)}
$$

In turn, the bidirectional time-varying Hong causality test statistic, denoted as $\mathrm{H}_{\mathrm{b}, \mathrm{t}}(\mathrm{k})$, is given by:

$$
H_{b, t}(k)=\frac{T \sum_{j=2-T}^{T-2} k^{2}\left(\frac{j}{M}\right) r_{12, t}^{2}(j)-C_{2 T}(k)}{\sqrt{2 D_{2 T}}(k)}
$$

where $M$ is a positive integer and $k(x)$ is the kernel function. The terms $C_{1 T}(k), C_{2 T}(k), D_{1 T}(k), D_{2 T}(k)$ used in the numerator and denominator of previous equations are determined by the kernel function $\mathrm{k}(\mathrm{x})$ and the sample size $T$. They can be calculated as follows:

$$
\begin{gathered}
C_{1 T}(k)=\sum_{j=1}^{T-1}\left(1-\frac{j}{T}\right) k^{2}\left(\frac{j}{M}\right), D_{1 T}(k)=\sum_{j=1}^{T-1}\left(1-\frac{j}{T}\right)\left(1-\frac{j+1}{T}\right) k^{4}\left(\frac{j}{M}\right) \\
C_{2 T}(k)=\sum_{j=1-T}^{T-1}\left(1-\frac{|j|}{T}\right) k^{2}\left(\frac{j}{M}\right), D_{2 T}(k)=\sum_{j=1-T}^{T-1}\left(1-\frac{|j|}{T}\right)\left(1-\frac{|j|+1}{T}\right) k^{4}\left(\frac{j}{M}\right)
\end{gathered}
$$

As indicated by Hong (2001), the constants $C_{i T}(k)$ and $D_{i T}(k)$ are approximately the mean and variance of the statistic $H_{i, t}(k)$.

In addition, the contemporaneous unidirectional AGDCC-GARCH Hong test from $\mathrm{y}_{2}$ to $\mathrm{y}_{1}$ allows the consideration of unidirectional spillover of contemporaneous information. This test statistic, denoted by $H_{10, t}(k)$, is defined as follows: 


$$
H_{10, t}(k)=\frac{T \sum_{j=0}^{T-2} k^{2}\left(\frac{j+1}{M}\right) r_{12, t}^{2}(j)-C_{1 T}(k)}{\sqrt{2 D_{1 T}}(k)}
$$

As noted by Lu et al. (2014), in the time-varying Hong causality tests it is not feasible to estimate all lagged dynamic correlations. However, this problem can be avoided by selecting an appropriate kernel function. Since in financial markets the lagged dynamic correlations usually tend to zero for large lags, the Bartlett kernel emerges as an interesting choice to be used in empirical studies. This kernel takes the following form:

$$
k(z)=\left\{\begin{array}{c}
1-|z|,|z|<1 \\
0,|z| \geq 1
\end{array}\right.
$$

When $\mathrm{j} \geq M$, the Bartlett kernel $k\left(\frac{j}{M}\right)=0$, therefore only dynamic cross correlations with lag $M>j>-M$ need to be estimated when using this kernel.

Under appropriate regularity conditions, the time-varying Hong causality tests are asymptotically distributed as a normal distribution with mean zero and variance unit, which facilitates to make rough judgements. The test of Lu et al. (2014) is a one-sided test and, hence, upper-tailed $\mathrm{N}(0,1)$ critical values should be used. If the test statistic $H_{i, t}(k)$ is larger than the critical value of the standard normal distribution, then the null hypothesis of no causality is rejected.

\section{Data description}

The data set in this study consists of weekly closing prices of crude oil and stock indices of six major developed oil-importing countries, namely France, Germany, Italy, Spain, the UK and the US. The stock market indices considered are: CAC 40 (France), DAX 30 (Germany), MIB 30 (Italy), IBEX 35 (Spain), FTSE 100 (United Kingdom) and S\&P 500 (United States). For the crude oil, the Brent oil price, expressed in US dollars per barrel, is used in the present study. The Brent oil is the benchmark price for roughly two thirds of the world's oil supply, in particular for the petroleum production from Europe, Africa and the Middle East. ${ }^{\text {iv }}$ The sample period ranges from January 4, 1993 to December 31, 2014, covering an interesting time frame that allows us to assess the effect of the recent global financial crisis on the dynamic interactions between oil prices and international stock markets. Weekly data on Brent crude oil prices are collected from the US Energy Information Administration (EIA) website, while stock returns are taken from Thomson Financial DataStream. Following the usual practice, oil price changes and stock returns are calculated as the first difference of the natural logarithmic of the price indices. In line 
with, among others, Arouri et al. (2011), Awartani \& Maghyereh (2013) and Bouri (2015), weekly data (sampled on Wednesdays) are utilized. Weekly data are less affected by noise and anomalies such as day-of-the-week effects than daily data. Moreover, according to the under-reaction hypothesis in the oil market, it may take some time before information about oil price changes becomes fully reflected in stock prices, which also justifies the use of the weekly frequency (Driesprong et al., 2008).

The descriptive statistics for oil price fluctuations and stock returns are provided in Table 1. The mean weekly changes in oil prices and stock returns are very close to zero and small compared to their standard deviations, which implies relatively high volatility in both crude oil and stock markets. Based on the standard deviation, oil price movements have higher volatility than stock returns, reflecting the great instability of crude oil prices during most of the sample period. The negative values of skewness coefficients suggest that the probability of observing large negative returns is higher than that of large positive returns in oil and stock markets. Furthermore, the kurtosis coefficient is greater than three in all cases, implying that the series of oil price changes and stock returns are leptokurtic (more peaked around the mean and with fatter tails than the Gaussian distribution). This departure from normality is confirmed by the Jarque-Bera test statistics, which reject the null hypothesis of normality at the $1 \%$ level for all the time series under scrutiny. The Ljung-Box Q-statistics for the first 10 lags in the return series and their squares indicate the existence of significant autocorrelation for oil price changes and stock returns of virtually all countries. This finding justifies the use of GARCH-type models to capture the volatility clustering in the data.

Table 1. Descriptive statistics for weekly oil price changes and stock returns

\begin{tabular}{lccccccc}
\hline & $\begin{array}{c}\text { Oil } \\
\text { price } \\
\text { changes }\end{array}$ & $\begin{array}{c}\text { French } \\
\text { stock } \\
\text { returns }\end{array}$ & $\begin{array}{c}\text { German } \\
\text { stock } \\
\text { returns }\end{array}$ & $\begin{array}{c}\text { Italian } \\
\text { stock } \\
\text { returns }\end{array}$ & $\begin{array}{c}\text { Spanish } \\
\text { stock } \\
\text { returns }\end{array}$ & $\begin{array}{c}\text { British } \\
\text { stock } \\
\text { returns }\end{array}$ & $\begin{array}{c}\text { US } \\
\text { stock } \\
\text { returns }\end{array}$ \\
\hline Mean & 0.00095 & 0.00078 & 0.00163 & 0.00058 & 0.00121 & 0.00077 & 0.00136 \\
Std. Dev. & 0.048 & 0.02991 & 0.03147 & 0.03238 & 0.03114 & 0.0234 & 0.02294 \\
Skew. & -0.23 & -0.35 & -0.72 & -0.35 & -0.40 & -0.34 & -0.66 \\
Kurtosis & 4.82 & 6.26 & 6.87 & 4.67 & 4.57 & 6.43 & 7.76 \\
JB & $168.0 * * *$ & $532.0 * * *$ & $514.1 * * *$ & $155.6 * * *$ & $148.0 * * *$ & $585.2 * * *$ & $1167.2 * * *$ \\
Q(10) & 11.95 & $36.74 * * *$ & $27.47 * * *$ & $22.74 * *$ & $26.15 * * *$ & $25.10^{* * *}$ & $29.15 * * *$ \\
$\mathrm{Q}^{2}(10)$ & $235.93 * * *$ & $277.46 * * *$ & $209.44 * * *$ & $137.54 * * *$ & $237.97 * * *$ & $297.45 * *$ & $241.61 * * *$ \\
\hline
\end{tabular}

Notes: This table presents the descriptive statistics for weekly oil price changes and stock returns of the different countries under consideration during the period from January 1993 to December 2014. They include mean and standard deviation (Std. Dev.) values, as well as Skewness (Skew.) and Kurtosis measures. JB is the statistic of the Jarque-Bera test for normality. Q(10) and $\mathrm{Q}^{2}(10)$ denote the Ljung-Box Q-statistics for serial correlation of order 10 in raw returns and squared returns, respectively. The symbols *, ** and *** indicate statistical significance at the $10 \%, 5 \%$ and $1 \%$ levels, respectively. 
The standard Augmented Dickey-Fuller (ADF) and Phillips-Perron (PP) unit root tests have been extensively used in economic and financial applications to determine the order of integration of time series data. However, a well-known weakness of these tests is that they lack power in the presence of structural breaks in the series under examination. As noted by Perron (1989), ignoring structural breaks may lead to the spurious acceptance of the unit root hypothesis. To avoid this possibility, the GARCH-based unit root test recently proposed by Narayan \& Liu (2015), which accounts for a time trend and two endogenous structural breaks and allows for the presence of heteroskedasticity in the data series, is applied to assess whether the crude oil price and stock market indices are unit root processes. ${ }^{\vee}$ Narayan \& Liu (2015) have demonstrated that their trend-GARCH-based test outperforms other GARCH-based unit root tests including those of Narayan \& Liu (2011) and Narayan et al. (2016). ${ }^{\mathrm{vi}}$

Table 2 presents the results of the trend-GARCH-based unit root test with two structural breaks of Narayan \& Liu (2015) applied on the stock market indices and the Brent crude oil price. As can be seen in Panel A, the time trend coefficient is positive and statistically significant at the $1 \%$ level for all the series examined under different specifications. This implies that the time trend is a key feature of stock market and oil price data, thus supporting the use of the trend-GARCH-based unit root test of Narayan \& Liu (2015). The results of this test in Panel B show that all the stock market indices have a unit root, excepting the US S\&P 500 and the British FT 100 indices at the 5\% significance level, although not at the $1 \%$ level. Instead, the unit root hypothesis is rejected for the Brent oil price at the $1 \%$ level. This finding of stationarity for the oil price coincides with the evidence obtained by Narayan \& Liu (2015) and Liu et al. (2016).

Table 2. Narayan \& Liu (2015) GARCH two structural break unit root test with a time trend

\begin{tabular}{|l|c|c|c|c|c|c|c|}
\hline & $\begin{array}{c}\text { Spanish stock } \\
\text { index }\end{array}$ & $\begin{array}{c}\text { British stock } \\
\text { index }\end{array}$ & $\begin{array}{c}\text { US stock } \\
\text { index }\end{array}$ & $\begin{array}{c}\text { German stock } \\
\text { index }\end{array}$ & $\begin{array}{c}\text { French stock } \\
\text { index }\end{array}$ & $\begin{array}{c}\text { Italian stock } \\
\text { index }\end{array}$ & Oil price \\
\hline Panel A. Time trend in the series. & & & & \\
\hline Trend & 1.1628 & 0.4350 & 0.1709 & 1.0045 & 0.2918 & 0.0028 & 0.0198 \\
{$[0.0000]$} & {$[0.0000]$} & {$[0.0000]$} & {$[0.0000]$} & {$[0.0000]$} & {$[0.0003]$} & {$[0.0000]$} \\
\hline Trend1 & 1.1005 & 0.3586 & 0.1472 & 0.7580 & 0.2045 & 0.0021 & 0.0170 \\
& {$[0.0000]$} & {$[0.0000]$} & {$[0.0000]$} & {$[0.0000]$} & {$[0.0000]$} & {$[0.0003]$} & {$[0.0000]$} \\
\hline Trend2 & 1.0323 & 0.3775 & 0.1072 & 1.0026 & 0.1293 & 0.0018 & 0.0108 \\
{$[0.0000]$} & {$[0.0000]$} & {$[0.0000]$} & {$[0.0000]$} & {$[0.0000]$} & {$[0.0003]$} & {$[0.0000]$} \\
\hline
\end{tabular}

Panel B. Narayan \& Liu (2015) unit root test. 


\begin{tabular}{|l|r|r|r|r|r|r|r|}
\hline T1 & $11 / 4 / 2010$ & $8 / 5 / 1998$ & $1 / 3 / 1994$ & $5 / 29 / 1996$ & $4 / 13 / 2004$ & $3 / 9 / 2004$ & $6 / 29 / 2004$ \\
\hline T2 & $7 / 24 / 2014$ & $10 / 12 / 2007$ & $5 / 7 / 2007$ & $10 / 10 / 2014$ & $5 / 7 / 2007$ & $3 / 12 / 2008$ & $1 / 20 / 2014$ \\
\hline$t$-statistic & -0.7497 & $-3.0324 * *$ & $-3.3698 * *$ & -2.3288 & -0.8468 & -1.5964 & $-3.6280 * * *$ \\
\hline
\end{tabular}

Notes: This table presents the results of the trend-GARCH two structural break unit root test of Narayan \& Liu (2015) for the daily stock market indices and Brent crude oil price. Panel A reports trend coefficients and the $p$-value (in brackets) for each variable. Trend is estimated from a simple OLS model which regresses the series considered on a constant and a time trend. Trend 1 is estimated from an OLS regression model with structural breaks and time trend. Trend 2 is estimated from an OLS regression model with structural breaks and time trend plus the squared of the respective price variable. Panel B contains the first and second break dates (T1 and T2) and the trend-GARCH $t$-statistic examining the null hypothesis of a unit root. The critical values of the GARCH unit root test of Narayan \& Liu (2015) are taken from Table 6 in the paper by Narayan \& Liu (2015). As usual, *,** and *** indicate rejection of the unit root hypothesis at the $10 \%, 5 \%$ and $1 \%$ significance levels, respectively.

\section{Empirical results}

\subsection{Time-varying Granger causality tests in mean and variance}

In this section, we present the results of the time-varying Granger causality in mean and variance tests of $\mathrm{Lu}$ et al. (2014) between crude oil and stock markets in a multiscale framework. The HTW transform is used to decompose the original time series of weekly oil price changes and stock returns for each country into eight scales, S1-S8. Concretely, $\mathrm{S} 1$ is the lower scale and represents short-term oil price and stock return fluctuations due to shocks occurring in a time horizon of 2 to 4 weeks. In addition, the wavelet scales S2S8 are associated with variations at time scales of length 4-8, 8-16, 16-32, 32-64, 64-128, 128-256 and 256-512 weeks, respectively. The wavelet coefficients at each scale reflect detail characteristics hidden in the original data. The Bartlett kernel and a number of lags equal to $10(M=10)$ have been selected for the dynamic causality procedure of Lu et al. (2014). ${ }^{\mathrm{vii}}$ As indicated earlier, the conditional correlation in the time-varying causality tests has been estimated using a AGDCC-GARCH( 1,1$)$ model. viii

Fig. 1. Dynamic AGDCC-GARCH(1,1) Hong causality-in-mean test statistics for each country UNITED STATES

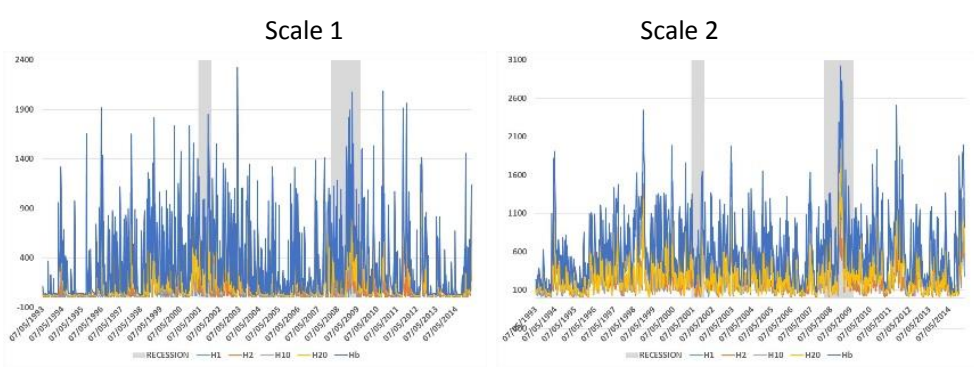




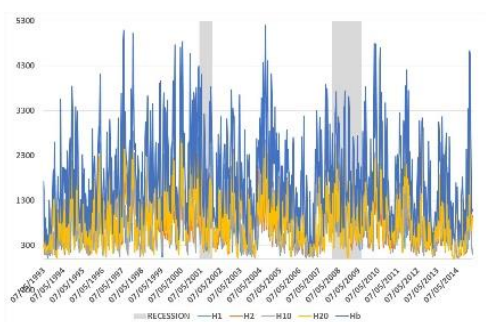

Scale 6

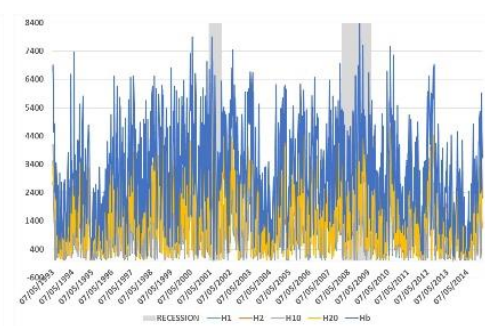

Scale 7

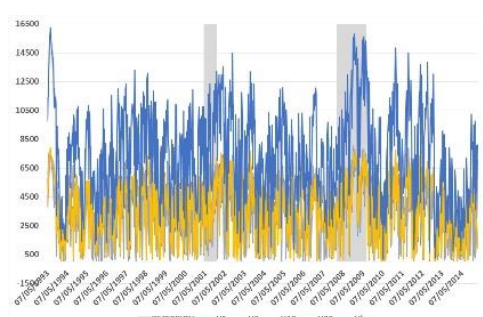

Scale 8
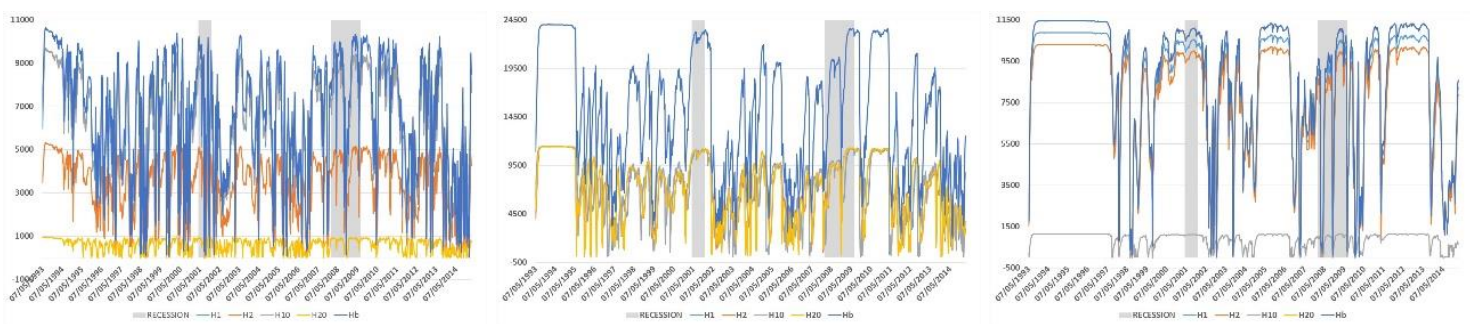

GERMANY

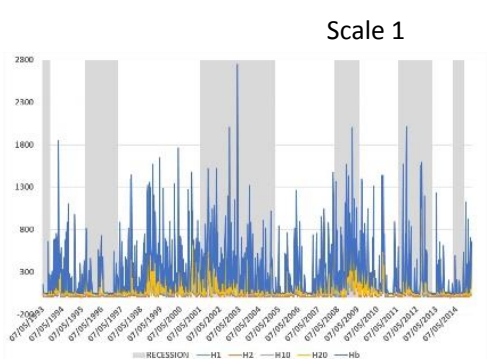

Scale 2

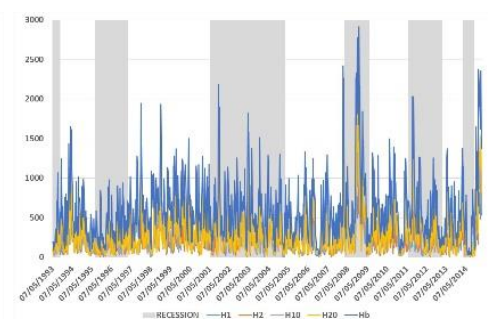

Scale 3

Scale 4

Scale 5
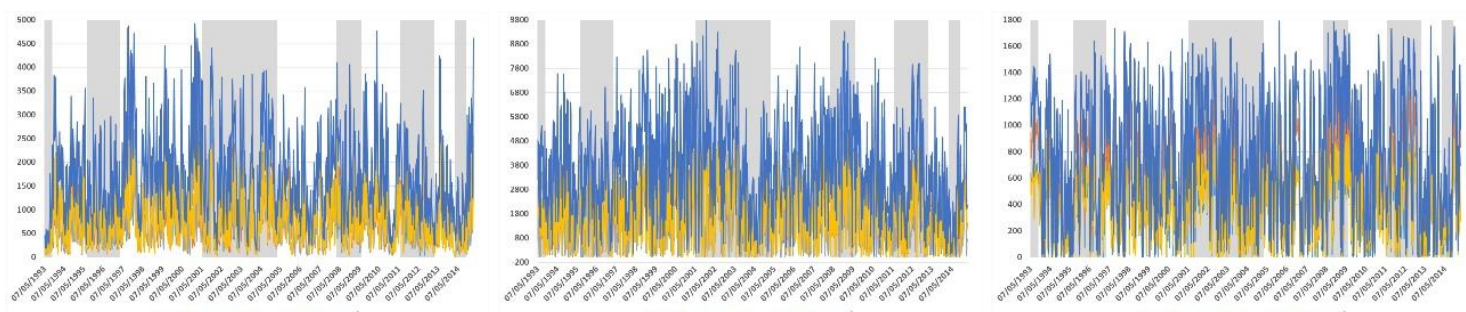

Scale 6

Scale 7

Scale 8
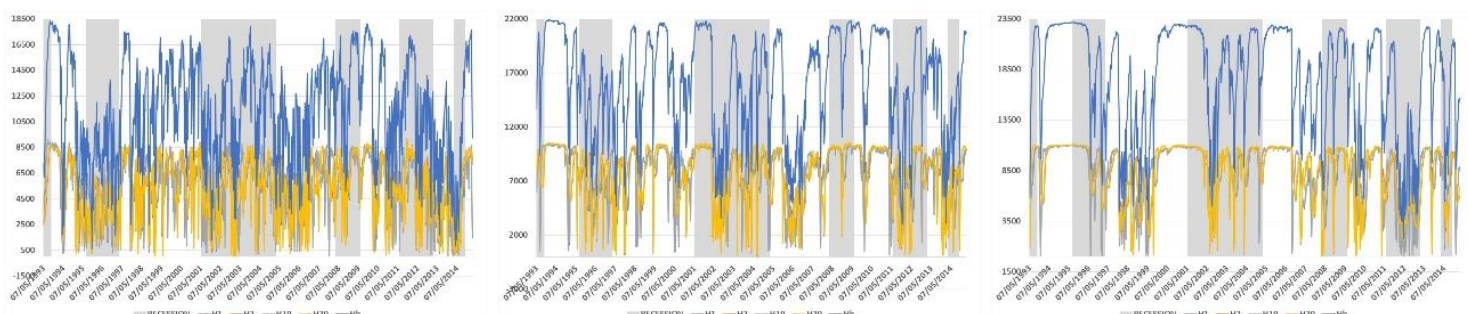

FRANCE

Scale 1

Scale 2 


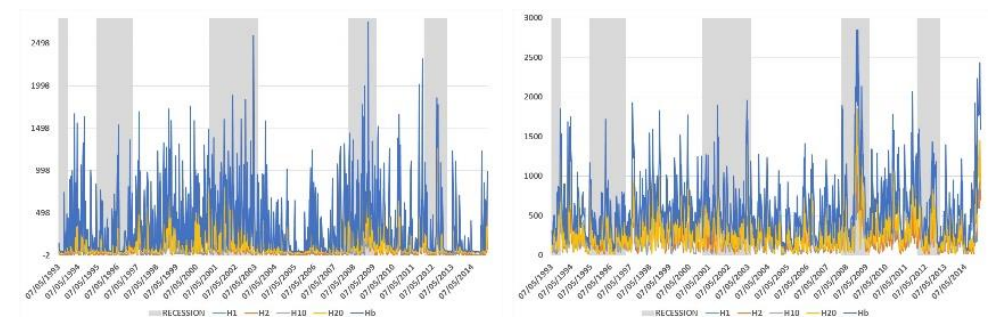

Scale 3

Scale 4

Scale 5
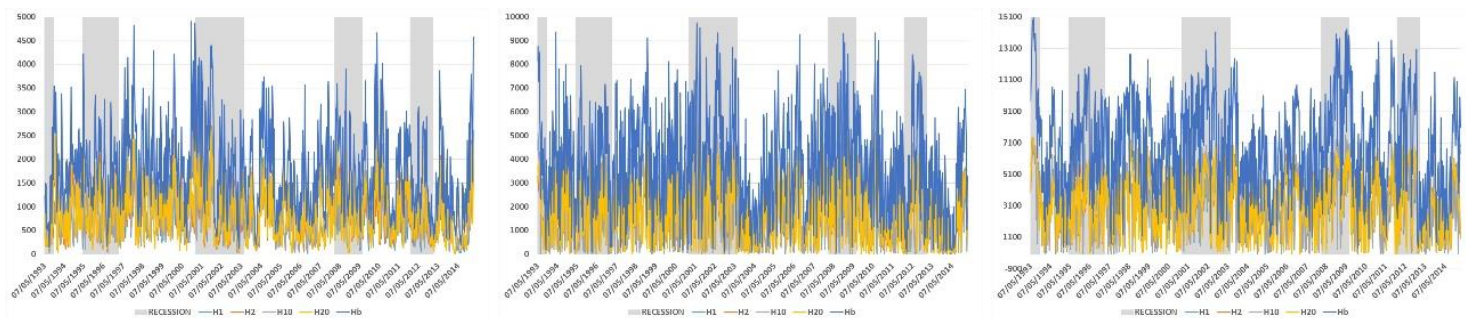

Scale 6

Scale 7

Scale 8
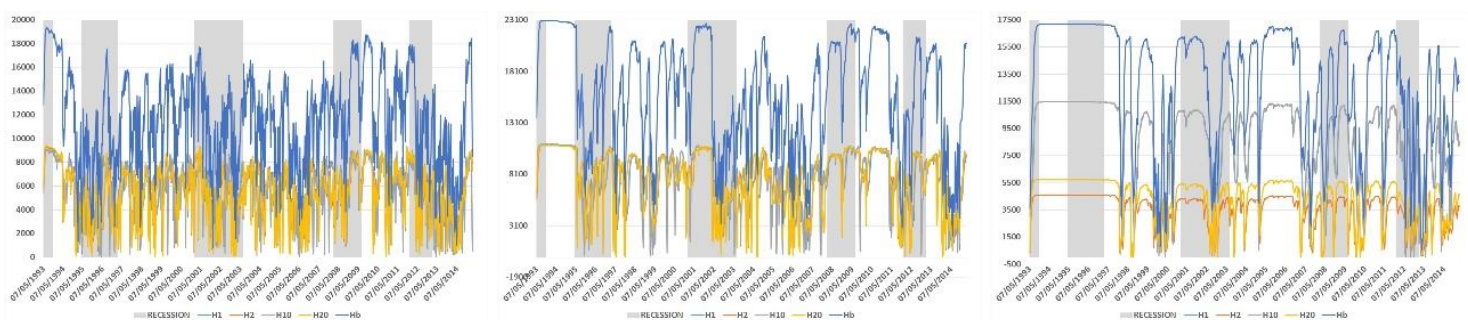

ITALY
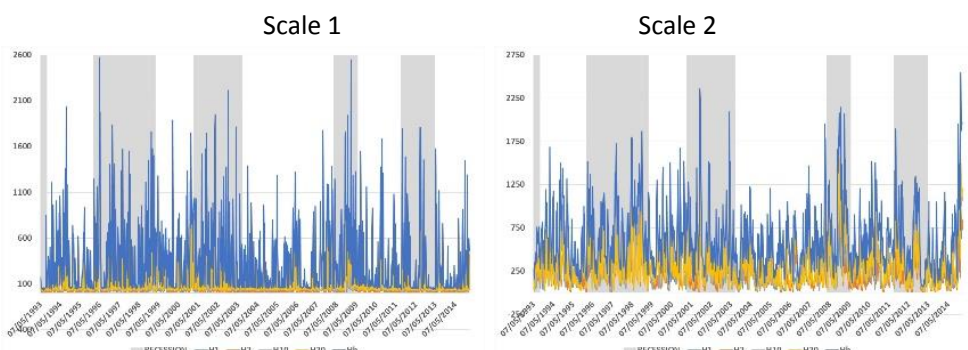

Scale 3

Scale 4

Scale 5

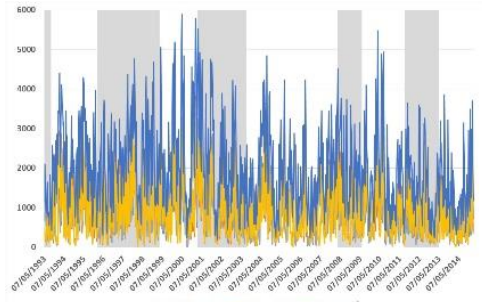

Scale 6

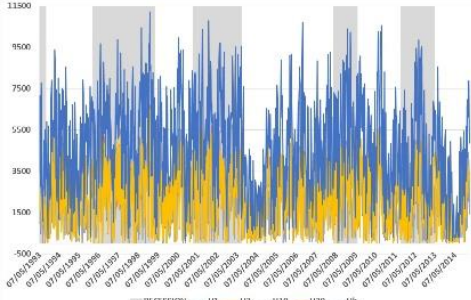

Scale 7

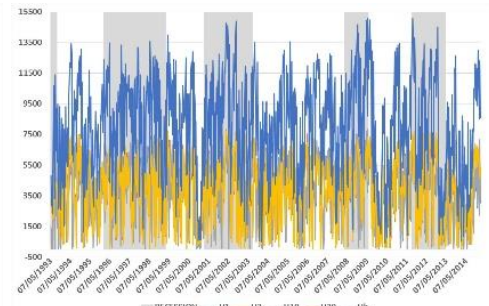

Scale 8 

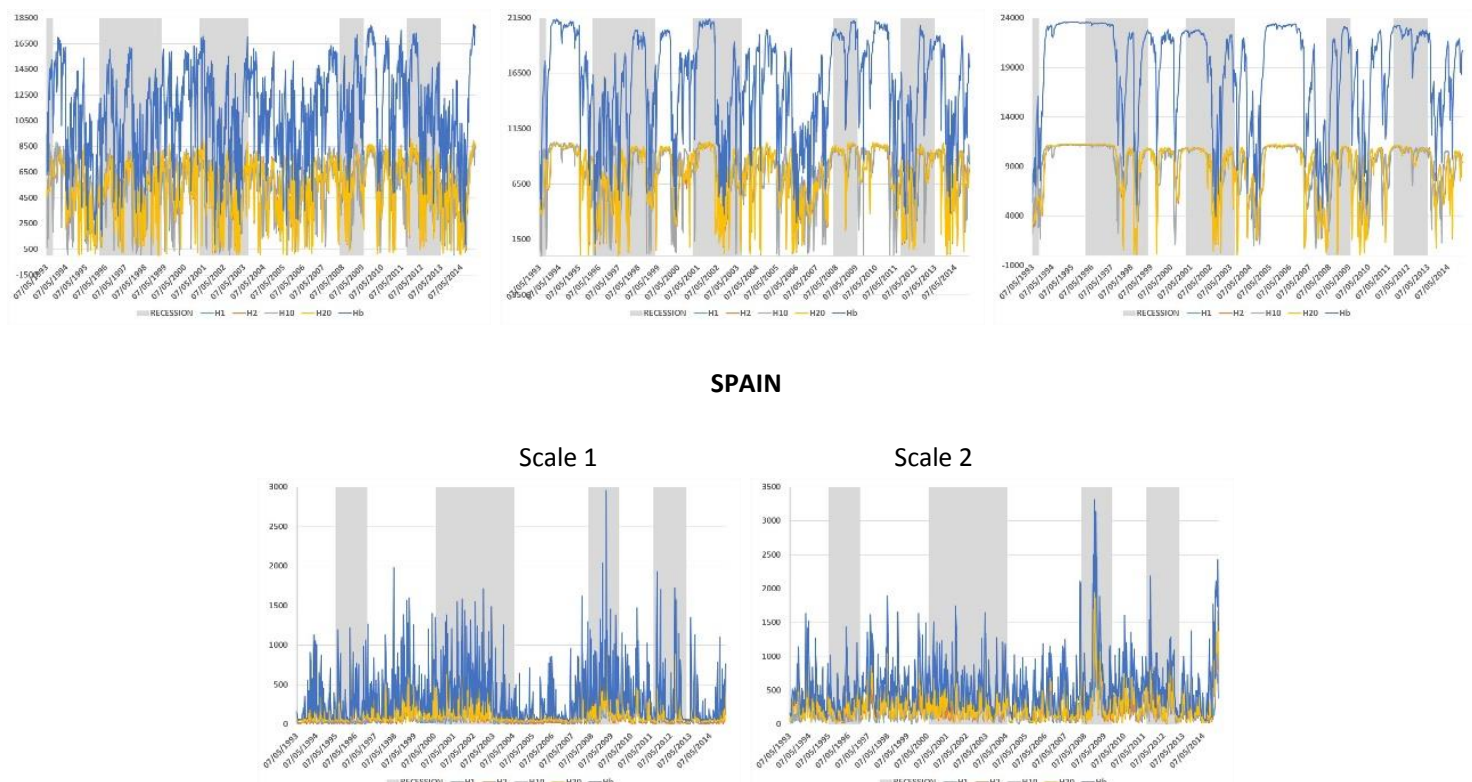

SPAIN
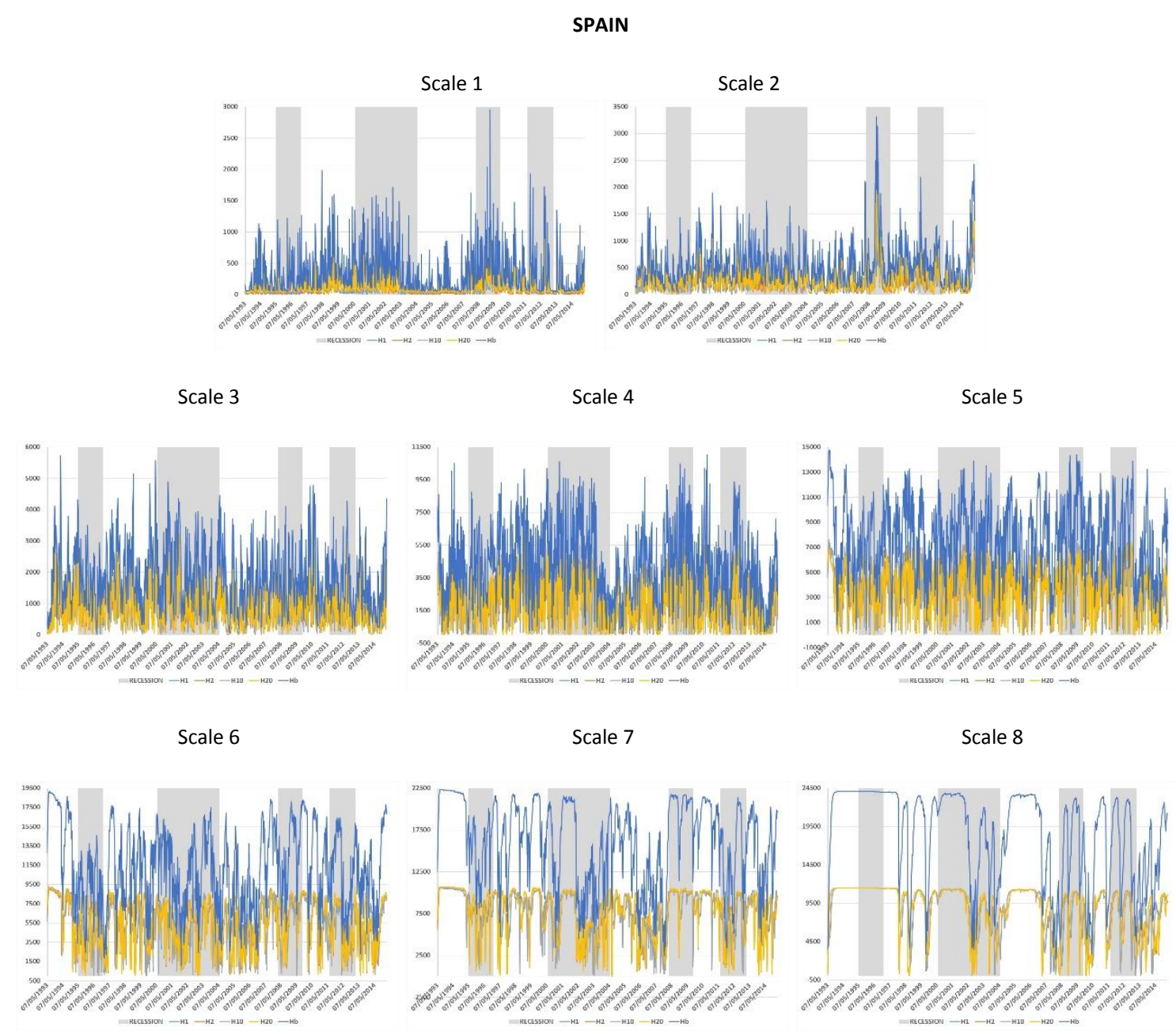

UNITED KINGDOM
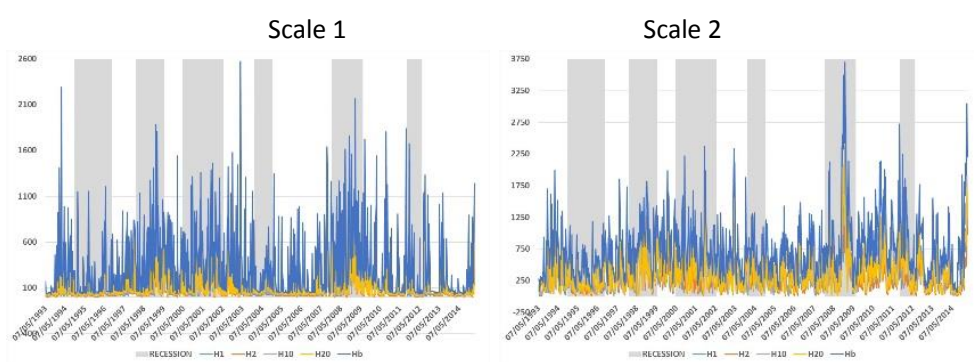

Scale 3

Scale 4

Scale 5 


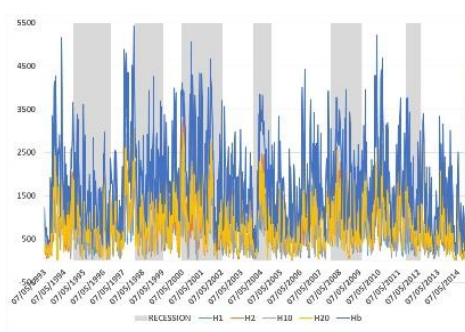

Scale 6

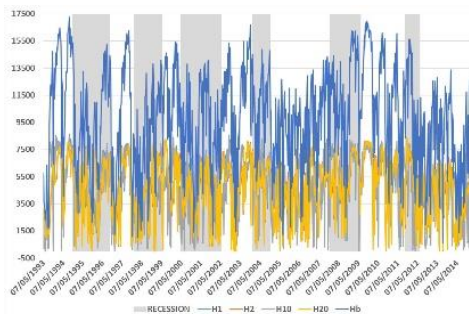

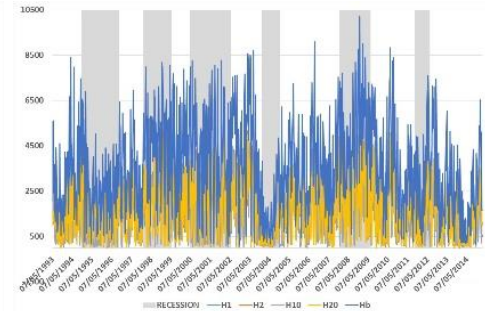

Scale 7

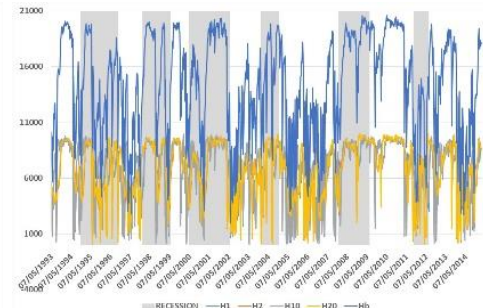

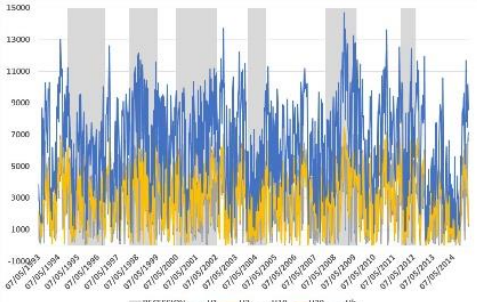

Scale 8

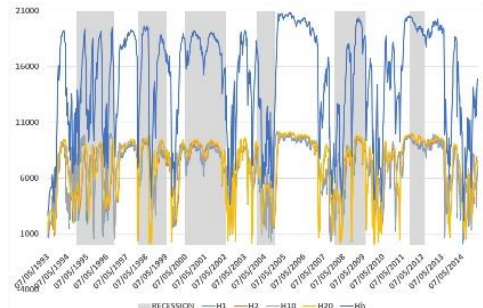

Notes: This figure depicts the sequence of dynamic AGDCC-GARCH $(1,1)$ Hong causality-in-mean test statistics on a scale-by-scale basis for the five directions of causality and for each country. $\mathrm{H}_{1}$ indicates unidirectional causality running from oil price changes to stock returns, $\mathrm{H}_{2}$ represents unidirectional causality running from stock returns to oil price movements, $\mathrm{H}_{10}$ denotes unidirectional causality from oil price changes to stock returns including the contemporaneous interaction between both variables and $\mathrm{H}_{20}$ indicates unidirectional causality from stock returns to oil price variations including the contemporaneous interaction. Finally, $\mathrm{H}_{\mathrm{b}}$ refers to the bidirectional causality between oil prices and stock returns. Shaded areas in graphs indicate recession periods based on the NBER dating.

Fig. 1 displays the sequence of dynamic AGDCC-GARCH $(1,1)$ causality-in-mean test statistics applied on a scale-by-scale basis for the five directions of causality and the six oil-importing countries under consideration. Specifically, $\mathrm{H}_{1}$ indicates unidirectional causality running from oil price changes to stock returns, $\mathrm{H}_{2}$ represents unidirectional causality running from stock returns to oil price movements, $\mathrm{H}_{10}$ denotes unidirectional causality from oil price changes to stock returns including the contemporaneous interaction between both variables and $\mathrm{H}_{20}$ reflects unidirectional causality from stock returns to oil price fluctuations also including the contemporaneous relationship between the two variables. Lastly, $\mathrm{H}_{\mathrm{b}}$ refers to the bidirectional causality between oil price changes and stock returns. Shaded areas in graphs indicate recession periods based on the NBER dating. As can be seen, the pattern of causality-in-mean is virtually identical for all the countries. There are significant unidirectional and bidirectional causal relations in mean at the $1 \%$ level during almost all the entire sample period for the different time scales, suggesting that oil and stock markets of the main developed oil-importing countries are intimately linked. The only exception is found in the case of the unidirectional causality in both directions when the contemporaneous linkage between the variables is not considered for the first time scale (S1), which corresponds to the very short-term and is typically associated to high frequency speculative traders. The lower unidirectional causal relations between crude oil and stock markets at the first scale imply that spillover effects 
in mean are less clear in the very short-term. Moreover, the magnitude of the causalityin-mean test statistics tends to increase with the time scale, suggesting that the causal links in mean are more pronounced at the coarser scales. In addition, a closer look at the graphs in Fig. 1 reveals that the causal interactions seem intensify during periods of turbulence, such as the September 2001 terrorist attacks in the US, the global financial crisis of 2007-2008 or the subsequent European debt crisis of 2009-2011.

Fig. 2. Dynamic AGDCC-GARCH(1,1) Hong causality-in-variance test statistics for each country

UNITED STATES
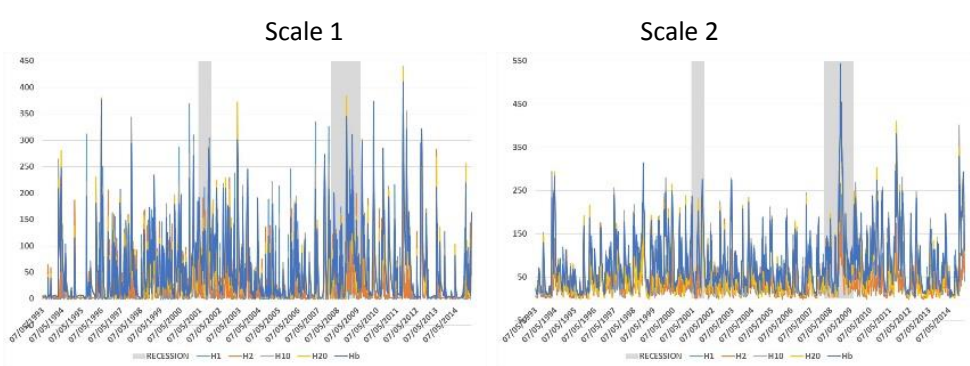

Scale 3

Scale 4

Scale 5
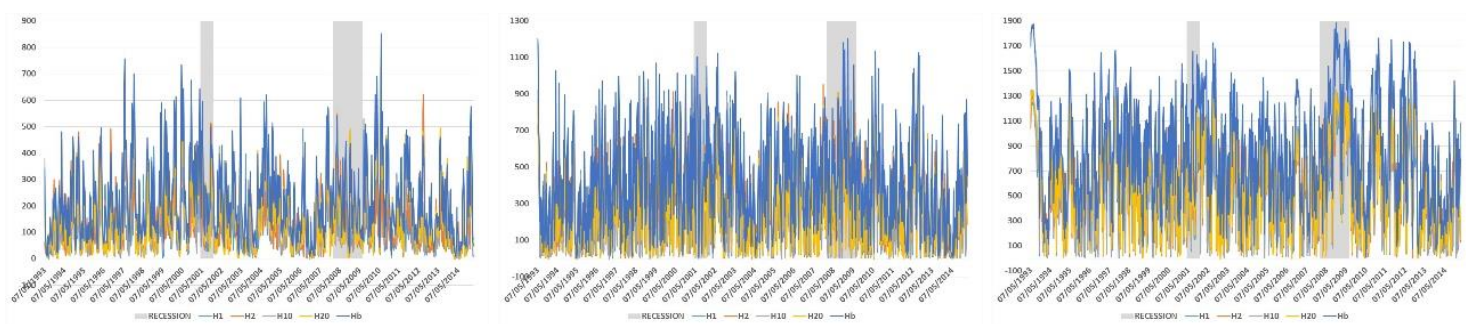

Scale 6

Scale 7

Scale 8
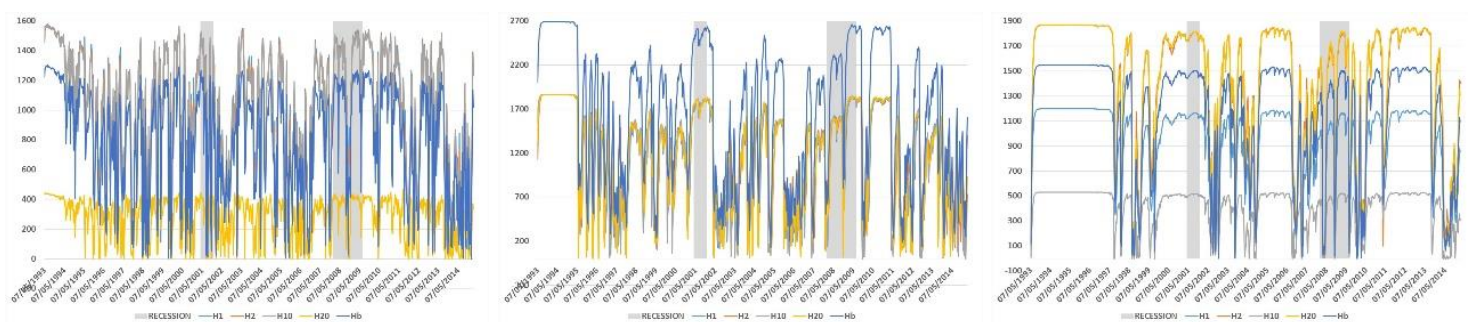

GERMANY
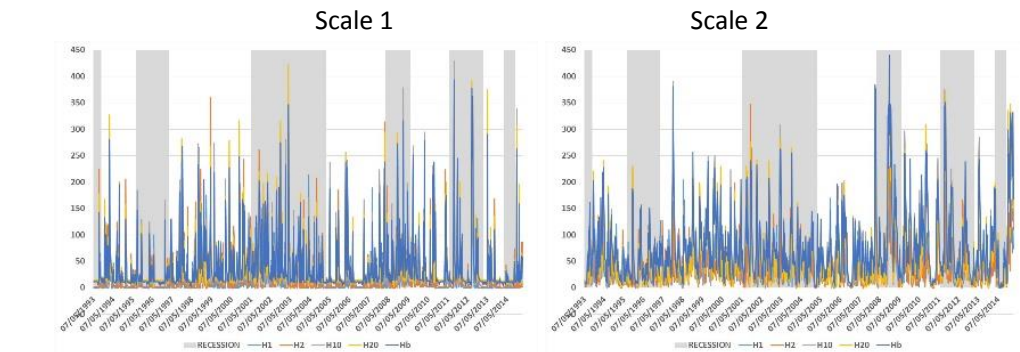


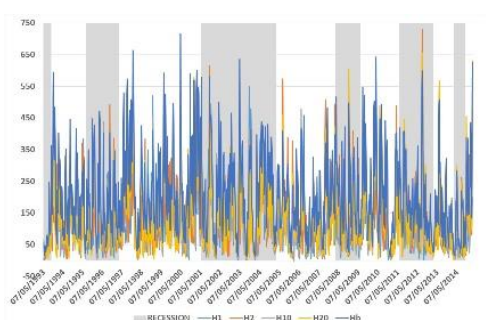

Scale 6

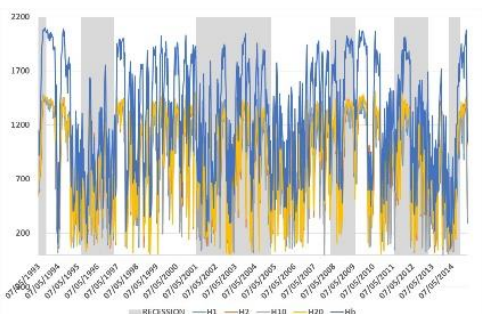

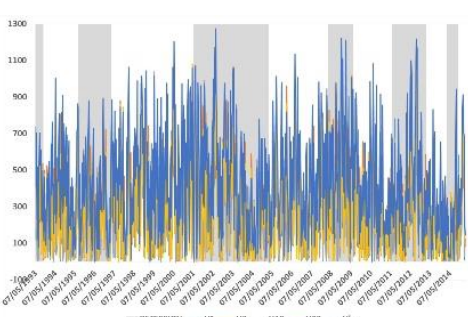

Scale 7
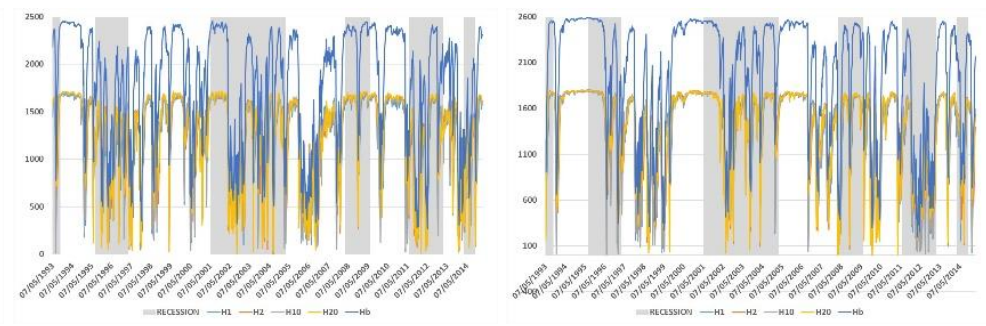

FRANCE

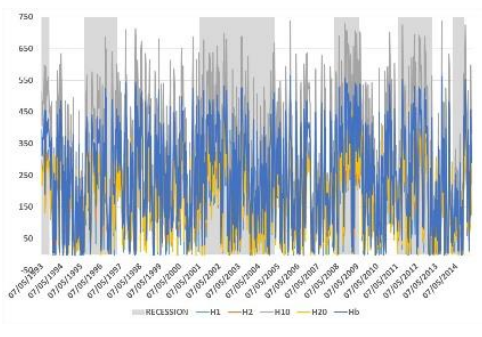

Scale 8

Scale 2
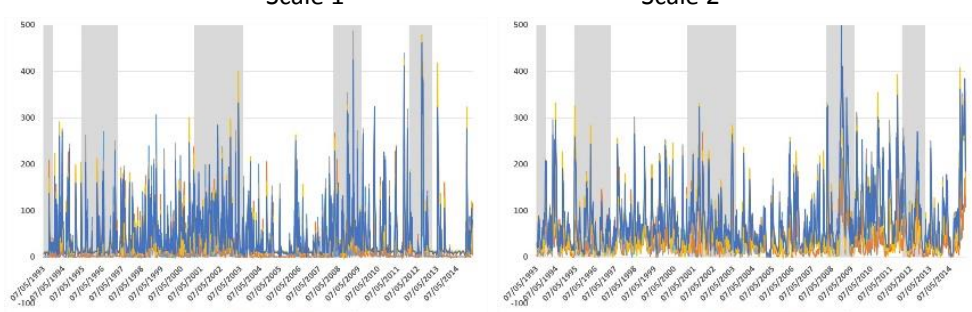

Scale 3

Scale 4

Scale 5

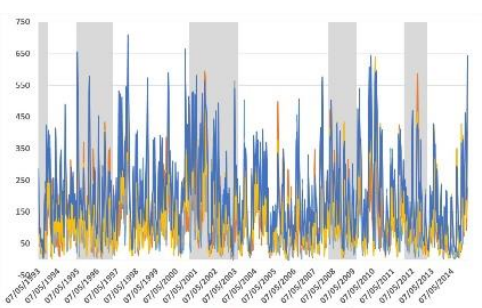

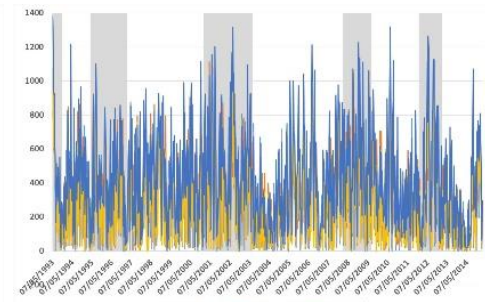

Scale 7

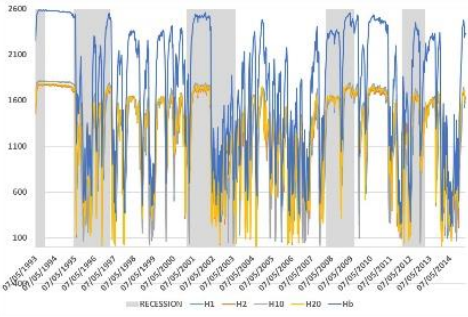

ITALY

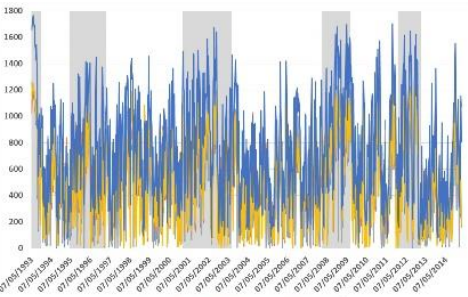

Scale 8

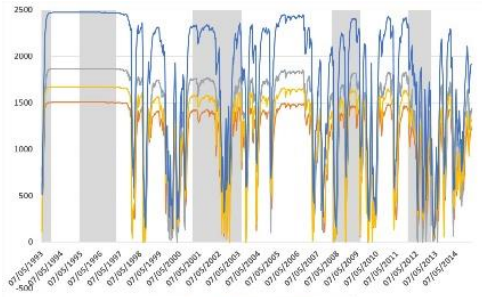

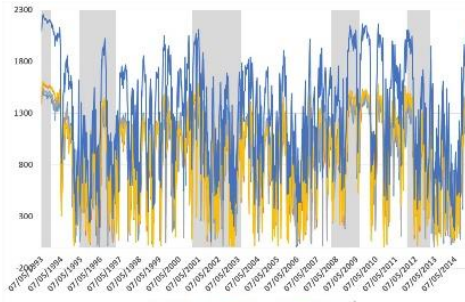

. . . . . . . . 

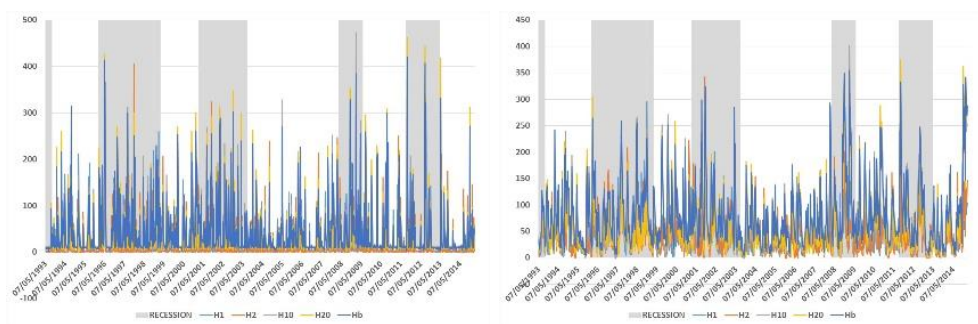

Scale 3

Scale 4

Scale 5
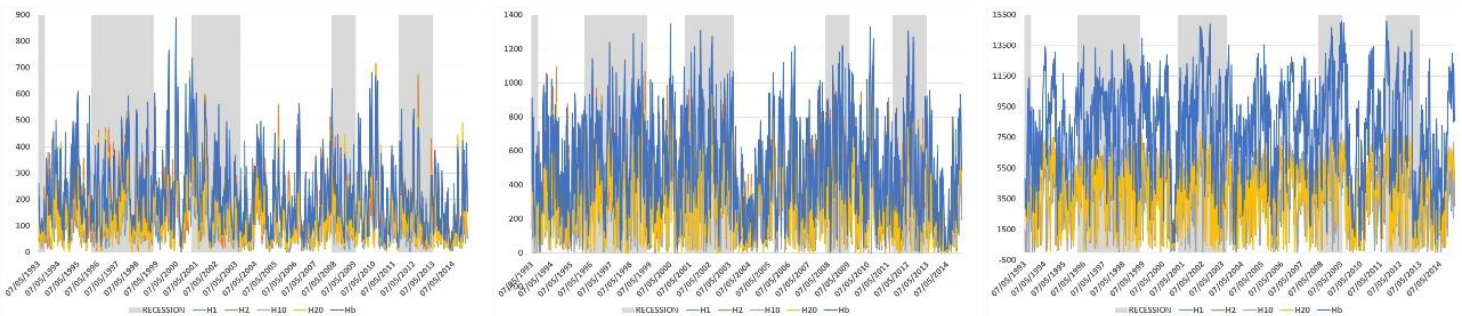

Scale 6

Scale 7

Scale 8
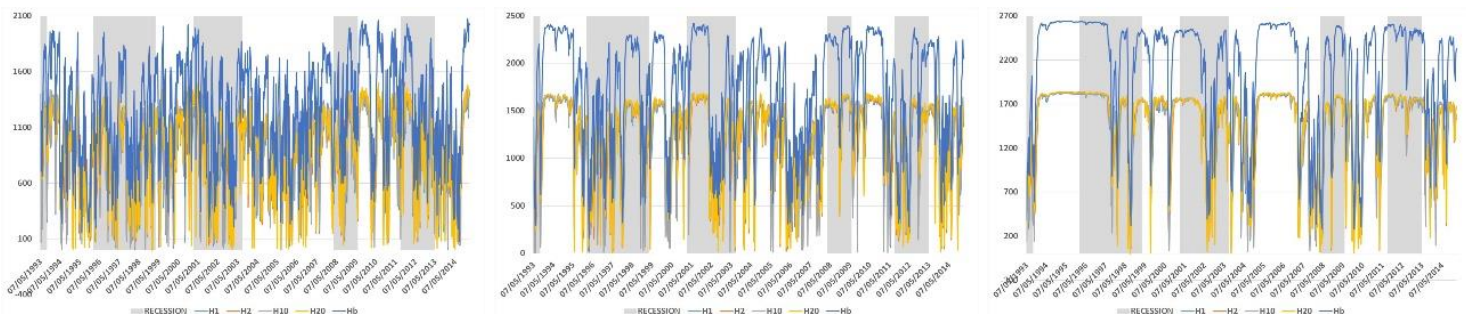

SPAIN
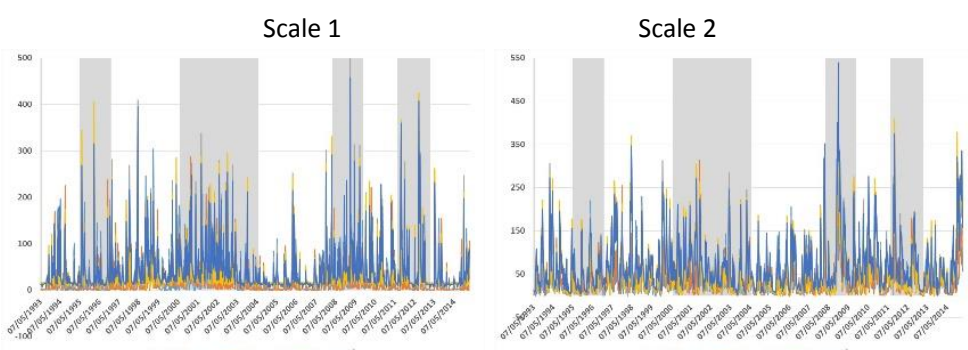

Scale 3

Scale 4

Scale 5

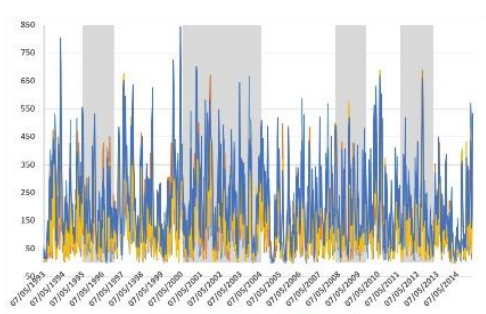

Scale 6

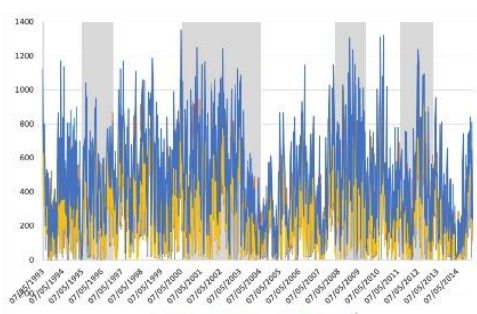

Scale 7

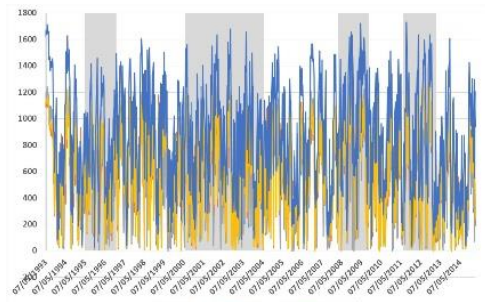

Scale 8 

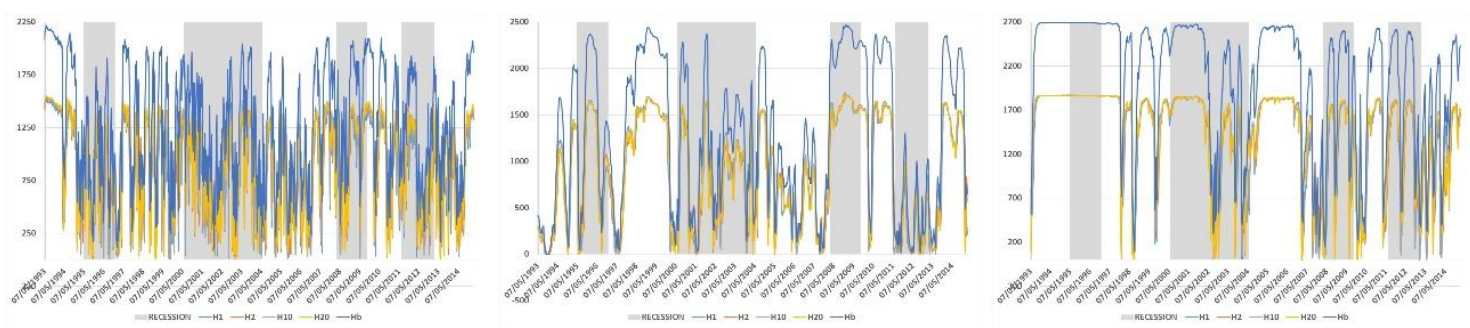

UNITED KINGDOM
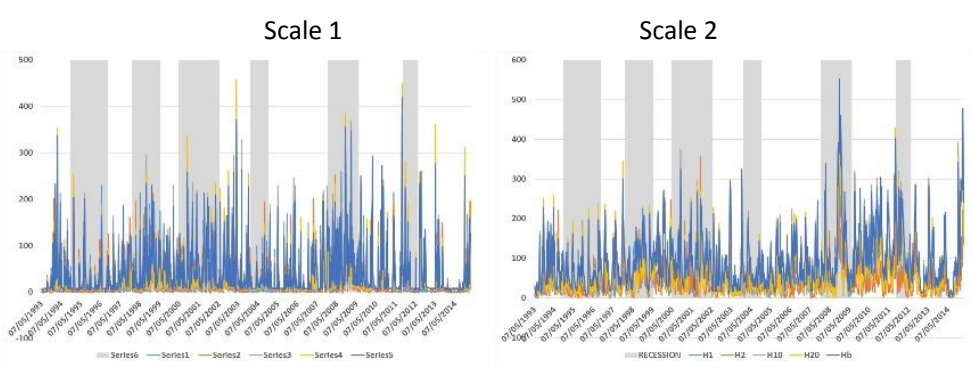

Scale 3

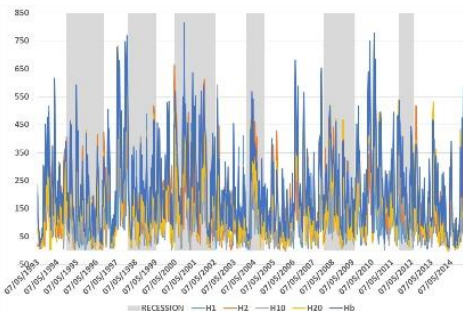

Scale 6

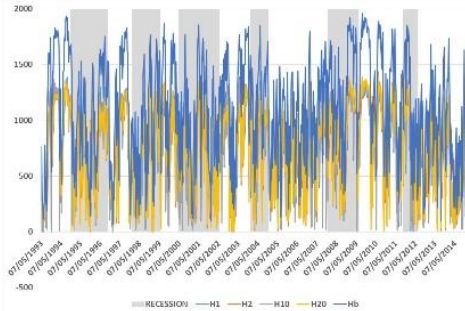

Scale 4

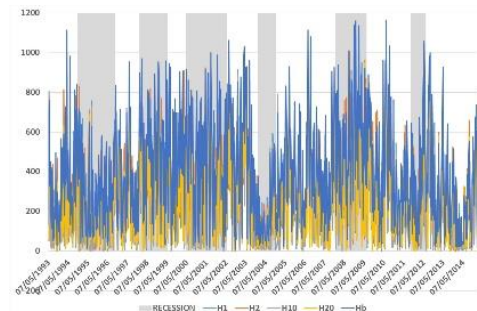

Scale 7

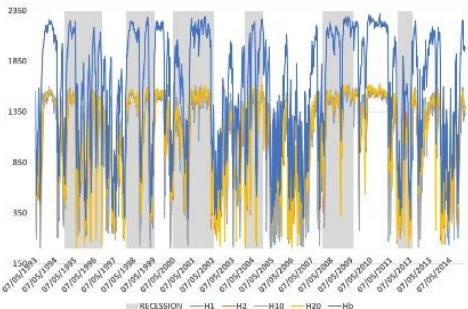

Scale 5
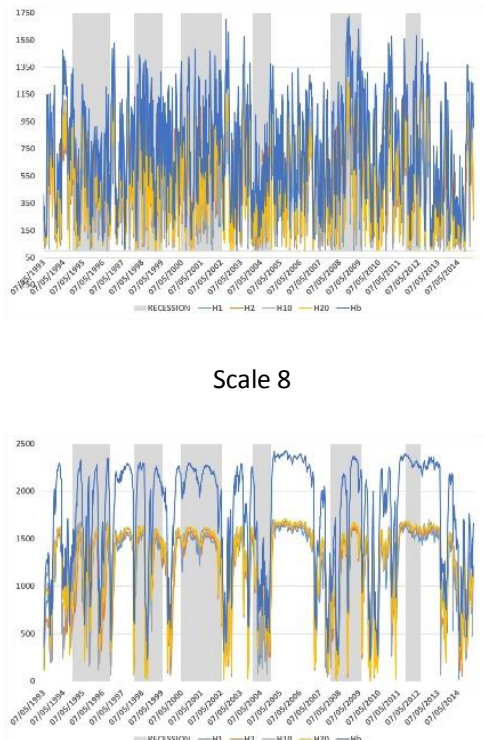

Notes: This figure shows the Time path of dynamic AGDCC-GARCH(1,1) Hong causality-in-variance test statistics on a scale-by-scale basis for the five directions of causality and for each country. $\mathrm{H}_{1}$ indicates unidirectional causality running from oil price changes to stock returns, $\mathrm{H}_{2}$ represents unidirectional causality running from stock returns to oil price movements, $\mathrm{H}_{10}$ denotes unidirectional causality from oil price changes to stock returns including the contemporaneous interaction between both variables and $\mathrm{H}_{20}$ indicates unidirectional causality from stock returns to oil price variations including the contemporaneous interaction. Finally, $\mathrm{Hb}$ refers to the bidirectional causality between oil prices and stock returns. Shaded areas in graphs indicate recession periods based on the NBER dating.

Fig. 2 depicts the time path of the dynamic AGDCC-GARCH(1,1) causality-in-variance test statistics on a scale-by-scale basis for the five directions of causality and the six countries examined. The evidence regarding the causality-in-variance is very similar to that of the causality-in-mean described above, demonstrating an important transmission of information between crude oil and stock markets, both in mean and volatility. A very 
homogeneous pattern of causality-in-variance between oil price changes and equity returns is found across countries, which is characterized by significant unidirectional and bidirectional causal relations over most the sample period for the different time scales considered. Again, the only exception appears in the first time scale for the unidirectional causality in both directions when the contemporaneous relationship between the variables is not considered. Furthermore, the magnitude of the causality-in-variance test statistics is higher at the upper scales and the causal linkages seem to be more pronounced during episodes of financial turmoil.

Tables 3 and 4 show the percentage of significant causal linkages in mean and variance at the $1 \%$ level, respectively, for the different time scales and countries under scrutiny. ${ }^{\text {ix }}$ The results of these tables corroborate the visual evidence from figures 1 and 2 , highlighting once again the homogeneous pattern of Granger causality in mean and variance for all the countries analyzed and the presence of significant causal interactions over practically the whole sample period.

Table 3. Percentage of significant causal linkages in mean for each country (in \%)

\begin{tabular}{|c|c|c|c|c|c|}
\hline Germany & $\mathrm{H}_{1}$ & $\mathrm{H}_{2}$ & $\mathrm{H}_{10}$ & $\mathrm{H}_{20}$ & $\mathbf{H}_{\mathrm{b}}$ \\
\hline S1 & 54.92 & 55.71 & 99.03 & 97.72 & 99.12 \\
\hline $\mathrm{S} 2$ & 96.13 & 96.40 & 97.80 & 98.86 & 99.65 \\
\hline S3 & 100 & 99.91 & 99.91 & 99.91 & 10098.95 \\
\hline S4 & 98.59 & 99.38 & 99.21 & 99.30 & 100 \\
\hline S5 & 88.93 & 100 & 96.40 & 90.51 & 94.99 \\
\hline S6 & 100 & 100 & 100 & 100 & 100 \\
\hline S7 & 100 & 100 & 100 & 100 & 100 \\
\hline S8 & 100 & 100 & 100 & 100 & 100 \\
\hline France & $\mathbf{H}_{1}$ & $\mathrm{H}_{2}$ & $\mathrm{H}_{10}$ & $\mathrm{H}_{20}$ & $\mathbf{H}_{\mathrm{b}}$ \\
\hline $\mathrm{S} 1$ & 60.37 & 60.90 & 95.96 & 93.41 & 97.72 \\
\hline $\mathrm{S} 2$ & 97.10 & 97.45 & 98.59 & 99.30 & 100 \\
\hline S3 & 99.91 & 99.91 & 99.91 & 100 & 100 \\
\hline S4 & 98.95 & 99.82 & 99.56 & 99.74 & 100 \\
\hline S5 & 100 & 100 & 100 & 100 & 100 \\
\hline S6 & 100 & 100 & 100 & 100 & 100 \\
\hline S7 & 100 & 100 & 100 & 100 & 100 \\
\hline S8 & 100 & 99.21 & 100 & 99.30 & 100 \\
\hline Italy & $\mathrm{H}_{1}$ & $\mathrm{H}_{2}$ & $\mathrm{H}_{10}$ & $\mathrm{H}_{20}$ & $\mathbf{H}_{\mathrm{b}}$ \\
\hline $\mathrm{S} 1$ & 57.09 & 54.36 & 97.36 & 97.44 & 99.65 \\
\hline $\mathrm{S} 2$ & 99.03 & 96.30 & 99.47 & 99.38 & 100 \\
\hline S3 & 99.91 & 99.91 & 99.82 & 99.91 & 100 \\
\hline S4 & 99.91 & 99.56 & 99.91 & 99.65 & 100 \\
\hline S5 & 99.74 & 99.91 & 99.82 & 99.91 & 100 \\
\hline S6 & 100 & 99.91 & 100 & 99.91 & 100 \\
\hline S7 & 100 & 100 & 100 & 100 & 100 \\
\hline S8 & 100 & 100 & 100 & 100 & 100 \\
\hline Spain & $\mathrm{H}_{1}$ & $\mathbf{H}_{2}$ & $\mathrm{H}_{10}$ & $\mathrm{H}_{20}$ & $\mathbf{H}_{\mathrm{b}}$ \\
\hline $\mathrm{S} 1$ & 64.24 & 69.95 & 98.95 & 99.56 & 99.74 \\
\hline $\mathrm{S} 2$ & 97.36 & 98.24 & 98.95 & 99.47 & 100 \\
\hline S3 & 98.42 & 99.47 & 98.77 & 99.56 & 100 \\
\hline S4 & 99.74 & 99.91 & 99.82 & 99.91 & 100 \\
\hline S5 & 99.74 & 99.65 & 99.82 & 99.74 & 100 \\
\hline S6 & 100 & 100 & 100 & 100 & 100 \\
\hline S7 & 100 & 100 & 100 & 100 & 100 \\
\hline S8 & 100 & 100 & 100 & 100 & 100 \\
\hline US & $\mathbf{H}_{1}$ & $\mathbf{H}_{2}$ & $\mathrm{H}_{10}$ & $\mathrm{H}_{20}$ & $\mathbf{H}_{\mathrm{b}}$ \\
\hline S1 & 42.62 & 57.64 & 67.05 & 79.09 & 83.83 \\
\hline S2 & 98.77 & 96.66 & 99.91 & 98.95 & 100 \\
\hline
\end{tabular}




\begin{tabular}{|c|c|c|c|c|c|}
\hline S3 & 99.74 & 99.65 & 99.82 & 99.74 & 100 \\
\hline S4 & 97.63 & 99.82 & 98.86 & 100 & 100 \\
\hline S5 & 100 & 99.91 & 99.91 & 100 & 100 \\
\hline S6 & 100 & 100 & 100 & 94.99 & 100 \\
\hline S7 & 100 & 100 & 100 & 100 & 100 \\
\hline S8 & 100 & 100 & 96.49 & 100 & 100 \\
\hline UK & $\mathrm{H}_{1}$ & $\mathrm{H}_{2}$ & $\mathrm{H}_{10}$ & $\mathrm{H}_{20}$ & $\mathbf{H}_{\mathrm{b}}$ \\
\hline $\mathrm{S} 1$ & 67.05 & 63.27 & 97.80 & 85.50 & 98.77 \\
\hline S2 & 98.51 & 98.86 & 99.56 & 99.65 & 100 \\
\hline S3 & 100 & 99.65 & 99.91 & 99.74 & 100 \\
\hline $\mathrm{S} 4$ & 99.82 & 99.74 & 99.82 & 99.74 & 100 \\
\hline S5 & 99.91 & 100 & 99.81 & 99.91 & 100 \\
\hline S6 & 99.91 & 99.91 & 99.91 & 100 & 100 \\
\hline S7 & 100 & 100 & 100 & 100 & 100 \\
\hline S8 & 100 & 100 & 100 & 100 & 100 \\
\hline
\end{tabular}

Notes: This table reports the percentage of cases with significant causal relations in mean at the $1 \%$ level during the whole sample period for each country. The percentages are calculated for the five directions of causality and the eight time scales under consideration. S1 is the lower scale and represents the oil and stock market fluctuations due to shocks occurring in a time horizon of 2 to 4 weeks. In turn, the wavelet scales S2-S8 are associated with oscillations of length 4-8, 8-16, 16-32, 32-64, 64-128, 128-256 and 256-512 weeks, respectively.

Table 4. Percentage of significant causal linkages in variance for each country (in \%)

\begin{tabular}{|c|c|c|c|c|c|}
\hline Germany & $\mathrm{H}_{1}$ & $\mathrm{H}_{2}$ & $\mathrm{H}_{10}$ & $\mathrm{H}_{20}$ & $\mathrm{H}_{\mathrm{b}}$ \\
\hline S1 & 44.20 & 57.38 & 99.82 & 99.91 & 99.91 \\
\hline $\mathrm{S} 2$ & 95.87 & 92.88 & 97.45 & 97.36 & 99.12 \\
\hline S3 & 99.47 & 99.91 & 99.74 & 100 & 100 \\
\hline S4 & 98.24 & 99.21 & 98.68 & 98.95 & 100 \\
\hline S5 & 93.67 & 93.67 & 98.51 & 94.64 & 97.80 \\
\hline S6 & 99.91 & 100 & 99.91 & 100 & 100 \\
\hline S7 & 100 & 99.91 & 100 & 100 & 100 \\
\hline S8 & 100 & 100 & 100 & 100 & 100 \\
\hline France & $\mathrm{H}_{1}$ & $\mathrm{H}_{2}$ & $\mathrm{H}_{10}$ & $\mathrm{H}_{20}$ & $\mathbf{H}_{b}$ \\
\hline S1 & 47.72 & 58.79 & 97.19 & 98.86 & 99.65 \\
\hline $\mathrm{S} 2$ & 96.84 & 94.29 & 98.24 & 98.24 & 99.82 \\
\hline S3 & 99.38 & 99.91 & 99.56 & 99.91 & 100 \\
\hline S4 & 98.51 & 99.47 & 99.30 & 99.65 & 100 \\
\hline S5 & 99.74 & 99.91 & 99.91 & 99.91 & 100 \\
\hline S6 & 100 & 100 & 100 & 100 & 100 \\
\hline S7 & 100 & 100 & 100 & 100 & 100 \\
\hline S8 & 99.91 & 99.82 & 100 & 99.74 & 100 \\
\hline Italy & $\mathrm{H}_{1}$ & $\mathbf{H}_{2}$ & $\mathrm{H}_{10}$ & $\mathrm{H}_{20}$ & $\mathbf{H}_{\mathrm{b}}$ \\
\hline $\mathrm{S} 1$ & 85.29 & 40.44 & 99.65 & 99.91 & 100 \\
\hline $\mathrm{S} 2$ & 98.41 & 96.39 & 99.03 & 99.56 & 100 \\
\hline S3 & 99.82 & 99.74 & 99.82 & 99.82 & 100 \\
\hline S4 & 99.74 & 99.03 & 99.91 & 99.12 & 100 \\
\hline S5 & 99.74 & 99.91 & 99.82 & 99.91 & 100 \\
\hline S6 & 100 & 99.91 & 100 & 99.91 & 100 \\
\hline S7 & 100 & 100 & 99.91 & 100 & 100 \\
\hline S8 & 100 & 100 & 100 & 99.91 & 100 \\
\hline Spain & $\mathrm{H}_{1}$ & $\mathbf{H}_{2}$ & $\mathrm{H}_{10}$ & $\mathrm{H}_{20}$ & $\mathbf{H}_{\mathrm{b}}$ \\
\hline S1 & 63.62 & 61.78 & 99.65 & 99.74 & 100 \\
\hline S2 & 97.10 & 94.64 & 97.89 & 97.80 & 99.82 \\
\hline S3 & 97.45 & 99.03 & 98.33 & 99.38 & 99.91 \\
\hline S4 & 98.86 & 99.65 & 99.30 & 99.74 & 100 \\
\hline S5 & 99.65 & 99.56 & 99.74 & 99.65 & 100 \\
\hline S6 & 100 & 100 & 100 & 100 & 100 \\
\hline S7 & 98.86 & 98.68 & 98.51 & 98.77 & 99.47 \\
\hline S8 & 100 & 100 & 100 & 100 & 100 \\
\hline US & $\mathrm{H}_{1}$ & $\mathrm{H}_{2}$ & $\mathrm{H}_{10}$ & $\mathrm{H}_{20}$ & $\mathbf{H}_{\mathrm{b}}$ \\
\hline S1 & 45.25 & 59.31 & 84.71 & 89.63 & 94.02 \\
\hline $\mathrm{S} 2$ & 99.21 & 95.25 & 99.74 & 98.86 & 100 \\
\hline S3 & 99.74 & 99.65 & 99.82 & 99.56 & 100 \\
\hline S4 & 98.59 & 99.38 & 99.30 & 99.74 & 100 \\
\hline S5 & 99.91 & 99.82 & 99.91 & 99.74 & 100 \\
\hline S6 & 100 & 100 & 100 & 96.66 & 100 \\
\hline S7 & 99.82 & 100 & 99.91 & 100 & 100 \\
\hline S8 & 100 & 99.91 & 97.80 & 100 & 100 \\
\hline UK & $\mathbf{H}_{1}$ & $\mathrm{H}_{2}$ & $\mathrm{H}_{10}$ & $\mathbf{H}_{20}$ & $\mathbf{H}_{\mathrm{b}}$ \\
\hline $\mathrm{S} 1$ & 54.39 & 61.60 & 98.86 & 98.59 & 99.65 \\
\hline $\mathrm{S} 2$ & 97.80 & 97.54 & 99.47 & 99.21 & 100 \\
\hline S3 & 100 & 99.65 & 100 & 99.82 & 100 \\
\hline $\mathrm{S} 4$ & 99.21 & 99.30 & 99.38 & 99.47 & 100 \\
\hline S5 & 99.65 & 99.91 & 99.65 & 99.82 & 100 \\
\hline S6 & 99.82 & 99.82 & 99.91 & 100 & 100 \\
\hline S7 & 100 & 100 & 99.91 & 99.91 & 100 \\
\hline
\end{tabular}


\begin{tabular}{|c|c|c|c|c|c|}
\hline S8 & 100 & 100 & 100 & 100 & 100 \\
\hline
\end{tabular} Notes: This table reports the percentage of cases with significant causal relations in variance at the $1 \%$ level during the whole sample period for each country. The percentages are calculated for the five directions of causality and the eight time scales under consideration. S1 is the lower scale and represents the oil and stock market fluctuations due to shocks occurring in a time horizon of 2 to 4 weeks. In turn, the wavelet scales S2-S8 are associated with oscillations of length 4-8, 8-16, 16-32, 32-64, 64-128, 128-256 and 256-512 weeks, respectively.

Tables 5 and 6 report the average values of the causality in mean and variance test statistics of the Lu et al. (2014)'s procedure, respectively, during the entire sample period for each country and the different time scales considered. Again, the results confirm the evidence displayed in figures 1 and 2, showing that the average magnitudes of the causal linkages in mean and variance increase with the time scale regardless of the country. Interestingly, the highest average values of the causal relations in mean and variance are achieved in the case of the bidirectional causality, suggesting the stronger nature of the bidirectional oil-stock interactions as compared to the unidirectional causal links.

Table 5. Average values of the causal relations in mean

\begin{tabular}{|c|c|c|c|c|c|}
\hline Germany & $\mathbf{H}_{1}$ & $\mathrm{H}_{2}$ & $\mathrm{H}_{10}$ & $\mathrm{H}_{20}$ & $\mathbf{H}_{\mathrm{b}}$ \\
\hline $\mathrm{S} 1$ & 125.49 & 141.75 & 153.66 & 179.76 & 314.45 \\
\hline $\mathrm{S} 2$ & 265.39 & 251.69 & 316.95 & 303.77 & 595.73 \\
\hline S3 & 808.98 & 815.66 & 844.77 & 858.13 & 1755.54 \\
\hline S4 & 1760.71 & 1775.03 & 1800.31 & 1826.19 & 3745.17 \\
\hline S5 & 385.17 & 584.50 & 783.83 & 398.66 & 783.83 \\
\hline S6 & 5382.48 & 5334.73 & 5426.48 & 5394.08 & 11308.23 \\
\hline S7 & 7614.89 & 7675.40 & 7643.16 & 7686.81 & 16073.99 \\
\hline S8 & 8455.18 & 8466.38 & 8469.39 & 8487.39 & 17782.61 \\
\hline France & $\mathrm{H}_{1}$ & $\mathrm{H}_{2}$ & $\mathrm{H}_{10}$ & $\mathbf{H}_{20}$ & $\mathbf{H}_{\mathrm{b}}$ \\
\hline $\mathrm{S} 1$ & 163.63 & 167.90 & 188.22 & 201.13 & 385.68 \\
\hline $\mathrm{S} 2$ & 269.82 & 241.34 & 342.44 & 316.94 & 610.75 \\
\hline S3 & 813.07 & 848.10 & 850.10 & 900.71 & 1799.02 \\
\hline $\mathrm{S} 4$ & 1792.61 & 1794.93 & 1803.81 & 1814.63 & 3774.00 \\
\hline S5 & 3211.69 & 3249.22 & 3251.12 & 3281.24 & 3818.94 \\
\hline S6 & 5573.58 & 5526.38 & 5575.83 & 5550.56 & 11678.55 \\
\hline S7 & 7591.02 & 7682.92 & 7601.46 & 7710.11 & 16035.07 \\
\hline S8 & 8653.06 & 3438.04 & 8644.89 & 4304.41 & 12957.47 \\
\hline Italy & $\mathrm{H}_{1}$ & $\mathrm{H}_{2}$ & $\mathrm{H}_{10}$ & $\mathrm{H}_{20}$ & $\mathbf{H}_{\mathrm{b}}$ \\
\hline $\mathrm{S} 1$ & 155.02 & 162.42 & 180.05 & 195.78 & 364.59 \\
\hline S2 & 297.52 & 255.42 & 345.54 & 316.87 & 629.83 \\
\hline S3 & 937.12 & 950.14 & 950.16 & 941.68 & 2000.41 \\
\hline S4 & 2247.36 & 2255.28 & 2254.10 & 2263.78 & 4725.42 \\
\hline S5 & 3736.71 & 3818.02 & 3790.71 & 3858.42 & 7971.90 \\
\hline S6 & 5363.32 & 5269.51 & 5374.85 & 5296.51 & 11184.77 \\
\hline S7 & 7374.19 & 7284.46 & 7400.84 & 7333.17 & 15419.99 \\
\hline S8 & 9139.26 & 9038.10 & 9133.51 & 9045.01 & 19086.90 \\
\hline Spain & $\mathrm{H}_{1}$ & $\mathrm{H}_{2}$ & $\mathrm{H}_{10}$ & $\mathbf{H}_{20}$ & $\mathbf{H}_{\mathrm{b}}$ \\
\hline S1 & 151.45 & 156.86 & 187.21 & 177.57 & 357.98 \\
\hline $\mathrm{S} 2$ & 245.06 & 253.37 & 298.23 & 315.16 & 573.78 \\
\hline S3 & 871.82 & 870.10 & 922.04 & 897.64 & 1845.80 \\
\hline S4 & 2101.42 & 2035.78 & 2109.69 & 2044.63 & 4340.09 \\
\hline S5 & 3660.80 & 3549.29 & 3704.54 & 3594.99 & 7616.26 \\
\hline S6 & 5316.12 & 5321.34 & 5350.51 & 5368.28 & 11205.10 \\
\hline S7 & 7571.58 & 7684.47 & 7597.18 & 7690.81 & 16030.41 \\
\hline S8 & 8808.79 & 8850.30 & 8824.45 & 8864.34 & 18554.69 \\
\hline US & $\mathrm{H}_{1}$ & $\mathrm{H}_{2}$ & $\mathrm{H}_{10}$ & $\mathrm{H}_{20}$ & $\mathbf{H}_{\mathrm{b}}$ \\
\hline $\mathrm{S} 1$ & 150.71 & 154.68 & 190.12 & 198.19 & 364.79 \\
\hline $\mathrm{S} 2$ & 315.09 & 240.77 & 385.80 & 307.58 & 648.14 \\
\hline S3 & 831.39 & 869.75 & 895.26 & 936.74 & 1859.18 \\
\hline $\mathrm{S} 4$ & 1142.58 & 1789.96 & 1342.95 & 1825.13 & 3132.91 \\
\hline S5 & 3481.22 & 3552.49 & 3542.97 & 3577.00 & 7426.39 \\
\hline S6 & 6018.95 & 3304.67 & 6008.56 & 590.39 & 6609.34 \\
\hline S7 & 7043.13 & 7055.02 & 7038.53 & 7048.48 & 14787.31 \\
\hline S8 & 8328.87 & 7888.21 & 881.31 & 8769.52 & 8769.52 \\
\hline
\end{tabular}




\begin{tabular}{|c|c|c|c|c|c|}
\hline $\mathbf{U K}$ & $\mathbf{H}_{\mathbf{1}}$ & $\mathbf{H}_{\mathbf{2}}$ & $\mathbf{H}_{\mathbf{1 0}}$ & $\mathbf{H}_{\mathbf{2 0}}$ & $\mathbf{H}_{\mathbf{b}}$ \\
\hline S1 & 151.24 & 144.86 & 172.55 & 173.58 & 338.29 \\
\hline S2 & 339.21 & 321.64 & 412.49 & 391.40 & 762.86 \\
\hline S3 & 828.04 & 915.71 & 880.24 & 971.44 & 1895.69 \\
\hline S4 & 1650.73 & 1744.18 & 1668.19 & 1718.72 & 3563.97 \\
\hline S5 & 3034.22 & 3092.48 & 3095.27 & 3143.31 & 6480.84 \\
\hline S6 & 4704.13 & 4615.61 & 4700.86 & 4620.68 & 9812.24 \\
\hline S7 & 6813.92 & 6795.11 & 6836.46 & 6814.66 & 14299.47 \\
\hline
\end{tabular}

Notes: This table shows the average values of the causality-in-mean test statistics of Lu et al. (2014) during the entire sample period for each country. These average values are calculated for the five directions of causality and the eight time scales under consideration. In particular, S1 is the lower scale and represents the oil and stock market fluctuations due to shocks occurring in a time horizon of 2 to 4 weeks. In turn, the wavelet scales S2-S8 are associated with oscillations of length 4-8, 8-16, 16-32, 32-64, 64-128, 128-256 and 256-512 weeks, respectively.

Table 6. Average values of the causal relations in variance

\begin{tabular}{|c|c|c|c|c|c|}
\hline Germany & $\mathrm{H}_{1}$ & $\mathbf{H}_{2}$ & $\mathrm{H}_{10}$ & $\mathbf{H}_{20}$ & $\mathbf{H}_{\mathrm{b}}$ \\
\hline $\mathrm{S} 1$ & 18.39 & 23.57 & 34.84 & 38.49 & 41.99 \\
\hline $\mathrm{S} 2$ & 38.22 & 37.90 & 63.12 & 62.93 & 74.00 \\
\hline S3 & 122.34 & 135.19 & 147.33 & 156.52 & 203.69 \\
\hline $\mathrm{S} 4$ & 281.87 & 309.90 & 297.64 & 320.50 & 436.42 \\
\hline S5 & 176.94 & 180.07 & 324.29 & 183.19 & 247.30 \\
\hline S6 & 868.58 & 889.84 & 894.71 & 912.43 & 1286.52 \\
\hline S7 & 1237.46 & 1238.45 & 1247.94 & 1248.23 & 1794.57 \\
\hline S8 & 1381.79 & 1384.43 & 1388.10 & 1389.97 & 1999.93 \\
\hline France & $\mathrm{H}_{1}$ & $\mathbf{H}_{2}$ & $\mathrm{H}_{10}$ & $\mathbf{H}_{20}$ & $\mathbf{H}_{\mathrm{b}}$ \\
\hline $\mathrm{S} 1$ & 22.70 & 26.22 & 40.97 & 43.62 & 48.69 \\
\hline $\mathrm{S} 2$ & 38.11 & 37.06 & 72.49 & 72.09 & 80.77 \\
\hline S3 & 123.65 & 141.99 & 151.36 & 165.02 & 211.11 \\
\hline $\mathrm{S} 4$ & 282.18 & 303.04 & 286.58 & 303.81 & 424.33 \\
\hline S5 & 525.88 & 520.59 & 542.34 & 537.40 & 767.70 \\
\hline S6 & 899.30 & 910.77 & 910.94 & 919.97 & 1313.85 \\
\hline S7 & 1221.61 & 1258.43 & 1225.36 & 1253.28 & 1789.18 \\
\hline S8 & 1412.83 & 1130.32 & 1413.00 & 1256.43 & 1864.88 \\
\hline Italy & $\mathrm{H}_{1}$ & $\mathrm{H}_{2}$ & $\mathrm{H}_{10}$ & $\mathrm{H}_{20}$ & $\mathbf{H}_{\mathrm{b}}$ \\
\hline $\mathrm{S} 1$ & 22.73 & 25.27 & 37.78 & 39.41 & 45.67 \\
\hline $\mathrm{S} 2$ & 43.86 & 43.74 & 66.45 & 66.47 & 80.42 \\
\hline S3 & 144.47 & 156.17 & 154.85 & 164.16 & 223.92 \\
\hline $\mathrm{S} 4$ & 347.27 & 373.73 & 349.25 & 371.14 & 520.43 \\
\hline S5 & 3736.71 & 3818.02 & 3790.71 & 3858.42 & 7971.90 \\
\hline S6 & 857.96 & 872.14 & 868.16 & 880.17 & 1255.41 \\
\hline S7 & 1201.16 & 1188.78 & 1212.55 & 1203.35 & 1733.96 \\
\hline S8 & 1485.00 & 1485.54 & 1483.89 & 1485.93 & 2142.37 \\
\hline Spain & $\mathrm{H}_{1}$ & $\mathrm{H}_{2}$ & $\mathrm{H}_{10}$ & $\mathrm{H}_{20}$ & $\mathbf{H}_{\mathrm{b}}$ \\
\hline S1 & 25.94 & 20.40 & 41.35 & 37.15 & 45.54 \\
\hline $\mathrm{S} 2$ & 34.27 & 37.56 & 58.57 & 61.05 & 70.20 \\
\hline S3 & 147.61 & 140.40 & 157.84 & 152.52 & 216.07 \\
\hline S4 & 340.97 & 329.82 & 336.86 & 329.29 & 482.63 \\
\hline S5 & 607.08 & 585.50 & 623.23 & 607.86 & 874.29 \\
\hline S6 & 867.50 & 879.32 & 883.77 & 892.78 & 1271.19 \\
\hline S7 & 888.32 & 867.53 & 884.45 & 868.77 & 1265.89 \\
\hline S8 & 1439.76 & 1439.94 & 1445.76 & 1445.30 & 2081.72 \\
\hline US & $\mathrm{H}_{1}$ & $\mathbf{H}_{2}$ & $\mathrm{H}_{10}$ & $\mathrm{H}_{20}$ & $\mathbf{H}_{\mathrm{b}}$ \\
\hline $\mathrm{S} 1$ & 27.86 & 26.73 & 47.58 & 46.49 & 54.02 \\
\hline $\mathrm{S} 2$ & 43.38 & 35.58 & 72.59 & 67.62 & 80.52 \\
\hline S3 & 128.28 & 141.00 & 163.78 & 173.67 & 220.44 \\
\hline $\mathrm{S} 4$ & 281.40 & 291.99 & 297.87 & 301.66 & 421.96 \\
\hline S5 & 574.23 & 589.78 & 593.50 & 605.08 & 852.01 \\
\hline S6 & 979.66 & 976.76 & 973.86 & 272.08 & 807.32 \\
\hline S7 & 1137.12 & 1144.47 & 1131.72 & 1137.29 & 1642.10 \\
\hline S8 & 919.51 & 1432.07 & 406.95 & 1433.73 & 1187.20 \\
\hline UK & $\mathrm{H}_{1}$ & $\mathrm{H}_{2}$ & $\mathrm{H}_{10}$ & $\mathrm{H}_{20}$ & $\mathbf{H}_{\mathrm{b}}$ \\
\hline $\mathrm{S} 1$ & 22.68 & 24.05 & 35.27 & 36.31 & 43.15 \\
\hline $\mathrm{S} 2$ & 51.60 & 44.36 & 83.46 & 77.71 & 94.37 \\
\hline S3 & 122.93 & 161.46 & 156.66 & 186.80 & 227.57 \\
\hline $\mathrm{S} 4$ & 265.53 & 286.33 & 266.86 & 284.29 & 397.75 \\
\hline S5 & 512.27 & 516.08 & 532.39 & 534.64 & 755.22 \\
\hline S6 & 760.87 & 754.64 & 772.72 & 768.41 & 1102.82 \\
\hline S7 & 1106.85 & 1103.04 & 1111.48 & 1109.05 & 1598.54 \\
\hline S8 & 1213.63 & 1201.28 & 1264.65 & 1252.78 & 1776.38 \\
\hline
\end{tabular}

Notes: This table shows the average values of the causality-in-variance test statistics of Lu et al. (2014) during the entire sample period for each country. These average values are calculated for the five directions of causality and the eight time scales under consideration. In particular, S1 is the lower scale and represents the oil and stock market fluctuations due to shocks occurring in a time horizon of 2 
to 4 weeks. In turn, the wavelet scales S2-S8 are associated with oscillations of length 4-8, 8-16, 16-32, 32-64, 64-128, 128-256 and 256-512 weeks, respectively.

The main empirical finding of this study is the presence of significant bidirectional causal linkages in mean and variance between oil price changes and stock returns at all time horizons over most of the sample period for all the countries. This evidence is consistent with the idea that crude oil and stock markets are tightly integrated and affect each other in the short-, medium- and long-run. The homogeneous pattern of oil-stock Granger causality relationships across investment horizons may be related to the financialization of commodity markets since the early 2000s. Financial investors have taken positions massively in commodity markets as an alternative to financial markets, distorting the pricing mechanism of commodities and therefore generating large price fluctuations and sometimes even price bubbles. As a result of the increased trading of oil derivatives and growth of commodity funds, oil prices have become vulnerable to external shocks from financial markets, responding immediately to information captured in other assets at the different investment horizons. As pointed out by Turhan et al. (2014), oil prices are no longer only determined by aggregate supply and demand, but also by investment preferences and investors' behavior. Another plausible reason for the homogeneous causal relations between oil and stock markets across time horizons could be the movement of investors away from passive investment strategies to more aggressive ones (Baruník et al., 2016). Additionally, the widespread use of electronic trading platforms may also have contributed to the increased homogeneity across investment horizons.

Another plausible explanation for the strong causal links in mean and variance between oil price changes and equity returns of developed oil-importing countries found in this study is related to the fact that prospects for economic growth have been a primary driver of the performance of both crude oil and stock markets over the last years. In particular, oil and stock markets have moved in the same direction in recent years following expectations about the world economy due to the predominance of demand-side oil price shocks driven by fluctuations in the global business cycle since the mid-1990s (MoyaMartínez et al., 2014). For example, rising oil prices and bullish stock markets reflect a positive development in the global economy caused by an increase in world aggregate demand. A critical implication of the significant causal interactions between oil and equity returns is that oil is no longer a safe haven that offers protection against adverse conditions in stock markets, thus diminishing the potential diversification benefits for investors. Therefore, investors and portfolio managers should pay special attention to the 
significant feedback effects between oil and stock returns when designing their investment and hedging strategies. Contrary to the common assumption in the existing literature, our findings indicate that a portfolio comprised of oil-related assets and stocks does not represent necessarily an optimal investment strategy since the combination of these two assets cannot guarantee a minimum of safety in times of economic downturn or financial turmoil. This result is in line with the argument of Ftiti et al. (2016) and Madaleno \& Pinho (2014), who emphasize the difficulties faced by investors to extract potential diversification benefits from portfolios formed by oil-related assets and stocks and to design profitable active trading strategies.

The evidence presented in this study is very similar to that of Huang et al. (2015), who also detect strong bidirectional Granger causality relationships between oil prices and Chinese stock returns at the sector level over all time horizons using wavelet methods. Our results are also in line with those provided by Ajmi et al. (2014), Anoruo (2011), Arouri \& Nguyen (2010), Ciner (2001) and Ding et al. (2016) find significant bidirectional Granger causality between oil price and equity markets employing a number of methodological approaches, although these latter studies do not consider various investment horizons. In contrast, our findings in terms of causality relationships differs from that reported by, among others, Balcilar \& Ozdemir (2013), Dagher \& El Hariri (2013), Hatemi-J et al. (2017) and Lee et al. (2012). The dissimilarities between the results of these studies and ours may be attributed to the use of different Granger causality procedures, time periods and data frequency. In addition, our result of increased causal relations during periods of economic downturn and financial turmoil are also similar to those of Baruník et al. (2016), Ftiti et al. (2016), Reboredo \& Rivera-Castro (2014) and Turhan et al. (2014) applying different econometric methods.

\subsection{Probit regression analysis}

A probit model is estimated in this sub-section in order to evaluate in a rigorous way the impact of crisis periods on the causal relations between crude oil and stock markets. In this regard, several recent studies such as Ftiti et al. (2016), Baruník et al (2016), Reboredo \& Rivera-Castro (2014) and Martín-Barragán (2015) have highlighted the importance of periods of economic and financial turmoil in explaining the comovement of oil and stock markets. However, given that the main findings of these studies are based solely on graphical illustrations, their results are not sufficiently reliable. The probit model formulated here to overcome this lack has the following form: 


$$
P_{r}\left(y_{t}=1\right)=\alpha_{0}+\alpha_{1} D_{1}+\alpha_{2} D_{2}+\alpha_{3} D_{3}+\alpha_{4} D_{4}+u_{t}
$$

The dependent variable, $y_{t}$, is based on the statistics of the AGDCC-GARCH(1,1) Hong causality test. In particular, it takes the value of 0 if the magnitude of the bidirectional causality test statistic at time $t$ is lower than its average value during the sampling period and 1 if the magnitude of the bidirectional causality test statistic at time $t$ is larger than its average value. The probit analysis focuses exclusively on the bidirectional causal links since the highest values of the causality test statistics for all the time horizons and countries are obtained when analyzing bidirectional causal relations. In addition, $u_{t}$ is a random error term.

The probit specification includes four dummy variables as explanatory variables. These dummy variables represent the four major crisis periods identified by the NBER (see shaded areas in the graphs of previous section) during the sample period. Specifically, $D_{1}$ is a dummy variable for the Asian crisis, which takes the value of 1 during the period of the Asian crisis of 1997-1998 and 0 otherwise, $D_{2}$ takes the value of 1 during the period of the early 2000s that encompasses the collapse of the dot com bubble in 2000, the terrorist attacks of September 11, 2001, and the Iraq war in 2003, and 0 otherwise. $D_{3}$ denotes a dummy variable for the global financial crisis of 2007-2009, which equals 1 during the period of greater financial turbulence and 0 otherwise. Finally, $D_{4}$ is a dummy variable that captures the effect of the recent European sovereign debt crisis of 20102012. To adequately define the dummies, we rely on the NBER country-specific information on the dating of crisis episodes because it provides the best proxy of extreme financial events taking into account time misalignments from one country to another, i.e. the starting and ending dates of a given crisis can differ across countries. It is easy to note that the five European countries considered (France, Germany, Italy, Spain and the UK) are affected by four principal crisis periods, while the US is only hit by two turbulent periods (the crisis of the early 2000s and the global financial crisis of 2007-2009). Hence, the corresponding probit model for the US will involve only two dummy variables $\left(D_{2}\right.$ and $\left.D_{3}\right)$.

Tables 7-12 present the marginal effects of the probit model for each country on the basis of the multiscale bidirectional causality in both mean and variance derived from the AGDCC-GARCH $(1,1)$ Hong causality test. Several interesting results emerge from these tables. Overall, a strong and significant causal links are detected across time scales regardless of the countries. For the US, the crisis of the early 2000 s and the global 
financial crisis of 2007-2009 have a highly significant explanatory power of bidirectional time-varying causal links in mean and variance between oil price changes and stock returns at the different time horizons considered. This finding is consistent with that of Ftiti et al. (2016), who show that the comovement of oil and stock returns increases drastically during the housing market boom of 2000 and the financial crisis of 2007-2008. This evidence is also coincident with Hamilton's (2009) claim stating that the episodes during the last quarter of 2007 and the first half of 2008 qualifies are among the biggest shocks in oil prices on record. Specifically, the causality in mean magnitude intensifies in the short run (at scales 2 and 3) during the crisis of early 2000 (D2) while it becomes more pronounced at the coarser scales (long run) during the Global financial crisis (D3). Similar results are obtained for the causality in variance. Thus, the causality intensity varies suddenly across scales following a successive booms and busts implying that crisis periods have different effects on the causality relationship between oil and stock returns. Generally speaking, the remaining countries are marked by similar causality patterns: both causalities follow an increasing trend across scales, given that the causality amplitudes continue in crescendo reaching their zenith at scale 8 . The four dummy variables register highly significant values meaning that any turbulent period impacts the oil-stock markets inter-plays. The oil-stock markets are governed by strong reciprocal attractions around crisis times. The same conclusions were reached in the recent works of Reboredo \& Riviera Castro (2016) who applied wavelet based cross correlation method and Jammazi \& Reboredo (2016) who considered a wavelet copula approach to explore the oil-stock markets dependence.

Regarding the European countries, the influence (in terms of the magnitude of marginal effects) of the crisis episodes on the time-varying causal linkages is lower in the case of Germany. This result is not surprising since the higher soundness, strength and international competitiveness of the German economy relative to the rest of Europe. Germany has been also favored by its triple-A rating, so that German sovereign bonds and stocks have become safe havens for international investors during the recent global financial and European sovereign debt crises. Bidirectional causal relations in mean and variance between oil price movements and German stock returns are significantly affected by the four turbulent periods under consideration at the different time horizons. However, the magnitude of marginal effects indicates that the Asian financial crisis exerts the lower influence on the causal links in Germany. In contrast, the European sovereign 
debt crisis, followed by the global financial crisis, have the greater impact on the causal interactions in mean and variance. It is also worth mentioning that the highest explanatory power on the bidirectional oil-stock market causality relationships is observed at the coarser scales, suggesting that the impact of the crisis periods on the causal relations is more pronounced in the long-run than in the short-run.

France, Italy and Spain are identified as the countries most vulnerable to turbulent periods. Their bidirectional time-varying oil-stock market causal links are much more affected by the four crisis periods than the other three countries. The global financial crisis of 2007-2009 and the Eurozone debt crisis of 2010-2012 emerge as the most severe crisis episodes as the marginal effects associated to these two crises achieve the highest values in the probit model. This latter finding supports the argument that since the onset of the global financial crisis, countries such as Italy and Spain, which are part of the GIIPS nations, have been labelled as euro area high-risk economies due to the rapid deterioration in their fiscal and debt positions as well as their pessimistic economic outlook. The high similarity of France to Italy and Spain regarding the pattern of exposure of oil-stock market causal interactions to crisis periods may be attributed to the so-called neighborhood effect in the spread of crisis across countries (Haile \& Pozo, 2008). Once again, the higher explanatory ability of causal linkages is found at the coarser scales.

Finally, the four crisis episodes also have a significant marginal effect on the bidirectional time-varying oil-equity market causality relationships in mean and variance at the different time horizons in the UK. The marginal effects for the UK are generally higher than in Germany, but slightly lower than in Italy, Spain and France. Furthermore, the marginal effects increase with the time scale, which means that the influence of crisis episodes on the causal links is stronger in the long-run. In addition, the euro area sovereign debt crisis, followed by the global financial crisis, appear as the periods with greater impact on the oil-stock market causal linkages in the UK.

Table 7. Probit regression model for the United States

\begin{tabular}{|c|c|c|c|c|c|c|c|c|}
\hline \multicolumn{9}{|c|}{ Causalitv-in-mean } \\
\hline Hb & S1 & S2 & S3 & S4 & S5 & S6 & S7 & S8 \\
\hline $\mathbf{D}_{1}$ & - & - & - & - & - & - & - & - \\
\hline $\mathbf{D}_{2}$ & $\begin{array}{l}0.247 * * \\
(18.056)\end{array}$ & $\begin{array}{l}0.711 \text { *** } \\
(31.638)\end{array}$ & $\begin{array}{c}0.962 * * * \\
(9.012)\end{array}$ & $\begin{array}{c}0.116 * * * \\
(19.824)\end{array}$ & $\begin{array}{c}0.392 * * * \\
(4.159)\end{array}$ & $\begin{array}{c}0.544 * * * \\
(2.204)\end{array}$ & $\begin{array}{c}0.105^{* * * *} \\
(60.189)\end{array}$ & $\begin{array}{c}0.274 * * * \\
(7.909)\end{array}$ \\
\hline $\mathbf{D}_{3}$ & $\begin{array}{c}0.569 * * * \\
(9.305)\end{array}$ & $\begin{array}{c}0.143 * * * \\
(6.004)\end{array}$ & $\begin{array}{l}0.245^{*} \\
(1.312)\end{array}$ & $\begin{array}{c}0.203 * * * * \\
(7.391)\end{array}$ & $\begin{array}{c}0.385 * * * \\
(42.026)\end{array}$ & $\begin{array}{c}0.599 * * \\
(3.156) \\
\end{array}$ & $\begin{array}{c}0.640 * * * \\
(31.107)\end{array}$ & $\begin{array}{c}0.655^{* * * *} \\
(13.075) \\
\end{array}$ \\
\hline $\mathbf{D}_{4}$ & - & - & - & - & - & - & - & - \\
\hline \multicolumn{9}{|c|}{ Causality-in-variance } \\
\hline $\mathbf{H b}$ & S1 & S2 & S3 & S4 & S5 & S6 & S7 & S8 \\
\hline $\mathbf{D}_{1}$ & - & - & - & - & - & - & - & - \\
\hline $\mathbf{D}_{2}$ & $\begin{array}{c}0.459 * * \\
(12.751)\end{array}$ & $\begin{array}{c}0.164 * * * \\
(5.875)\end{array}$ & $\begin{array}{c}0.289 * * * \\
(2.408)\end{array}$ & $\begin{array}{l}0.899 * \\
(1.669)\end{array}$ & $\begin{array}{c}0.372 * * * \\
(27.106)\end{array}$ & $\begin{array}{c}0.669 * * * \\
(6.609)\end{array}$ & $\begin{array}{c}0.156 * * * \\
(8.600)\end{array}$ & $\begin{array}{c}0.494 * * * \\
(17.092)\end{array}$ \\
\hline
\end{tabular}




\begin{tabular}{|c|c|c|c|c|c|c|c|c|}
\hline $\mathbf{D}_{3}$ & $\begin{array}{c}0.115^{*} \\
(1.114)\end{array}$ & $\begin{array}{c}0.052 * * \\
(1.852)\end{array}$ & $\begin{array}{c}0.140 * * * \\
(3.405)\end{array}$ & $\begin{array}{c}0.164 * * * \\
(6.409)\end{array}$ & $\begin{array}{c}0.406 * * * \\
(3.641)\end{array}$ & $\begin{array}{c}0.924 * * * \\
(14.992)\end{array}$ & $\begin{array}{c}0.41 * * * \\
(10.241)\end{array}$ & $\begin{array}{c}0.293 * * * \\
(4.002)\end{array}$ \\
\hline $\mathbf{D}_{4}$ & - & - & - & - & - & - & - & - \\
\hline
\end{tabular}

Notes: This table reports the estimation results of the probit regression model specified in Eq. (19) in order to assess the impact of the main periods of crisis on bidirectional causal linkages in mean and variance between oil price changes and stock returns at the different time scales $\left(\mathrm{S}_{\mathrm{i}}\right)$ for the US. In particular, D1, D2, D3 and D4 are the dummy variables associated to the Asian financial crisis of 1997-1998, the crisis of the early 2000s, the global financial crisis of 2007 2009 and the European sovereign debt crisis, respectively. Figures in parenthesis are $t$-statistics. The asterisks $* *$ and *** denote statistical significance at the $5 \%$ and $1 \%$ levels, respectively.

Table 8. Probit regression model for Germany

\begin{tabular}{|c|c|c|c|c|c|c|c|c|}
\hline \multicolumn{9}{|c|}{ Causality in mean } \\
\hline $\mathrm{Hb}$ & S1 & S2 & S3 & S4 & S5 & S6 & S7 & S8 \\
\hline$\overline{D_{1}}$ & $\begin{array}{c}0.044 * * * \\
(4.805) \\
\end{array}$ & $\begin{array}{l}0.091 * * \\
(14.053) \\
\end{array}$ & $\begin{array}{c}0.126 * * * \\
(5.324)\end{array}$ & $\begin{array}{c}0.159^{* * *} \\
(2.907) \\
\end{array}$ & $\begin{array}{c}0.183^{* * *} \\
(2.657) \\
\end{array}$ & $\begin{array}{c}0.248 * * * \\
(5.054) \\
\end{array}$ & $\begin{array}{l}0.34 * * * \\
(61.410)\end{array}$ & $\begin{array}{r}0.413 \text { *** } \\
(15.371)\end{array}$ \\
\hline $\mathbf{D}_{2}$ & $\begin{array}{c}0.072 * * * \\
(2.118) \\
\end{array}$ & $\begin{array}{c}0.112 * * * \\
(2.124) \\
\end{array}$ & $\begin{array}{c}0.146 * * * \\
(5.975) \\
\end{array}$ & $\begin{array}{l}0.179^{*} \\
(9.541) \\
\end{array}$ & $\begin{array}{c}0.213 * * * \\
(11.608) \\
\end{array}$ & $\begin{array}{c}0.287^{*} \\
(14.897) \\
\end{array}$ & $\begin{array}{l}0.312 \text { *** } \\
(17.603) \\
\end{array}$ & $\begin{array}{c}0.360^{* * * *} \\
(2.805) \\
\end{array}$ \\
\hline$\overline{\mathbf{D}_{3}}$ & $\begin{array}{c}0.135 * * * \\
(6.643) \\
\end{array}$ & $\begin{array}{c}0.163 * * * \\
(51.143) \\
\end{array}$ & $\begin{array}{l}0.194 * * * \\
(11.672) \\
\end{array}$ & $\begin{array}{c}0.234 * * * \\
(15.861) \\
\end{array}$ & $\begin{array}{c}0.267 * * * \\
(7.640) \\
\end{array}$ & $\begin{array}{c}0.327 * * * \\
(4.604) \\
\end{array}$ & $\begin{array}{c}0.358 \text { *** } \\
(8.274)\end{array}$ & $\begin{array}{c}0.488^{* * * *} \\
(6.720) \\
\end{array}$ \\
\hline $\mathbf{D}_{4}$ & $\begin{array}{c}0.186 * * \\
(1.8111)\end{array}$ & $\begin{array}{c}0.170 * * * \\
(4.970)\end{array}$ & $\begin{array}{c}0.218^{* * * *} \\
(3.712)\end{array}$ & $\begin{array}{c}0.271 * * * \\
(26.511)\end{array}$ & $\begin{array}{c}0.313 * * * \\
(65.189)\end{array}$ & $\begin{array}{c}0.367 * * * \\
(9.409)\end{array}$ & $\begin{array}{c}0.439 \text { *** } \\
(10.183)\end{array}$ & $\begin{array}{l}0.506^{* * * *} \\
(41.791)\end{array}$ \\
\hline \multicolumn{9}{|c|}{ Causality in variance } \\
\hline $\mathbf{H b}$ & S1 & S2 & S3 & S4 & S5 & S6 & S7 & S8 \\
\hline$D_{1}$ & $\begin{array}{c}0.054 * * * \\
(7.401) \\
\end{array}$ & $\begin{array}{c}0.106^{* * * *} \\
(8.285) \\
\end{array}$ & $\begin{array}{c}0.129^{* * * *} \\
(14.621) \\
\end{array}$ & $\begin{array}{c}0.163 * * * \\
(25.611) \\
\end{array}$ & $\begin{array}{c}0.204 * * * \\
(12.655) \\
\end{array}$ & $\begin{array}{c}0.266 * * * * \\
(1.962) \\
\end{array}$ & $\begin{array}{c}0.294^{* * * *} \\
(5.622) \\
\end{array}$ & $\begin{array}{r}0.437 \text { **** } \\
(10.603) \\
\end{array}$ \\
\hline $\mathbf{D}_{2}$ & $\begin{array}{c}0.081 * * * \\
(3.955)\end{array}$ & $\begin{array}{c}0.140^{* * * *} \\
(4.025)\end{array}$ & $\begin{array}{l}0.197 * * * \\
(32.362)\end{array}$ & $\begin{array}{c}0.260 * * * \\
(15.400)\end{array}$ & $\begin{array}{c}0.284 * * * \\
(17.648)\end{array}$ & $\begin{array}{c}0.304 * * * \\
(6.471)\end{array}$ & $\begin{array}{l}0.389 * * * \\
(25.006)\end{array}$ & $\begin{array}{c}0.462 * * * * \\
(2.244)\end{array}$ \\
\hline $\mathbf{D}_{3}$ & $\begin{array}{c}0.134 * * \\
(12.744)\end{array}$ & $\begin{array}{c}0.165 * * * \\
(18.114)\end{array}$ & $\begin{array}{c}0.234 * * \\
(1.654)\end{array}$ & $\begin{array}{c}0.281 \text { *** } \\
(16.215)\end{array}$ & $\begin{array}{c}0.312 * * * \\
(6.714)\end{array}$ & $\begin{array}{c}0.342 \text { *** } \\
(41.906)\end{array}$ & $\begin{array}{c}0.415^{* * * *} \\
(18.588)\end{array}$ & $\begin{array}{l}0.495^{*} \\
(3.471)\end{array}$ \\
\hline $\mathbf{D}_{4}$ & $\begin{array}{c}0.167 * * * \\
(17.607)\end{array}$ & $\begin{array}{c}0.201 * * * \\
(2.618)\end{array}$ & $\begin{array}{l}0.256^{*} \\
(3.693)\end{array}$ & $\begin{array}{l}0.294 * * \\
(37.476)\end{array}$ & $\begin{array}{c}0.336 * * * \\
(13.003)\end{array}$ & $\begin{array}{l}0.358^{*} \\
(7.251)\end{array}$ & $\begin{array}{l}0.470^{* * *} \\
(23.755)\end{array}$ & $\begin{array}{l}0.544 * * * \\
(60.822)\end{array}$ \\
\hline
\end{tabular}

Notes: This table reports the estimation results of the probit regression model specified in Eq. (19) in order to assess the impact of the main periods of crisis on bidirectional causal linkages in mean and variance between oil price changes and stock returns at the different time scales $\left(\mathrm{S}_{\mathrm{i}}\right)$ for Germany. In particular, D1, D2, D3 and D4 are the dummy variables associated to the Asian financial crisis of 1997-1998, the crisis of the early 2000s, the global financial crisis of 20072009 and the European sovereign debt crisis, respectively. Figures in parenthesis are $t$-statistics. The asterisks $* *$ and *** denote statistical significance at the $5 \%$ and $1 \%$ levels, respectively.

Table 9. Probit regression model for France

\begin{tabular}{|c|c|c|c|c|c|c|c|c|}
\hline \multicolumn{9}{|c|}{ Causality-in-mean } \\
\hline $\mathrm{Hb}$ & S1 & S2 & S3 & S4 & S5 & S6 & S7 & S8 \\
\hline $\mathbf{D}_{1}$ & $\begin{array}{c}0.154 * * * \\
(2.471) \\
\end{array}$ & $\begin{array}{c}0.214 * * * \\
(7.473) \\
\end{array}$ & $\begin{array}{l}0.254 * * * \\
(12.740) \\
\end{array}$ & $\begin{array}{l}0.296 * * \\
(14.471)\end{array}$ & $\begin{array}{c}0.361 * * * \\
(74.115)\end{array}$ & $\begin{array}{c}0.483 * * * \\
(9.885)\end{array}$ & $\begin{array}{l}0.517^{* * * *} \\
(17.226) \\
\end{array}$ & $\begin{array}{l}0.537 * * * \\
(22.711)\end{array}$ \\
\hline $\mathbf{D}_{2}$ & $\begin{array}{c}0.128 * * * \\
(4.471) \\
\end{array}$ & $\begin{array}{c}0.165^{* *} \\
(1.854) \\
\end{array}$ & $\begin{array}{c}0.197 \\
(31.002) \\
\end{array}$ & $\begin{array}{l}0.249 * * * \\
(24.454) \\
\end{array}$ & $\begin{array}{c}0.471 * * * \\
(7.741) \\
\end{array}$ & $\begin{array}{l}0.502 * * * \\
(11.654) \\
\end{array}$ & $\begin{array}{c}0.540 \text { *** } \\
(2.812) \\
\end{array}$ & $\begin{array}{c}0.668 * * * \\
(8.142) \\
\end{array}$ \\
\hline $\mathbf{D}_{3}$ & $\begin{array}{c}0.194 * * * \\
(18.722)\end{array}$ & $\begin{array}{l}0.238^{* * *} \\
(3.744)\end{array}$ & $\begin{array}{c}0.274 * * * \\
(24.741)\end{array}$ & $\begin{array}{c}0.350 * * * \\
(17.997)\end{array}$ & $\begin{array}{c}0.498 * * * \\
(2.417)\end{array}$ & $\begin{array}{l}0.561 * * * \\
(74.280)\end{array}$ & $\begin{array}{c}0.615^{* * * *} \\
(14.422)\end{array}$ & $\begin{array}{c}0.714^{* * * *} \\
(16.014)\end{array}$ \\
\hline $\mathbf{D}_{4}$ & $\begin{array}{c}0.254 * * \\
(15.644)\end{array}$ & $\begin{array}{c}0.28 * * * \\
(14.852)\end{array}$ & $\begin{array}{c}0.321 * * * \\
(5.741)\end{array}$ & $\begin{array}{c}0.412 * * * \\
(2.841)\end{array}$ & $\begin{array}{c}0.507 * * * \\
(44.621)\end{array}$ & $\begin{array}{c}0.641 * * * \\
(4.007)\end{array}$ & $\begin{array}{c}0.661 \text { **** } \\
(4.651)\end{array}$ & $\begin{array}{l}0.738^{* * * *} \\
(25.611)\end{array}$ \\
\hline \multicolumn{9}{|c|}{ Causality in variance } \\
\hline $\mathbf{H b}$ & S1 & S2 & $\mathbf{S 3}$ & S4 & S5 & S6 & S7 & S8 \\
\hline $\mathbf{D}_{1}$ & $\begin{array}{c}0.102 * * * * \\
(14.004) \\
\end{array}$ & $\begin{array}{l}0.171^{*} \\
(2.695) \\
\end{array}$ & $\begin{array}{c}0.240^{* * * *} \\
(7.412) \\
\end{array}$ & $\begin{array}{c}0.283 * * * \\
(15.147) \\
\end{array}$ & $\begin{array}{c}0.341 * * * \\
(4.471) \\
\end{array}$ & $\begin{array}{c}0.458 \\
(1.088) \\
\end{array}$ & $\begin{array}{c}0.489 * * * \\
(14.551) \\
\end{array}$ & $\begin{array}{c}0.527 * * * \\
(3.471) \\
\end{array}$ \\
\hline $\mathbf{D}_{2}$ & $\begin{array}{c}0.057 * * * \\
(4.471)\end{array}$ & $\begin{array}{c}0.108 * * * \\
(9.541)\end{array}$ & $\begin{array}{c}0.124 * * * \\
(14.877)\end{array}$ & $\begin{array}{c}0.145^{* * * *} \\
(9.741)\end{array}$ & $\begin{array}{l}0.215 * * \\
(4.655)\end{array}$ & $\begin{array}{c}0.312 * * * \\
(9.055)\end{array}$ & $\begin{array}{c}0.360 * * * * \\
(9.041)\end{array}$ & $\begin{array}{c}0.462 * * * \\
(7.991)\end{array}$ \\
\hline $\mathbf{D}_{\mathbf{3}}$ & $\begin{array}{c}0.113 * * * \\
(7.685)\end{array}$ & $\begin{array}{c}0.147 * * * \\
(3.688)\end{array}$ & $\begin{array}{c}0.183^{* * * *} \\
(2.741)\end{array}$ & $\begin{array}{l}0.246 * * * \\
(22.741)\end{array}$ & $\begin{array}{c}0.329 * * \\
(1.854)\end{array}$ & $\begin{array}{l}0.438^{* * * *} \\
(32.471)\end{array}$ & $\begin{array}{c}0.485^{* * * *} \\
(5.471)\end{array}$ & $\begin{array}{c}0.658^{* * * *} \\
(2.005)\end{array}$ \\
\hline $\mathbf{D}_{4}$ & $\begin{array}{c}0.169 * * * \\
(6.142)\end{array}$ & $\begin{array}{c}0.224 * * * \\
(14.471)\end{array}$ & $\begin{array}{l}0.278 * * * * \\
(18.544)\end{array}$ & $\begin{array}{l}0.301 * * * \\
(12.915) \\
\end{array}$ & $\begin{array}{c}0.378 * * * \\
(26.411)\end{array}$ & $\begin{array}{l}0.462 * * \\
(39.471)\end{array}$ & $\begin{array}{l}0.608 * * * \\
(17.117) \\
\end{array}$ & $\begin{array}{c}0.745 * * * \\
(5.241) \\
\end{array}$ \\
\hline
\end{tabular}

Notes: This table reports the estimation results of the probit regression model specified in Eq. (19) in order to assess the impact of the main periods of crisis on bidirectional causal linkages in mean and variance between oil price changes and stock returns at the different time scales $\left(\mathrm{S}_{\mathrm{i}}\right)$ for France. In particular, D1, D2, D3 and D4 are the dummy variables associated to the Asian financial crisis of 1997-1998, the crisis of the early 2000s, the global financial crisis of 20072009 and the European sovereign debt crisis, respectively. Figures in parenthesis are $t$-statistics. The asterisks $* *$ and *** denote statistical significance at the $5 \%$ and $1 \%$ levels, respectively. 
Table 10. Probit regression model for Italy

\begin{tabular}{|c|c|c|c|c|c|c|c|c|}
\hline \multicolumn{9}{|c|}{ Causality-in-mean } \\
\hline $\mathbf{H b}$ & S1 & S2 & S3 & S4 & S5 & S6 & S7 & S8 \\
\hline $\mathbf{D}_{1}$ & $\begin{array}{c}0.142 * * \\
(4.411) \\
\end{array}$ & $\begin{array}{c}0.188^{* * * *} \\
(9.400)\end{array}$ & $\begin{array}{c}0.22 * * * \\
(2.844) \\
\end{array}$ & $\begin{array}{c}0.292 * * * \\
(5.417)\end{array}$ & $\begin{array}{c}0.338 * * \\
(4.693) \\
\end{array}$ & $\begin{array}{c}0.384 * * * \\
(14.417) \\
\end{array}$ & $\begin{array}{c}0.485 * * * \\
(58.623) \\
\end{array}$ & $\begin{array}{c}0.536 * * * \\
(6.874) \\
\end{array}$ \\
\hline $\mathbf{D}_{2}$ & $\begin{array}{c}0.113 * * * \\
(14.471) \\
\end{array}$ & $\begin{array}{c}0.156 * * * \\
(6.471) \\
\end{array}$ & $\begin{array}{l}0.192 * * \\
(2.471) \\
\end{array}$ & $\begin{array}{c}0.246 * * \\
(1.556) \\
\end{array}$ & $\begin{array}{c}0.364 * * * \\
(4.123)\end{array}$ & $\begin{array}{c}0.431 * * * \\
(6.741) \\
\end{array}$ & $\begin{array}{c}0.470 * * * \\
(41.622) \\
\end{array}$ & $\begin{array}{c}0.557 * * * * \\
(7.006) \\
\end{array}$ \\
\hline $\mathbf{D}_{3}$ & $\begin{array}{c}0.213 * * * \\
(4.412)\end{array}$ & $\begin{array}{c}0.266 * * * \\
(18.335)\end{array}$ & $\begin{array}{c}0.326 \\
(2.798) \\
\end{array}$ & $\begin{array}{c}0.351 * * * \\
(12.541) \\
\end{array}$ & $\begin{array}{c}0.423 * * * \\
(10.744) \\
\end{array}$ & $\begin{array}{c}0.506 * * * \\
(74.412)\end{array}$ & $\begin{array}{c}0.642 * * * \\
(5.447)\end{array}$ & $\begin{array}{c}0.741 \text { *** } \\
(18.162) \\
\end{array}$ \\
\hline $\mathbf{D}_{4}$ & $\begin{array}{c}0.172 \\
(7.412)\end{array}$ & $\begin{array}{c}0.246 \\
(0.072) \\
\end{array}$ & $\begin{array}{c}0.342 * * * \\
(18.471)\end{array}$ & $\begin{array}{c}0.433 * * * \\
(15.944) \\
\end{array}$ & $\begin{array}{c}0.461 * * * \\
(44.109)\end{array}$ & $\begin{array}{c}0.540 * * * \\
(11.471) \\
\end{array}$ & $\begin{array}{c}0.642 * * * \\
(26.411) \\
\end{array}$ & $\begin{array}{c}0.759 * * * \\
(3.511) \\
\end{array}$ \\
\hline \multicolumn{9}{|c|}{ Causality-in-variance } \\
\hline $\mathbf{H b}$ & S1 & S2 & S3 & S4 & S5 & S6 & S7 & S8 \\
\hline $\mathbf{D}_{1}$ & $\begin{array}{c}0.082 * * * \\
(3.688)\end{array}$ & $\begin{array}{c}0.144 * * * \\
(19.052)\end{array}$ & $\begin{array}{c}0.162 * * * \\
(24.411) \\
\end{array}$ & $\begin{array}{l}0.214 * * \\
(29.231) \\
\end{array}$ & $\begin{array}{c}0.346^{* * * *} \\
(17.699)\end{array}$ & $\begin{array}{c}0.422 * * \\
(1.788) \\
\end{array}$ & $\begin{array}{c}0.563 \text { **** } \\
(14.471)\end{array}$ & $\begin{array}{r}0.584 * * * * \\
(23.633)\end{array}$ \\
\hline $\mathbf{D}_{2}$ & $\begin{array}{c}0.114 * * * \\
(4.613)\end{array}$ & $\begin{array}{c}0.147 * * * \\
(6.471)\end{array}$ & $\begin{array}{c}0.189 * * * \\
(41.003)\end{array}$ & $\begin{array}{c}0.256 * * * \\
(2.455)\end{array}$ & $\begin{array}{c}0.351 * * * \\
(11.471)\end{array}$ & $\begin{array}{c}0.431 * * * \\
(15.006)\end{array}$ & $\begin{array}{c}0.492 * * * \\
(18.177)\end{array}$ & $\begin{array}{c}0.541 * * * \\
(4.485)\end{array}$ \\
\hline $\mathbf{D}_{3}$ & $\begin{array}{c}0.047 * * * \\
(5.641)\end{array}$ & $\begin{array}{c}0.130 * * * \\
(12.744)\end{array}$ & $\begin{array}{c}0.195 * * * \\
(8.998)\end{array}$ & $\begin{array}{l}0.344 * * * \\
(4.612)\end{array}$ & $\begin{array}{c}0.458 * * * \\
(23.699)\end{array}$ & $\begin{array}{c}0.61 * * * \\
(52.47)\end{array}$ & $\begin{array}{c}0.654 * * * \\
(2.133)\end{array}$ & $\begin{array}{c}0.678 * * * \\
(7.384)\end{array}$ \\
\hline $\mathbf{D}_{4}$ & $\begin{array}{c}0.125^{* * *} * \\
(21.144)\end{array}$ & $\begin{array}{c}0.184 * * * \\
(17.621)\end{array}$ & $\begin{array}{c}0.237 * * * \\
(4.874)\end{array}$ & $\begin{array}{c}0.413^{* * * *} \\
(16.588)\end{array}$ & $\begin{array}{c}0.47 * * * \\
(5.321)\end{array}$ & $\begin{array}{l}0.521^{*} \\
(1.854)\end{array}$ & $\begin{array}{c}0.584 * * * \\
(14.621)\end{array}$ & $\begin{array}{c}0.741 * * * \\
(38.966) \\
\end{array}$ \\
\hline
\end{tabular}

Notes: This table reports the estimation results of the probit regression model specified in Eq. (19) in order to assess the impact of the main periods of crisis on bidirectional causal linkages in mean and variance between oil price changes and stock returns at the different time scales $\left(\mathrm{S}_{\mathrm{i}}\right)$ for Italy. In particular, D1, D2, D3 and D4 are the dummy variables associated to the Asian financial crisis of 1997-1998, the crisis of the early 2000s, the global financial crisis of 20072009 and the European sovereign debt crisis, respectively. Figures in parenthesis are $t$-statistics. The asterisks $* *$ and $* * *$ denote statistical significance at the $5 \%$ and $1 \%$ levels, respectively.

Table 11. Probit regression model for Spain

\begin{tabular}{|c|c|c|c|c|c|c|c|c|}
\hline \multicolumn{9}{|c|}{ Causalitv-in-mean } \\
\hline $\mathrm{Hb}$ & S1 & $\mathbf{S 2}$ & S3 & $\mathbf{S 4}$ & S5 & 56 & S7 & S8 \\
\hline $\mathrm{D}_{1}$ & $\begin{array}{c}0.112 * * * \\
(7.744)\end{array}$ & $\begin{array}{c}0.163 \text { **** } \\
(2.745) \\
\end{array}$ & $\begin{array}{c}0.215^{* * * *} \\
(6.005)\end{array}$ & $\begin{array}{c}0.269^{* * * *} \\
(4.508)\end{array}$ & $\begin{array}{c}0.311 * * * \\
(8.966)\end{array}$ & $\begin{array}{l}0.34 * * * * \\
(14.758)\end{array}$ & $\begin{array}{c}0.391 \\
(1.472)\end{array}$ & $\begin{array}{c}0.512^{* * *} \\
(2.671)\end{array}$ \\
\hline $\mathbf{D}_{2}$ & $\begin{array}{c}0.145^{* * * *} \\
(12.412) \\
\end{array}$ & $\begin{array}{c}0.185 * * \\
(1.805) \\
\end{array}$ & $\begin{array}{c}0.233 * * * * \\
(11.471) \\
\end{array}$ & $\begin{array}{c}0.276 * * * \\
(36.850) \\
\end{array}$ & $\begin{array}{c}0.342 * * * \\
(21.705)\end{array}$ & $\begin{array}{c}0.402 * * * \\
(18.159) \\
\end{array}$ & $\begin{array}{c}0.463 * * * \\
(8.844)\end{array}$ & $\begin{array}{l}0.493 * * * \\
(25.688) \\
\end{array}$ \\
\hline $\mathbf{D}_{\mathbf{3}}$ & $\begin{array}{c}0.186 * * * \\
(10.255) \\
\end{array}$ & $\begin{array}{c}0.236 * * * \\
(17.341) \\
\end{array}$ & $\begin{array}{c}0.289 * * * \\
(41.344) \\
\end{array}$ & $\begin{array}{c}0.352 * * * \\
(8.961) \\
\end{array}$ & $\begin{array}{c}0.43 * * * * \\
(5.741)\end{array}$ & $\begin{array}{c}0.485 * * * \\
(17.522) \\
\end{array}$ & $\begin{array}{c}0.676^{* * * *} \\
(22.175) \\
\end{array}$ & $\begin{array}{c}0.743 * * * \\
(5.621) \\
\end{array}$ \\
\hline $\mathbf{D}_{4}$ & $\begin{array}{c}0.204 * * * \\
(15.471) \\
\end{array}$ & $\begin{array}{c}0.273 * * * * \\
(4.875) \\
\end{array}$ & $\begin{array}{l}0.34 * * * \\
(17.072)\end{array}$ & $\begin{array}{c}0.483 * * * \\
(6.471) \\
\end{array}$ & $\begin{array}{c}0.513 * * * \\
(2.874) \\
\end{array}$ & $\begin{array}{l}0.594 * \\
(1.927)\end{array}$ & $\begin{array}{c}0.713 * * * \\
(38.092) \\
\end{array}$ & $\begin{array}{c}0.773 * * * \\
(9.512) \\
\end{array}$ \\
\hline \multicolumn{9}{|c|}{ Causality-in-variance } \\
\hline $\mathbf{H b}$ & S1 & S2 & $\mathbf{S 3}$ & S4 & S5 & S6 & S7 & S8 \\
\hline$D_{1}$ & $\begin{array}{c}0.092 * * * \\
(5.114)\end{array}$ & $\begin{array}{c}0.174 * * * * \\
(4.641)\end{array}$ & $\begin{array}{c}0.215 * * * \\
(8.317) \\
\end{array}$ & $\begin{array}{c}0.270^{* * * *} \\
(41.006)\end{array}$ & $\begin{array}{c}0.365^{* * *} \\
(12.147) \\
\end{array}$ & $\begin{array}{c}0.452 * * * \\
(9.422) \\
\end{array}$ & $\begin{array}{c}0.486 * * * * \\
(14.007)\end{array}$ & $\begin{array}{c}0.543 * * * \\
(9.877)\end{array}$ \\
\hline $\mathbf{D}_{2}$ & $\begin{array}{c}0.127 * * * * \\
(4.001) \\
\end{array}$ & $\begin{array}{l}0.149 * * \\
(1.744) \\
\end{array}$ & $\begin{array}{c}0.167 * * * * \\
(6.577) \\
\end{array}$ & $\begin{array}{l}0.23 * * * * \\
(2.041) \\
\end{array}$ & $\begin{array}{c}0.320 * * * * \\
(41.622) \\
\end{array}$ & $\begin{array}{c}0.364 * * * \\
(6.111) \\
\end{array}$ & $\begin{array}{c}0.426^{* * * *} \\
(4.345) \\
\end{array}$ & $\begin{array}{c}0.462 * * * * \\
(5.901) \\
\end{array}$ \\
\hline $\mathbf{D}_{\mathbf{3}}$ & $\begin{array}{c}0.157 * * * * \\
(13.622)\end{array}$ & $\begin{array}{c}0.195 * * * \\
(37.452)\end{array}$ & $\begin{array}{c}0.277 * * * * \\
(42.115)\end{array}$ & $\begin{array}{c}0.325^{* * * *} \\
(14.021)\end{array}$ & $\begin{array}{c}0.418 * * * \\
(17.147) \\
\end{array}$ & $\begin{array}{l}0.498^{* * *} \\
(13.328)\end{array}$ & $\begin{array}{c}0.662 * * * \\
(30.004)\end{array}$ & $\begin{array}{c}0.734 * * * \\
(2.174)\end{array}$ \\
\hline $\mathbf{D}_{4}$ & $\begin{array}{c}0.201 * * * \\
(6.241)\end{array}$ & $\begin{array}{c}0.241 * * * \\
(9.505)\end{array}$ & $\begin{array}{l}0.286 * * * \\
(25.877)\end{array}$ & $\begin{array}{c}0.374 * * * \\
(4.149)\end{array}$ & $\begin{array}{c}0.452 * * * \\
(22.991)\end{array}$ & $\begin{array}{l}.588 * * * \\
(10.471)\end{array}$ & $\begin{array}{c}0.621 * * * \\
(3.474)\end{array}$ & $\begin{array}{l}.771 * * * \\
(18.991)\end{array}$ \\
\hline
\end{tabular}

Notes: This table reports the estimation results of the probit regression model specified in Eq. (19) in order to assess the impact of the main periods of crisis on bidirectional causal linkages in mean and variance between oil price changes and stock returns at the different time scales $\left(\mathrm{S}_{\mathrm{i}}\right)$ for Spain. In particular, D1, D2, D3 and D4 are the dummy variables associated to the Asian financial crisis of 1997-1998, the crisis of the early 2000s, the global financial crisis of 20072009 and the European sovereign debt crisis, respectively. Figures in parenthesis are $t$-statistics. The asterisks $* *$ and *** denote statistical significance at the $5 \%$ and $1 \%$ levels, respectively.

Table 12. Probit regression model for United Kingdom

\begin{tabular}{|c|c|c|c|c|c|c|c|c|}
\hline \multicolumn{8}{|c|}{ Causalitv-in-mean } \\
\hline Hb & S1 & S2 & S3 & S4 & S5 & S6 & S7 & S8 \\
\hline $\mathbf{D}_{\mathbf{1}}$ & $0.042^{*}$ & $0.109^{* * *}$ & $0.137^{* * *}$ & $0.192^{* * *}$ & $0.271^{* * *}$ & $0.429^{* * *}$ & $0.491^{* *}$ & $0.564^{* * * *}$ \\
& $(1.257)$ & $(12.147)$ & $(2.206)$ & $(2.094)$ & $(12.277)$ & $(3.202)$ & $(1.421)$ & $(13.028)$ \\
\hline $\mathbf{D}_{\mathbf{2}}$ & $0.128^{* * *}$ & $0.126^{* * *}$ & $0.196^{* * *}$ & $0.230^{*}$ & $0.301^{* * *}$ & $0.369^{* * *}$ & $0.412^{* * *}$ & $0.541^{* * * *}$ \\
& $(2.945)$ & $(3.100)$ & $(5.431)$ & $(1.861)$ & $(8.651)$ & $(2.79)$ & $(17.140)$ & $(8.252)$ \\
\hline $\mathbf{D}_{\mathbf{3}}$ & $0.151^{* * * *}$ & $0.244^{* * *}$ & $0.274^{* * *}$ & $\left(0.318^{* * *}\right.$ & $0.336^{* * *}$ & $0.451^{* * *}$ & $0.635^{* * * *}$ & $0.716^{* * * *}$ \\
& $(14.048)$ & $(51.241)$ & $(14.955)$ & $(7.015)$ & $(9.141)$ & $(6.069)$ & $(7.351)$ & $(6.198)$ \\
\hline $\mathbf{D}_{\mathbf{4}}$ & $0.183^{* *}$ & $0.268^{* * *}$ & $0.356^{* * *}$ & $0.369^{* * *}$ & $0.431^{* * *}$ & $0.470^{* * * *}$ & $0.542^{* * * *}$ & $0.613^{* * * *}$ \\
& $(7.614)$ & $(11.725)$ & $(48.052)$ & $(16.332)$ & $(12.136)$ & $(4.887)$ & $(24.459)$ & $(55.097)$ \\
\hline \multicolumn{8}{|c|}{ Causalitv-in-variance } \\
\hline
\end{tabular}




\begin{tabular}{|c|c|c|c|c|c|c|c|c|}
\hline $\mathbf{H b}$ & $\mathbf{S 1}$ & $\mathbf{S 2}$ & $\mathbf{S 3}$ & $\mathbf{S 4}$ & $\mathbf{S 5}$ & $\mathbf{S 6}$ & $\mathbf{S 7}$ & $\mathbf{S 8}$ \\
\hline $\mathbf{D}_{\mathbf{1}}$ & $0.058^{* * *}$ & $0.109^{* * *}$ & $0.174 * * *$ & $0.272^{* * *}$ & $0.310^{* * *}$ & $0.367 * * *$ & $0.495 * * *$ & $0.571 * * *$ \\
& $(6.023)$ & $(4.087)$ & $(3.451)$ & $(27.366)$ & $(9.145)$ & $(3.041)$ & $(9.103)$ & $(18.160)$ \\
\hline $\mathbf{D}_{\mathbf{2}}$ & $0.131^{* * *}$ & $0.156^{* * *}$ & $0.162^{* * *}$ & $0.259^{* * *}$ & $0.236 * * *$ & $0.306 * * *$ & $0.382^{* * *}$ & $0.491^{* * *}$ \\
& $(7.515)$ & $(21.961)$ & $(34.441)$ & $(16.408)$ & $(18.007)$ & $(28.185)$ & $(7.964)$ & $(20.499)$ \\
\hline $\mathbf{D}_{\mathbf{3}}$ & $0.171 * * *$ & $0.231^{* * *}$ & $0.348^{* * *}$ & $0.415^{* *}$ & $0.428^{* * *}$ & $0.467 *$ & $0.553 * * *$ & $0.640 * * *$ \\
& $(12.478)$ & $(18.744)$ & $(14.074)$ & $(4.274)$ & $(24.274)$ & $(14.041)$ & $(41.089)$ & $(17.661)$ \\
\hline $\mathbf{D}_{\mathbf{4}}$ & $0.254 * * *$ & $0.284 * * *$ & $0.377 * * *$ & $0.454 * * *$ & $0.438^{* * *}$ & $0.518 * * *$ & $0.602 * * *$ & $0.748^{* * *}$ \\
& $(42.851)$ & $(2.154)$ & $(29.855)$ & $(6.109)$ & $(24.501)$ & $(24.109)$ & $(37.085)$ & $(8.270)$ \\
\hline
\end{tabular}

Notes: This table reports the estimation results of the probit regression model specified in Eq. (19) in order to assess the impact of the main periods of crisis on bidirectional causal linkages in mean and variance between oil price changes and stock returns at the different time scales $\left(\mathrm{S}_{\mathrm{i}}\right)$ for the UK. In particular, D1, D2, D3 and D4 are the dummy variables associated to the Asian financial crisis of 1997-1998, the crisis of the early 2000s, the global financial crisis of 20072009 and the European sovereign debt crisis, respectively. Figures in parenthesis are $t$-statistics. The asterisks $* *$ and *** denote statistical significance at the $5 \%$ and $1 \%$ levels, respectively.

\subsection{Robustness analysis}

In this sub-section, we examine whether our results are data frequency-dependent by using alternative data frequencies. The sampling frequency is not a trivial matter as there is a recent body of research attempting to figure out whether the choice of data frequency has a critical impact on the results of empirical work in financial economics (Narayan \& Sharma, 2015; Narayan et al., 2013; Narayan et al., 2015; Yildirim, 2016). Following this growing literature, in order to check the robustness of our results we re-estimate the timevarying Granger causality test of Lu et al. (2014) employing daily and monthly data, two data frequencies quite popular in the financial literature. For the sake of brevity, this robustness test is conducted on the raw data of crude oil price changes and stock returns for the six developed countries under consideration.

Tables 13 and 14 report the percentage of significant bidirectional causal linkages in mean and variance, respectively, between oil price fluctuations and stock returns for all countries using weekly, daily and monthly data. The results for the daily and monthly frequencies are largely consistent, in terms of causality both in mean and variance, with those obtained for the weekly frequency previously employed. This finding confirms the presence of strong bidirectional causal relations between crude oil price changes and stock returns regardless of the country during most of the sample period. However, it is worth mentioning that the percentage of significant causal links, both in mean and variance, is slightly lower when using daily data. This result is expected taking into account the higher levels of noise and variability in daily data compared to weekly and monthly data. In contrast, the percentage of significant causal relations, both in mean and variance, is slightly higher when using monthly data, which may be attributed to the fact that the monthly data are more stable and tend to capture better the long-run links between the data series than higher frequencies (e.g. daily or weekly). To sum up, our robustness 
check shows that the causal linkages between oil price and stock returns do not vary substantially across the different data frequencies considered, indicating that the pattern of Granger causality between crude oil and stock markets is not significantly data frequency-dependent.

Table 13. Percentage of significant bidirectional causal links in mean (in \%)

\begin{tabular}{|c|c|c|c|}
\hline Country & Weekly data & Daily data & Monthly data \\
\hline Germany & $88.39 \%$ & $77.11 \%$ & $100.00 \%$ \\
\hline France & $93.05 \%$ & $78.00 \%$ & $100.00 \%$ \\
\hline Italy & $98.42 \%$ & $86.57 \%$ & $100.00 \%$ \\
\hline Spain & $84.43 \%$ & $86.97 \%$ & $100.00 \%$ \\
\hline UK & $96.66 \%$ & $92.85 \%$ & $100.00 \%$ \\
\hline US & $90.24 \%$ & $94.36 \%$ & $100.00 \%$ \\
\hline
\end{tabular}

Notes: This table presents the percentage of cases with significant bidirectional causal linkages in mean at the $1 \%$ level between raw data of changes in oil prices and stock returns during the entire sample period for the six countries under examination.

Table 14. Percentage of significant bidirectional causal links in variance (in \%).

\begin{tabular}{|c|c|c|c|}
\hline Country & Weekly data & Daily data & Monthly data \\
\hline Germany & $89.01 \%$ & $81.78 \%$ & $100.00 \%$ \\
\hline France & $94.64 \%$ & $84.90 \%$ & $100.00 \%$ \\
\hline Italy & $98.15 \%$ & $85.04 \%$ & $100.00 \%$ \\
\hline Spain & $83.11 \%$ & $85.22 \%$ & $100.00 \%$ \\
\hline UK & $96.75 \%$ & $92.70 \%$ & $100.00 \%$ \\
\hline US & $93.23 \%$ & $95.54 \%$ & $100.00 \%$ \\
\hline
\end{tabular}

Notes: This table presents the percentage of cases with significant bidirectional causal linkages in variance at the $1 \%$ level between raw data of changes in oil prices and stock returns during the entire sample period for the six countries under examination.

\section{Concluding remarks}

The oil-stock market relationship has been largely debated in the energy finance literature given its relevance for asset allocation, portfolio optimization and risk management purposes as well as for energy policy planning and preservation of financial stability. This paper examines the presence of time-varying Granger causality in mean and variance between oil price fluctuations and stock returns at different time horizons in six major oilimporting economies, namely France, Germany, Italy, Spain, the UK and the US, combining wavelet decomposition techniques and dynamic Granger causality tests. This novel research framework provides a suitable platform for characterizing the timevarying causal linkages between crude oil price and the stock market from a multiscale perspective. Firstly, the multiscale information associated with oil price changes and stock returns is extracted through the application of the Haar à trous wavelet (HTW) transform. Secondly, a modified version of the time-varying Granger causality test 
proposed by Lu et al. (2014) is employed to investigate the existence of dynamic causal relations in mean and variance between oil and stock markets in a multi-scale framework. In particular, the AGDCC-GARCH model introduced by Cappiello et al. (2006) is used to estimate the dynamic conditional oil-stock correlation in the framework of the dynamic Granger causality test of Lu et al. (2014).

The empirical results of the causality in mean and causality in variance analyses reveal a rich pattern of Granger causality characterized by significant bidirectional causal links between oil price changes and equity returns at the different time scales over most of the sample period for all countries. This finding implies a mutual risk transmission between oil and stock markets because of the financialization of the crude oil market and the unison movement of oil and stock markets over the last few decades mainly driven by changes in global aggregate demand. The results also show that the causal interactions tend to be stronger at the coarser time scales and are particularly pronounced during periods of economic and financial turmoil such as the recent global financial crisis and European sovereign debt crisis.

The evidence presented in this study is of potential interest to a variety of economic agents for designing optimal portfolio strategies, hedging and risk management practices and efficient policy measures. In this regard, investors, portfolio managers and speculators should be aware that oil-related assets and stocks do not represent an optimal combination in terms of risk minimization for a well-diversified portfolio because crude oil cannot seen as a safe haven to protect against sharp losses in stock markets at any investment horizon. Furthermore, policy makers should not ignore the strong interactions between crude oil and equity markets when they try to implement the best possible economic and energy policies aimed at minimizing any destabilizing impact of oil price shocks and avoiding contagion risk, particularly during crisis periods.

\section{Acknowledgments}

This work was supported by a grant from the "Ramón Areces Foundation public call to bid, 2013", titled Interest and inflation risk: study of the American stock market. 


\section{References}

Aielli, G.P. (2013). Dynamic conditional correlation: On properties and estimation. Journal of Business and Economic Statistics, 31, 282-299.

Ajmi, A.D., El-Montasser, G., Hammoudeh, S., \& Nguyen, D.C. (2014). Oil prices and MENA stock markets: new evidence from nonlinear and asymmetric causalities during and after the crisis period. Applied Economics, 46, 2167-2177.

Alikhanov, A. (2013). To What Extent are Stock Returns Driven by Mean and Volatility Spillover Effects? - Evidence from Eight European Stock Markets. Review of Economic Perspectives, 13, 3-29.

Aloui, R., Hammoudeh, S., \& Nguyen, D.K. (2013). A time-varying copula approach to oil and stock market dependence: the case of transition economies. Energy Economics, 39, 208-221.

Aloui, C., \& Jammazi, R. (2009). The effects of crude oil shocks on stock market shifts behaviour: A regime switching approach. Energy Economics, 31, 789-799.

Anoruo, E. (2011). Testing for linear and nonlinear causality between crude oil price changes and stock market returns. International Journal of Economic Sciences and Applied Research, 4, 75-92.

Apergis, N., \& Miller, S.M. (2009). Do structural oil-market shocks affect stock prices? Energy Economics, 31, 569-575.

Arouri, M.E.H., \& Nguyen, D.K. (2010). Oil prices, stock markets and portfolio investment: Evidence from sector analysis in Europe over the last decade. Energy Policy, $38,4528-4539$.

Awartani, B., \& Maghyereh, A.I. (2013). Dynamic spillovers between oil and stock markets in the Gulf Cooperation Council Countries. Energy Economics, 36, 28-42.

Balcilar, M., \& Ozdemir, Z.A. (2013). The causal nexus between oil prices and equity markets in the U.S.: A regime-switching model. Energy Economics, 39, 271-282.

Baruník, J., Kočenda, E., \& Vácha, L. (2016). Gold, Oil and Stocks: Dynamic Correlations. International Review of Economics and Finance, 42, 186-201.

Bouri, E. (2015). A broadened causality in variance approach to assess the risk dynamics between crude oil prices and the Jordanian stock market. Energy Policy, 85, 271-279.

Bouri, E., Chen, Q., Lien, D., \& Lv, X. (2017). Causality between oil prices and the stock market in China: The relevance of the reformed oil product pricing mechanism. International Review of Economics and Finance, 48, 34-48.

Cappiello, L., Engle, R., \& Sheppard, K. (2006). Asymmetric dynamics in the correlations of global equity and bond returns. Journal of Financial Econometrics, 4, 537 572 .

Cheung, Y., \& Ng, L.K. (1996). A causality-in-variance test and its application to financial market prices. Journal of Econometrics, 72, 33-48. 
Chuang, C., Kuan, C., \& Lin, H. (2009). Causality in quantiles and dynamic stock returnvolume relations. Journal of Banking and Finance, 33, 1351-1360.

Ciner, C. (2001). Energy shocks and financial markets: Nonlinear linkages. Studies in Nonlinear Dynamics and Econometrics, 5, 203-212.

Cong, R.G., Mei, Y.M., Jiao, J.-L., \& Fan, Y. (2008). Relationships between oil price shocks and stock market: an empirical analysis from China. Energy Policy, 36, 35443553 .

Cuñado, J., \& Pérez de Gracia, F. (2014). Oil Price shocks and stock market returns: Evidence for some European countries. Energy Economics, 42, 365-377.

Dagher, L., \& El Hariri, S. (2013). The impact of global oil price shocks on the Lebanese stock market. Energy, 63, 366-374.

Ding, H., Kim, H.-G., \& Park, S.Y. (2016). Crude oil and stock markets: Causal relationships in tails? Energy Economics, 59, 58-69.

Driesprong, G., Jacobsen, B., \& Maat, B. (2008). Striking oil: another puzzle. Journal of Financial Economics, 89, 307-327.

Edelstein, P., \& Kilian, L. (2009). How sensitive are consumer expenditures to retail energy prices?, Journal of Monetary Economics, 56, 766-779.

Engle, R.F. (2002). Dynamic conditional correlation: A simple class of multivariate generalized autoregressive conditional heteroscedasticity models. Journal of Business and Economic Statistics, 20, 339-350.

Filis, G., Degiannakis, S., \& Floros, C. (2011). Dynamic correlation between stock market and oil prices: The case of oil-importing and oil-exporting countries. International Review of Financial Analysis, 20, 152-164.

Fisher, I. (1930). The Theory of Interest. New York: Macmillan.

Ftiti, Z., Guesmi, K., \& Abid, I. (2016). Oil price and stock market co-movement: What can we learn from time-scale approaches? International Review of Financial Analysis, 46, 266-280.

Ghosh, S., \& Kanjilal, K. (2016). Co-movement of international crude oil price and Indian stock market: Evidences from nonlinear cointegration tests. Energy Economics, 53, 111117.

Goupillaud, P., Grossmann, A., \& Morlet, J. (1984). Cycle-octave and related transforms in seismic signal analysis. Geoexploration, 23, 85-102.

Granger, C.W.J. (1969). Investigating causal relations by econometric models and crossspectral methods. Econometrica, 37, 424-438.

Grossman, A., \& Morlet, J. (1984). Decomposition of hardy functions into square integrable wavelets of constant shape. SIAM Journal on Mathematical Analysis, 15, 723736.

Haile, F., \& Pozo, S. (2008). Currency crisis contagion and the identification of transmission channels. International Review of Economics and Finance, 17, 572-588. 
Hamilton, J.D. (2009). Oil prices and the economic downturn. Testimony prepared for the Joint Economic Committee of the United States Congress.

Hafner, C.M., \& Herwartz, H. (2006). A Lagrange multiplier test for causality in variance. Economic Letters, 93, 137-141.

Hatemi-J, A. (2012). Asymmetric causality tests with an application. Empirical Economics, 43, 447-456.

Hatemi-J, A., Al Shayeb, A., \& Roca, E. (2017). The effect of oil prices on stock prices: fresh evidence from asymmetric causality tests. Applied Economics, 49, 1584-1592, DOI: 10.1080/00036846.2016.1221045

Haven, E., Liu, X., \& Shen, L. (2012). De-noising option prices with the wavelet method. European Journal of Operational Research, 222, 101-112.

Hong, Y. (2001). A test for volatility spillover with application to exchange rates, Journal of Econometrics, 103, 183-224.

Huang, R.D., Masulis, R.W., \& Stoll, H.R. (1996). Energy shocks and financial markets. Journal of Futures Markets, 16, 1-27.

Huang, S., An, H., Gao, X., \& Huang, X. (2015). Identifying the multiscale impacts of crude oil price shocks on the stock market in China at the sector level. Physica A: Statistical Mechanics and its Applications, 434, 13-24.

Jammazi, R. (2012). Cross dynamics of oil-stock interactions: a redundant wavelet analysis. Energy, 44, 760-777.

Jammazi, R., \& Nguyen, D.K. (2015). Responses of international stock markets to oil price surges: a regime-switching perspective. Applied Economics, 47, 4408-4422.

Jammazi, R., \& Reboredo, J.C. (2016). Dependence and risk management in oil and stock markets. A wavelet-copula analysis. Energy, 107, 866-888.

Jones, C.M., \& Kaul, G. (1996). Oil and the stock markets. Journal of Finance, 55, 463491.

Khalfaoui, R., Boutahar, M., \& Boubaker, H. (2015). Analyzing volatility spillovers and hedging between oil and stock markets: Evidence from wavelet analysis. Energy Economics, 49, 540-549.

Kilian, L. (2008). The economic effects of energy price shocks. Journal of Economic Literature, 46, 871-909.

Kyrtsou, C., \& Labys, W.C. (2006). Evidence for chaotic dependence between US inflation and commodity prices. Journal of Macroeconomics, 28, 256-266.

Lee, B.J., Yang, C.H., \& Huang, B.H. (2012). Oil price movements and stock market revisited: a case of sector stock price indexes in the G7 countries. Energy Economics, 34, 1284-1300.

Lee, C.-C., \& Zeng, J.-H. (2011). The impact of oil price shocks on stock market activities: Asymmetric effect with quantile regression. Mathematics and Computers in Simulation, 81, 1910-1920. 
Liu, M.-H., Margaritis, D., \& Zhang, Y. (2016). Competition and petrol pricing in the smartphone era: Evidence from Singapore. Economic Modelling, 53, 144-155.

Lu, F.B., Hong, Y.M., Wang, S.Y., Lai, K.K., \& Liu, J. (2014). Time-varying Granger causality tests for applications in global crude oil markets. Energy Economics, 42, 289298.

Madaleno, M., \& Pinho, C. (2014). Wavelet dynamics for oil-stock world interactions. Energy Economics, 45, 120-133.

Martín-Barragán, B., Ramos, S.B., \& Veiga, H. (2015). Correlations between oil and stock markets: A wavelet-based approach. Economic Modelling, 50, 212-227.

Miller, J.I., \& Ratti, R.A. (2009). Crude oil and stock markets: Stability, instability, and bubbles. Energy Economics, 31, 559-568.

Moya-Martínez, P., Ferrer-Lapeña, R., \& Escribano-Sotos, F. (2014). Oil price risk in the Spanish stock market: An industry perspective, Economic Modelling, 37, 280-290.

Murtagh, F., Starck, J.L., \& Renaud, O. (2004). On neuro-wavelet modeling. Decision Support Systems, 37, 475-484.

Naifar, N., \& Al Dohaiman, M.S. (2013). Nonlinear analysis among crude oil prices, stock markets' return and macroeconomic variables. International Review of Economics and Finance, 27, 416-431.

Narayan, P.K., Ahmed, H.A., \& Narayan, S. (2015). Do momentum-based trading strategies work in the commodity futures markets? Journal of Futures Markets, 35, 868891.

Narayan, P.K., \& Liu, R. (2011). Are shocks to commodity prices persistent? Applied Energy, 88, 409-416.

Narayan, P.K., \& Liu, R. (2015). A unit root model for trending time-series energy variables. Energy Economics, 50, 391-402.

Narayan, P.K., Liu, R., \& Westerlund, J. (2016). A GARCH model for testing market efficiency. Journal of International Financial Markets, Institutions and Money, 41, 121138.

Narayan, P.K., \& Narayan, S. (2010). Modelling the impact of oil prices on Vietnam's stock prices. Applied Energy, 87, 356-361.

Narayan, P.K., Narayan, S., \& Sharma, S.S. (2013). An analysis of commodity markets: what gain for investors? Journal of Banking and Finance, 37, 3878-3889.

Narayan, P.K., \& Popp, S. (2010). A new unit root test with two structural breaks in level and slope at unknown time. Journal of Applied Statistics, 37, 1425-1438.

Narayan, P.K., \& Sharma, S.S. (2011). New evidence on oil price and firm returns. Journal of Banking and Finance, 35, 3253-3262.

Narayan, P.K., \& Sharma, S.S. (2015). Does data frequency matter for the impact of forward premium on spot exchange rate? International Review of Financial Analysis, 39, 45-63. 
Park, J., \& Ratti, R.A. (2008). Oil price shocks and stock markets in the US and 13 European countries. Energy Economics, 30, 2587-2608.

Perron, P. (1989). The great crash, the oil price shock, and the unit root hypothesis. Econometrica, 57, 1361-1401.

Reboredo, J., \& Rivera-Castro, M.A. (2014). Wavelet-based evidence of the impact of oil prices on stock returns. International Review of Economics and Finance, 29, 145-176.

Sadorsky, P. (1999). Oil price shocks and stock market activity. Energy Economics, 2, 449-469.

Turhan, M.I., Sensoy, A., Ozturk, K., \& Hacihasanoglu, E. (2014). A view to the longrun dynamic relationship between crude oil and the major asset classes. International Review of Economics and Finance, 33, 286-299.

Williams, B.J. (1938). The theory of investment value. Cambridge: Harvard University Press.

Xu, B. (2015). Oil prices and UK industry-level stock returns. Applied Economics, 47, 2608-2627.

Yildirim, Z. (2016). Global financial conditions and asset markets: evidence from fragile emerging economies. Economic Modelling, 57, 208-220.

Zhu, H.M., Li, S.F., \& Yu, K. (2011). Crude oil shocks and stock markets: A panel threshold cointegration approach. Energy Economics, 33, 987-994.

Zhu, H.M., Li, R., \& Li, S. (2014). Modelling dynamic dependence between crude oil prices and Asia-Pacific stock market returns. International Review of Economics and Finance, 29, 208-223. 


\section{Appendix}

Table A1. Summary of previous studies on the causal link between oil price and stock returns

\begin{tabular}{|c|c|c|c|}
\hline Study & Causality method & Countries analyzed & Key findings \\
\hline $\begin{array}{l}\text { Arouri \& Nguyen } \\
\text { (2010) }\end{array}$ & Linear VAR model & $\begin{array}{l}\text { Europe (Dow Jones stoxx } \\
600 \text { index and } 12 \\
\text { European sector stock } \\
\text { indices) }\end{array}$ & $\begin{array}{l}\text { Bidirectional causality between oil price changes and Dow Jones } \\
\text { stock returns and between oil price changes and most sector indices }\end{array}$ \\
\hline $\begin{array}{l}\text { Dagher \& El Hariri } \\
\text { (2013) }\end{array}$ & Linear VAR model & Lebanon & $\begin{array}{l}\text { Unidirectional causality from oil price changes to Lebanese stock } \\
\text { returns }\end{array}$ \\
\hline Lee et al. (2012) & Linear VAR or VEC model & $\begin{array}{l}\text { G7 countries (aggregate } \\
\text { national stock indices and } \\
12 \text { sector stock indices) }\end{array}$ & $\begin{array}{l}\text { Oil price changes do not Granger cause aggregate stock indices in any } \\
\text { of the G7 countries } \\
\text { Aggregate stock returns Granger cause oil price changes in Germany, } \\
\text { the UK and the US }\end{array}$ \\
\hline Ciner (2001) & $\begin{array}{l}\text { Linear VAR model } \\
\text { Nonlinear Granger causality test of } \\
\text { Hiemstra and Jones (1994) }\end{array}$ & United States & $\begin{array}{l}\text { No linear Granger causality between oil futures and US stock returns } \\
\text { Bidirectional nonlinear Granger causality between oil futures and US } \\
\text { stock returns. }\end{array}$ \\
\hline Ajmi et al. (2014) & $\begin{array}{l}\text { Linear VAR model } \\
\text { Nonlinear asymmetry causality test } \\
\text { of Kyrtsou and Labys (2006) }\end{array}$ & $\begin{array}{l}\text { MENA (Middle East and } \\
\text { North Africa) countries }\end{array}$ & $\begin{array}{l}\text { Bidirectional linear causality between oil price changes and almost all } \\
\text { MENA countries. }\end{array}$ \\
\hline
\end{tabular}




\begin{tabular}{|c|c|c|c|}
\hline & & & $\begin{array}{l}\text { Significant asymmetric causal links between oil price changes and } \\
\text { stock returns of MENA countries. } \\
\text { Substantial differences across MENA countries in terms of } \\
\text { asymmetric causality. }\end{array}$ \\
\hline Anoruo (2011) & $\begin{array}{l}\text { Linear VAR model } \\
\text { Nonlinear asymmetry causality test } \\
\text { of Kyrtsou and Labys (2006) }\end{array}$ & United States & $\begin{array}{l}\text { Bidirectional linear causality between oil price changes and US stock } \\
\text { returns. } \\
\text { Bidirectional nonlinear causality between oil price changes and US } \\
\text { stock returns. }\end{array}$ \\
\hline Hatemi-J et al. (2017) & $\begin{array}{l}\text { Asymmetric causality test of } \\
\text { Hatemi-J (2012) }\end{array}$ & $\begin{array}{l}\text { World market and G7 } \\
\text { countries }\end{array}$ & $\begin{array}{l}\text { Increasing oil prices cause stock returns in the rising world market, } \\
\text { the US market and the Japan market. } \\
\text { Decreasing oil prices cause stock returns only in the falling Germany } \\
\text { stock market. }\end{array}$ \\
\hline $\begin{array}{l}\text { Balcilar \& Ozdemir } \\
\text { (2013) }\end{array}$ & Markov switching-VAR model & $\begin{array}{l}\text { A number of sectors of } \\
\text { the US S\&P500 stock } \\
\text { index }\end{array}$ & $\begin{array}{l}\text { No significant lead-lag Granger causality relationships are found. } \\
\text { Oil futures returns have significant predictive power for each of the } \\
\text { S\&P500 sub-index returns during various sub-periods, while there is } \\
\text { weak evidence on the case of vice-versa. } \\
\text { The regime predictive power of the oil market for the stock market is } \\
\text { much stronger than in the opposite case. }\end{array}$ \\
\hline Ding et al. (2016) & $\begin{array}{l}\text { Quantile causality framework of } \\
\text { Chuang et al. (2009) }\end{array}$ & $\begin{array}{l}\text { China, Hong Kong, } \\
\text { Korea, Japan and the US }\end{array}$ & $\begin{array}{l}\text { Significant causal links between crude oil and stock returns mainly } \\
\text { under extreme conditions in oil and stock markets. } \\
\text { Bidirectional causal links between oil and stock returns for the US, } \\
\text { Hong Kong, China and Japan in the tails. }\end{array}$ \\
\hline
\end{tabular}




\begin{tabular}{|l|l|l|l|}
\hline Bouri (2015) & $\begin{array}{l}\text { Causality in variance test of Hafner } \\
\text { and Herwartz (2006) }\end{array}$ & Jordan & $\begin{array}{l}\text { Unidirectional risk spillovers from the oil price to the Jordanian stock } \\
\text { market after the global financial crisis }\end{array}$ \\
\hline Bouri et al. (2017) & $\begin{array}{l}\text { Causality in mean and variance } \\
\text { approach of Cheung and } \mathrm{Ng} \mathrm{(1996)} \\
\text { and Hong (2001) }\end{array}$ & $\begin{array}{l}\text { Chinese sector stock } \\
\text { indices }\end{array}$ & $\begin{array}{l}\text { Stronger causality in mean since the refined oil pricing reform of } \\
\text { March 2013. } \\
\text { Causality in variance has almost disappeared after that reform. }\end{array}$ \\
\hline
\end{tabular}




\section{Table A2. Summary of previous studies on the oil-stock nexus using wavelet methods}

\begin{tabular}{|c|c|c|c|}
\hline Study & Approach & Countries analyzed & Key findings \\
\hline $\begin{array}{l}\text { Reboredo \& } \\
\text { Rivera-Castro } \\
(2014)\end{array}$ & $\begin{array}{l}\text { Wavelet correlations calculated with } \\
\text { the MODWT }\end{array}$ & $\begin{array}{l}\text { The US and Europe } \\
\text { at the aggregate } \\
\text { and sector levels }\end{array}$ & $\begin{array}{l}\text { Oil price changes have no effect on stock returns in the pre-crisis period (excepting for the } \\
\text { Oil \& Gas sector). } \\
\text { Increased interdependence and contagion between oil and stock returns since the onset of } \\
\text { the global financial crisis at both the aggregate and sector levels for all time scales. } \\
\text { Feedback effects between oil and stock markets at all time scales in the post-financial crisis } \\
\text { period. }\end{array}$ \\
\hline $\begin{array}{l}\text { Martín-Barragán } \\
\text { et al. (2015) }\end{array}$ & $\begin{array}{l}\text { Wavelet correlations calculated with } \\
\text { the MODWT }\end{array}$ & $\begin{array}{l}\text { Germany, Japan, } \\
\text { the UK and the US }\end{array}$ & $\begin{array}{l}\text { The correlation between oil and stock markets changes during periods of oil price shocks. } \\
\text { Oil shocks tend to decrease oil-stock correlation at higher frequencies, while the correlation } \\
\text { increases at lower frequencies. }\end{array}$ \\
\hline $\begin{array}{l}\text { Baruník et al. } \\
\text { (2016) }\end{array}$ & $\begin{array}{l}\text { Nonparametric realized volatility } \\
\text { and DCC-GARCH methods } \\
\text { Wavelet correlations calculated with } \\
\text { the MODWT }\end{array}$ & The US & $\begin{array}{l}\text { Superior performance of wavelet analysis over standard benchmark approaches. } \\
\text { Dramatic increase in the oil-stock correlation since the onset of the global financial crisis in } \\
2008 . \\
\text { Correlations before and after the crisis are homogeneous at different investment horizons, } \\
\text { while there is a marked heterogeneity in correlations across time horizons around crisis } \\
\text { times. }\end{array}$ \\
\hline Jammazi (2012) & $\begin{array}{l}\text { Wavelet correlations and Wavelet } \\
\text { cross-correlations calculated with } \\
\text { the HTW transform }\end{array}$ & $\begin{array}{l}\text { The US, Canada, } \\
\text { Germany, Japan } \\
\text { and the UK }\end{array}$ & $\begin{array}{l}\text { The oil-stock link is more pronounced at longer time horizons for most countries. } \\
\text { The causal linkages between oil and stock markets differ notably across countries, although } \\
\text { they tend to be stronger at larger time scales. }\end{array}$ \\
\hline $\begin{array}{l}\text { Khalfaoui et al. } \\
\text { (2015) }\end{array}$ & $\begin{array}{l}\text { Wavelet-based bivariate GARCH- } \\
\text { BEKK model }\end{array}$ & G7 countries & $\begin{array}{l}\text { Mean and volatility spillovers between oil and stock markets vary considerably among } \\
\text { countries and within each country across time scales. }\end{array}$ \\
\hline
\end{tabular}




\begin{tabular}{|c|c|c|c|}
\hline & $\begin{array}{l}\text { Wavelet coherence and phase- } \\
\text { difference analysis }\end{array}$ & & $\begin{array}{l}\text { Wavelet coherence indicates that the comovement of oil and stock markets increases over } \\
\text { scales. } \\
\text { The oil market tends to lead the stock markets. }\end{array}$ \\
\hline $\begin{array}{l}\text { Huang et al. } \\
(2015)\end{array}$ & $\begin{array}{l}\text { Wavelet analysis based on the HTW } \\
\text { transform combined with a VAR } \\
\text { model }\end{array}$ & $\begin{array}{l}\text { China at the sector } \\
\text { level }\end{array}$ & $\begin{array}{l}\text { Bidirectional Granger causality relationships between the crude oil price and most sector } \\
\text { stock indices in the short, medium and long term. }\end{array}$ \\
\hline $\begin{array}{l}\text { Jammazi \& } \\
\text { Reboredo (2016) }\end{array}$ & $\begin{array}{l}\text { Wavelet analysis based on the HTW } \\
\text { transform combined with copula } \\
\text { methodology }\end{array}$ & World market & $\begin{array}{l}\text { Weak oil-stock market dependence before the global financial crisis for lower time scales. } \\
\text { The degree of dependence between oil and stock markets is more pronounced since the } \\
\text { onset of the global financial crisis for all time scales. } \\
\text { The dependence tends to be stronger at coarser scales. } \\
\text { The stock market appears to lead oil prices, especially for coarser scales. }\end{array}$ \\
\hline $\begin{array}{l}\text { Madaleno \& } \\
\text { Pinho (2014) }\end{array}$ & $\begin{array}{l}\text { Continuous wavelet transform } \\
\text { (Wavelet coherence and phase- } \\
\text { difference analysis) }\end{array}$ & $\begin{array}{l}\text { World stock } \\
\text { market at the } \\
\text { aggregate and } \\
\text { sector levels }\end{array}$ & $\begin{array}{l}\text { The oil-stock is not homogeneous across scales and over time. } \\
\text { Most of the oil-stock interaction occurs at lower frequencies. } \\
\text { Increased dependence between oil and stock markets after } 2011 \text {. } \\
\text { Stock markets lead oil prices for the lower frequencies. }\end{array}$ \\
\hline Ftiti et al. (2016) & $\begin{array}{l}\text { Evolutionary spectral analysis } \\
\text { Continuous wavelet transform } \\
\text { (Wavelet coherence and phase- } \\
\text { difference analysis) }\end{array}$ & G7 countries & $\begin{array}{l}\text { The interdependence between oil prices and stock returns is more pronounced in the short } \\
\text { and medium terms than in the long time scales. } \\
\text { Stock markets are more sensitive to oil shocks originating from demand shocks. }\end{array}$ \\
\hline
\end{tabular}


${ }^{\mathrm{i}}$ In particular, the causality test proposed by Hong (2001) is a generalized version of the Granger causality test designed by Cheung \& $\mathrm{Ng}$ (1996), which is based on the sum of squared sample cross correlations giving equal weight to each of the sample cross correlations.

ii Lu et al. (2014) also employ simple rolling correlations to estimate the dynamic correlation between the time series involved. The rolling estimator suffers, however, from two basic drawbacks. First, it highly depends on the size of the estimation window. Second, it assigns equal weights to old and new data, even though it is likely that recent observations are more important for current correlations than older observations. For these reasons, Lu et al. (2014) prefer the DCC-GARCH estimator to the rolling correlation estimator.

iii The authors wish to thank an anonymous reviewer for suggesting the use of an AGDCC-GARCH model in this study.

${ }^{\text {iv }}$ However, the choice of another crude oil price should not significantly affect the empirical results as it has been widely documented that the major international crude oil price benchmarks are closely related (Reboredo \& Rivera-Castro, 2014).

${ }^{v}$ It is worth noting that the ADF-type unit root test proposed by Narayan \& Popp (2010) also accounts for time trend and structural breaks, but however this test does not model conditional heteroskedasticity.

${ }^{\mathrm{vi}}$ For a detailed description of the Narayan and Liu trend-GARCH-based unit root test, see Narayan \& Liu (2015).

vii Choosing alternative numbers of lags has no material consequences on the results of the time-varying Granger causality tests of Lu et al. (2014).

viii The estimates of the AGDCC-GARCH(1,1) model outperform those of the DCC-GARCH $(1,1)$ model used in the original time-varying Granger causality test of Lu et al. (2014) in terms of log-likelihood value and lower value of standard information criteria (Akaike, Bayesian, Hannan-Quinn) for all countries under scrutiny.

ix The detailed percentages of significance for each year are also available upon request. 